\title{
IMPLEMENTING THE JAVA MUSIC CLUB IN RESIDENTIAL CARE: IMPACT ON COGNITIVE AND PSYCHOSOCIAL HEALTH
}

\author{
By \\ Geneva Millett \\ Bachelor of Arts (Hons.), University of Guelph, 2016 \\ A thesis \\ Presented to Ryerson University \\ in partial fulfillment of the \\ requirements for the degree of \\ Master of Arts \\ in the Program of \\ Clinical Psychology \\ Toronto, Ontario, Canada, 2019 \\ (c) Geneva Millett, 2019
}




\section{AUTHOR'S DECLARATION FOR ELECTRONIC SUBMISSION OF A THESIS}

I hereby declare that I am the sole author of this thesis. This is a true copy of the thesis, including any required final revisions, as accepted by my examiners.

I authorize Ryerson University to lend this thesis to other institutions or individuals for the purpose of scholarly research.

I further authorize Ryerson University to reproduce this thesis by photocopying or by other means, in total or in part, at the request of other institutions or individuals for the purpose of scholarly research.

I understand that my thesis may be made electronically available to the public. 
Implementing the Java Music Club in Residential Care: Impact on Cognitive and Psychosocial Health

Master of Arts, 2019

Geneva Millett

Clinical Psychology

Ryerson University

\begin{abstract}
Background: $90 \%$ of long-term care (LTC) residents experience cognitive impairment. Social support may benefit cognition by decreasing depression and loneliness. Objective: To investigate the effects of the Java Music Club, a manualized social support program, on cognition and psychosocial health among LTC residents. Methods: The Java Music Club was implemented 1x/week for three months. Participants ( $n=24,91.7 \%$ female) completed cognitive tasks and psychosocial questionnaires before (T1), after (T2), and three months following (T3) participation. Qualitative interviews to explore perceptions of the Java Music Club were conducted at T2 with participants and recreation coordinators. Results: Decreased loneliness from T1-T2 $(t=3.31, p=.003)$ and T2-T3 reductions in depressive symptoms $(F=3.459, p=$ $.043)$ and subjective memory complaints $(F=3.837, p=.048)$. Qualitative interviews illustrated important group elements, and that the Java Music Club was enjoyable and promoted social engagement. Conclusions: Participation in the Java Music Club is a promising approach to counter loneliness, depressive symptoms and subjective memory complaints in LTC residents.
\end{abstract}




\section{Acknowledgement}

First, I would like to thank my supervisor, Dr. Alexandra Fiocco, for providing me with the opportunity to pursue research that I am passionate about, and who's support and knowledge were essential to the effective completion of this master's project. I would also like to thank my committee members; Dr. Karen Milligan for her insights and guidance regarding qualitative methods, Dr. Maureen Reed for acting on my examining committee, and both for their insightful questions, feedback and suggestions.

I would also like to thank the Stress and Healthy Aging Research (StAR) lab for all of the moral support over the last two years, and the ever-present sounding board for the important considerations that come with research. I would also like to thank StAR lab research assistants, who helped with the cognitive testing and qualitative interviews, and without whom the study could not have been completed.

To my family and friends - your support was paramount to my entire master's degree. You had unwavering faith in me and were always there to lend an ear. I would also like to make a special comment to my grandmother. Her experience with Alzheimer's disease showed me the necessity of research to improve the quality of life of older adults experiencing cognitive impairment, and she is the impetus behind my work. 


\section{Table of Contents}

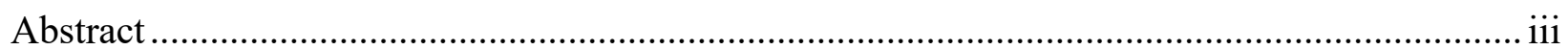

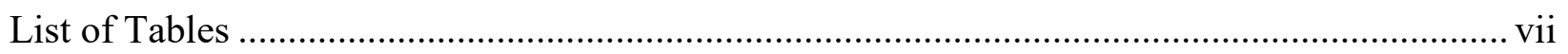

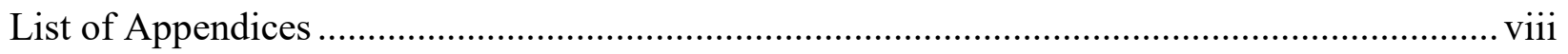

Implementing the Java Music Club in Residential Care: Impact on Cognitive and Psychosocial

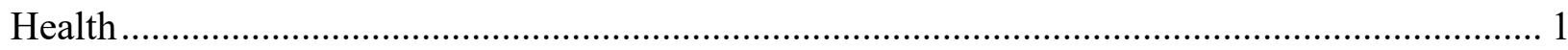

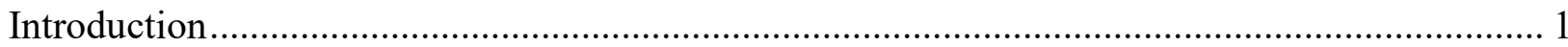

Older Adults in Residential Care ...................................................................................... 2

Psychosocial Wellbeing of Older Adults in Residential Care ............................................. 3

Psychosocial Wellbeing and Cognitive Function ........................................................ 6

The Beneficial Effects of Social Support in Late Life.................................................... 9

Social Support Interventions within Residential Care ................................................. 13

Social Programming in Residential Facilities............................................................... 15

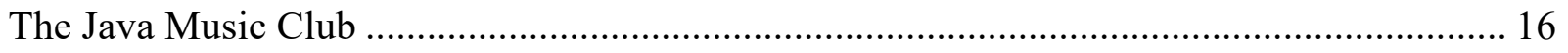

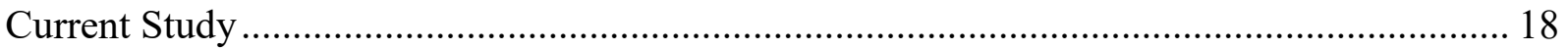

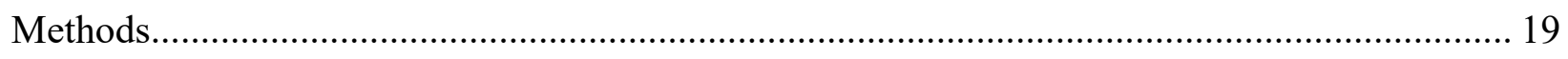

Participants and Participant Recruitment.................................................................... 19

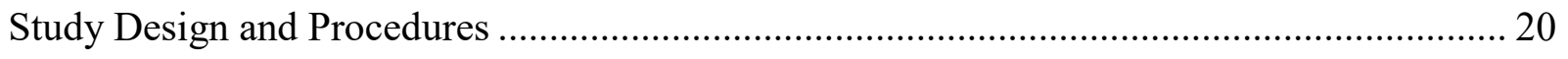

Measures and Questionnaires ................................................................................... 22

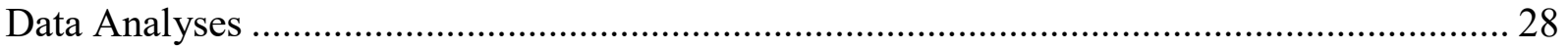


Quantitative......

Qualitative.

Results 30

Participants. 30

Objective 1: Effects of the Java Music Club on Cognitive Function from T1 to T2............... 34

Objective 2: Effects of the Java Music Club on Psychosocial Health from T1 to T2 ...... 34

Objective 3: Effects of the Java Music Club at 3-month Follow Up 35

Objective 4: Qualitative Investigation of the Java Music Club 36

Discussion 46

Limitations and Future Directions 55

Conclusion . 57

Appendices. 59

References. 96 


\section{List of Tables}

Table 1: Demographics information for all participants who completed testing session at

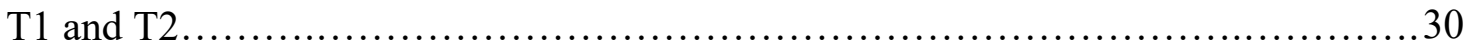

Table 2: Correlations between predictor variables, outcome variable, and possible

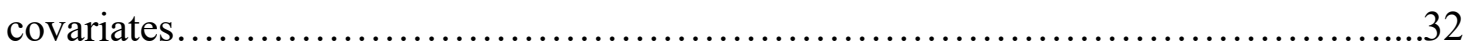

Table 3: Mean (standard deviation) performance on cognitive tests across testing sessions.....34

Table 4: Mean (standard deviation) self-reported psychosocial wellbeing across testing

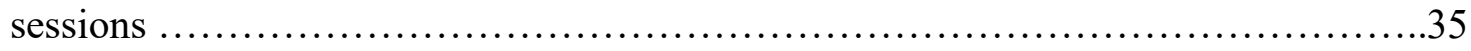

Table 5: Themes and sub-themes developed using thematic analysis ......................45 


\section{List of Appendices}

Appendix A: Consent Forms..................................................... 59

Appendix B: Cognitive Test Battery...........................................69

Appendix C: Psychosocial Questionnaires..........................................76

Appendix D: Qualitative Interviews........................................ 93 
Implementing the Java Music Club in Residential Care: Impact on Cognitive and Psychosocial Health

\section{Introduction}

Five-hundred and sixty-four thousand Canadians are currently living with dementia, with 25,000 new cases being diagnosed each year (Alzheimer's Society of Canada, 2016). These rates of impairment are especially dire in long term care (LTC) settings, where $90 \%$ of residents experience some form of cognitive impairment, with one in three being severely impaired (Canadian Institute for Health Information, 2016). Further, studies consistently associate cognitive impairment with reduced quality of life (Saraçl1 et al., 2015) and increased mortality compared to those who are cognitively healthy (Smetanin et al., 2009). Accordingly, the development of interventions that can reduce the rates of cognitive impairment and mitigate the impacts of cognitive impairment on quality of life within LTC settings warrant further attention (Magaziner et al., 2000; World Health Organization, 2015).

Successful Aging is a term that is used within the aging literature that includes the following essential elements: low probability of disease and disease-related disability, high cognitive and physical functional capacity and active engagement with life (Rowe \& Kahn, 1997). Despite initiatives to promote successful aging within residential care centers, elements of these three core components such as cognitive impairment, stress, depression, and social isolation, are common (Magaziner et al., 2000; Scocco, Rapattoni, \& Fantoni, 2006; Pinquart \& Sörensen, 2001). This research contributes to the promotion of successful aging within residential care by investigating the beneficial effects of a peer support group called the Java Music Club on cognition and psychosocial health. The Java Music Club is a social program 
aimed at fostering connection and support between residents through the use of themed music, photos and discussion.

The proceeding sections will review the extant literature examining the current status of residential care and psychosocial wellbeing, the relationship between various mental health factors and cognition, and the beneficial effects of social support on these constructs. Current social programming within residential care will then be discussed, followed by a description of the Java Music Club and study objectives.

\section{Older Adults in Residential Care}

Residential care is a term that encompasses a variety of living arrangements for older adults, including retirement homes, assisted living, LTC and nursing homes. Currently in Canada, there are nearly five million older adults above the age of $65,7.9 \%$ of whom live in residential care (Statistics Canada, 2011). The prevalence of older adults living in residential care increases with age, such that $29.6 \%$ and $43.5 \%$ of those $>85$ and $>90$ years, respectively, live in a collective dwelling (Statistics Canada, 2011).

There are various reasons why older adults and their familial caregivers will consider residential care in late life. Multiple factors appear to play a role in this decision, including the physical and mental health status of the caregiver, the perceived burden on loved ones, a decline in health and functional abilities, loneliness or isolation at home, negative social interactions and one or more hospital admissions (Heppenstall et al., 2014; Jamieson et al., 2019). Despite these reasons for transitioning to LTC, the process can be difficult (Lee, Woo, \& Mackenzi, 2002), with residents and their families experiencing anxiety and fear surrounding the changes and unknowns that arise with relocation (Ellis, 2010). Furthermore, the transition to LTC has been associated with several negative health outcomes, including decreased quality of life and sense of 
autonomy, and increased feelings of loneliness, depression, and stress (Scocco et al., 2006; Pinquart \& Sörensen, 2001; Brownie et al., 2014).

Different characteristics of the move to residential care have been found to influence the success of the transition. For example, less successful transitions have been associated with feelings of powerlessness and declining health (Lee, Simpson \& Froggatt, 2013). Further, adults who feel that they are not in control of the move are more likely to self-report feelings of sadness, depression and resentment (Brownie et al., 2014).

Given the potential for poor outcomes associated with the transition to LTC, there is a current and growing need to implement effective ways of promoting the psychological wellbeing of older adults in residential care, and a healthy transition to this setting from the community.

\section{Psychosocial Wellbeing of Older Adults in Residential Care}

The promotion of successful aging within residential care is more than the prevention of disease. Successful aging emphasizes the importance of mental and physical functioning, and active engagement with life, through interpersonal relations and productive activity (Rowe \& Kahn, 1997). Despite this fact, research has found that various psychosocial factors that are negatively associated with healthy aging and life satisfaction (Bradshaw, Playford, \& Riazi, 2012) are experienced to a significant degree within residential settings.

Stress and depression are two highly correlated psychological variables that negatively impact quality of life. Depression is a prevalent lifetime disorder that is characterized by depressed mood and loss of interest or pleasure for a period of two or more weeks. Stress has many definitions; however, a common conceptualization is that stress occurs when an individual perceives the demands of the environment to surpass the adaptive capacity of the individual, which is then appraised as imposing threat to the individual (Lazarus \& Launier, 1978). Both 
stress and depression are commonly experienced among persons in residential care and have further been shown to increase after admission (Scocco, Rapattoni, \& Fantoni, 2006; Koopmans, Zuidema, Leontjevas, \& Gerritsen, 2010; Victor, 2012).

The transition to residential care can present a particularly stressful life event for older adults (Morse, 2000). In a prospective cohort study, Glass, Kasl, and Berkman (1997) found that the two most common stressful life events for older adults was the death of a close friend and moving into a residential facility. Further, increase in the number of stressful life events experienced was associated with an increase in depressive symptoms. Depression has been associated with unstable health conditions, decreased self-sufficiency, withdrawal, sleep disturbance, pain, reduced cognition, increased falls, and other serious health issues (The Canadian Institute of Health Information [CIHI], 2013; Anstey et al., 2007; Choi et al., 2019). Rates of depression vary depending on severity; however, in Canadian residential care it has been documented to be as high as $44 \%$ (CIHI, 2013). Not only is depression prevalent within residential care, it is reportedly under recognized by care staff (Teresi, Abrams, Holmes, Ramirez, \& Eimicke, 2001), which poses a significant barrier to accessing treatment (Yoon, Moon \& Pitner, 2018).

The reciprocal relationship between depression and stress is well documented in the literature. For example, a longitudinal study by Moos, Schutte, Brennan and Moos (2005) assessed older adult participants at baseline, 1 year, 4 years, and 10 years later, and found that life stressors at baseline were associated with increased depressive symptoms at all follow-up periods. Further, increased depressive symptoms over time were also associated with increased life stressors including interpersonal, financial, and health related stressors, and negative life events. The finding that depressed individuals report significantly more negative stressful events 
than non-depressed individuals (Dickinson, Potter, Hybels, McQuoid, \& Steffens, 2011; Yoon, Moon \& Pitner, 2018) suggests that depressed individuals may be more susceptible to the negative cognitive effects of stress.

Loneliness is the subjective experience that occurs when one perceives that their social needs are not being met (Victor, 2012). Lower levels of loneliness and having someone to talk to has been found to account for $18 \%$ of variance in satisfaction with life ratings (Ellwardt, Aartsen, Deeg, \& Steverink, 2013) and is significantly related to quality of life in older adults (Victor, 2012). Despite the important role that active social engagement plays in successful aging, (Rowe $\&$ Kahn, 1997) loneliness has been found to increase in the oldest old ( $>80$ years of age, Pinquart \& Sörensen, 2001; Golden et al., 2009). It is also more common in those living in residential care compared to those living in the community, such that loneliness is experienced by up to $55 \%$ among older adults living in institutional settings (Pinquart \& Sörensen, 2001; Nyqvist, Cattan, Andersson, Forsman, \& Gustafson, 2013). Given that loneliness in the community is one of the reasons why an older adult and their family may consider residential care (Heppenstall et al., 2014), the increased rate of loneliness within residential care is a significant concern.

Autonomy significantly contributes to mental and physical wellbeing (Andresen \& Puggaard, 2008), quality of life (Murphy \&Welford, 2012, Rowe \& Kahn, 1997) and successful aging (Murphy \& Welford, 2012). However, as we age, reliance on the assistance from others inevitably increases. Autonomy remains important to older adults (Ball et al., 2000), yet is often reduced during the transition to residential care as carers make more decisions regarding daily life for the older adult. During the process of moving into residential care, decisions of daily life are often reduced, as is the freedom to take part in formerly valued activities (Kane, 1997). Providing opportunities for autonomy through self-selection of activities is often not prioritized 
within these settings (Welford, Murphy, Rodgers, \& Frauenlob, 2012). This may potentially contribute to a steady decline in autonomous decision making, thereby increasing dependency and contributing to reduced psychosocial and cognitive wellbeing, and quality of life (Shawler, Rowles, \& High, 2001).

The mental health factors listed above are not only important due to their damaging effects on overall quality of life and psychosocial wellbeing, but also due to their deleterious effects on cognitive functioning.

\section{Psychosocial Wellbeing and Cognitive Function}

The precise prevalence of chronic stress within residential care is unknown, however, there are various life events that occur during this time that are associated with increased perceived stress, including dealing with chronic comorbid illnesses, reduced cognitive health, the transition to residential care, and loss of long-term social relationships (Osmanovic-Thunstrom, Mossello, Akerstedt, Fratiglioni, \& Wang, 2015; Luchesi et al., 2016). It is commonly understood and reported in the literature that older adults who are exposed to high levels of stress experience more physical and mental health complications compared to older adults who do not (Krause, 2001).

Research has found associations between stress and reduced cognitive functioning in tasks assessing various cognitive domains including working memory, processing speed and episodic memory (Stawski, Sliwinski, \& Smyth, 2006; VonDras, Powless, Olson, Wheeler, \& Snudden, 2005). In a study of 6207 biracial older adult men and women from the Chicago Health and Aging Project, perceived stress was associated with lower initial cognitive scores as well as faster rates of cognitive decline over 6.8 years, measured by a composite cognitive score composed of perceptual speed and immediate and delayed recall (Aggarwal et al., 2014). The 
detrimental effects of stress have also been implicated in both subjective and objective cognitive functioning, when other potentially confounding factors such as depression are held constant (Potter, Hartman \& Ward, 2009). For example, a 10-year longitudinal study found that participants who reported perceived long-term stress experienced subjective declines and negative changes in their cognitive functioning, and more memory failures over the study period compared to participants who reported low perceived stress (Rönnlund, Sundström, Sörman, \& Nilsson, 2013). Although Rönnlund et al. (2013) did not find similar effects on objective cognitive performance, a 35-year longitudinal study found that self-reported constant stress in midlife was related with an increased risk of developing dementia, such that hazard ratios of dementia diagnosis for those reporting stress at one, two, or three follow-up sessions compared to non-stressed respondents was 1.10, 1.73 and 2.51, respectively (Johansson et al., 2010). In light of the cumulative stressors that can occur during this period (Kahana, Kelly-Moore, \& Kahana, 2012), stress in residential care should be a public health priority.

A systematic review by Seitz, Purandare, and Conn (2010) found that the prevalence of depression within residential care is between $5-25 \%$, and the prevalence of depressive symptoms is even greater (14-82\%, median prevalence of $29 \%)$. Depression has also been associated with cognitive decline, as well as the transition to more severe forms of dementia, such as Alzheimer's disease (McDermott \& Ebmeier, 2009). In an effort to elucidate the direction of the relationship between late-life depression and cognitive impairment, several longitudinal studies have been conducted. Studies ranging from four to 26 years in length support the temporal precedence of depressive symptoms within this relationship, such that baseline symptoms of depression have been shown to have detrimental effects on global cognition, executive functioning, attention, memory and processing speed (Paterniti, Verdier-Taillefer, Dufouil, \& 
Alpérovitch, 2002; Dotson, Resnick, \& Zonderman, 2008; Royall, Palmer, Chiodo, \& Polk, 2012; Chodosh, Kado, Seeman, \& Karlamangla, 2007; Comijs, Jonker, Beekman, \& Deeg, 2001; Spira et al., 2012). Within this framework, longitudinal studies have investigated the differential effects of various depressive symptom characteristics on cognitive functioning. For example, participants aged 59 to 71 years who endorse a greater number of depressive symptoms with a persistent course (i.e., CES-D scores above 16 at 2- and/or 4-year follow up) experience greater cognitive decline than those who experience relatively subtle symptoms with an episodic course (Paterniti et al., 2002; Dotson et al., 2008). Further, the endorsement of each additional symptom of depression at baseline corresponds to a 5\% decline in cognition five years later (Wilson, de Leon, Bennett, Bienias, \& Evans, 2004).

Findings from two meta-analyses confirm the temporal relationship between depression and cognitive impairment, such that a history of depression increases the risk of deficits in executive function, memory, attention, and receiving a diagnosis of Alzheimer's Disease in later life (Ownby, Crocco, Acevedo, John, \& Loewenstein, 2006; Rock, Roiser, Riedel, \& Blackwell, 2014). Research also suggests that older adults may be more sensitive to the cognitive effects of depressive symptoms, such that participants over the age of 60 with severe depressive symptoms (i.e., mean Hamilton Depression Rating Scale score of 28.5) experienced greater impairment in tasks of executive functioning than those below the age of 60 with severe depressive symptoms (i.e., mean Hamilton Depression Rating Scale score of 32.3; Lockwood, Alexopoulos, \& van Gorp, 2002).

A recent longitudinal study by Yoon, Shin, and Han (2017) suggests that the association between depression and cognition is malleable in older adults with mild cognitive impairment. Specifically, participants who experienced improvements in their depressive symptoms at one- 
year-follow up also showed improvements on tests of global cognitive functioning. These findings are consistent with Butters et al. (2009) who found that treatment of depressive symptoms for those who demonstrated cognitive impairment at baseline was associated with significant improvements in cognitive functioning, specifically in the domain of initiation and conceptualization, which are reflective of executive functioning.

The research outlined above demonstrates the importance in addressing psychosocial constructs such as stress and depression because they are significantly related to quality of life and have important implications for cognitive health. Interventions that can target the constructs are warranted in order to promote successful aging and cognitive function of older adults living in residential care.

\section{The Beneficial Effects of Social Support in Late Life}

Current research suggests that individuals who report feeling more socially connected and having more meaningful social relationships experience better well-being and slower rates of cognitive decline than those who do not (Amieva et al., 2010; Pillemer \& Holtzer, 2016;

Holtzman et al., 2004; Gow, Pattie, Whiteman, Whalley, \& Deary, 2007; Zahodne, Nowinski, Gershon, \& Manly, 2014). Broadly defined, social support reflects both the perception and actual extent to which someone is cared for, is provided assistance, and is part of a network of social relationships (Antonucci \& Jackson, 1990). The Medical Outcomes Study - Social Support Survey (MOS-SSS) is a commonly used measurement tool that assesses social support in older adults, in which social support is divided into four primary dimensions: 1) tangible support (i.e., direct ways of providing support such as financially or by providing services), 2) emotional/informational support (i.e., the perception of being cared for and receiving advice), 3) 
affectionate support (i.e., sense of being loved) and 4) positive social interaction (i.e., the presence of someone you enjoy spending time with; Sherbourne \& Stewart, 1991).

There have been multiple theories proposed for how social support exerts its beneficial effects on cognition, two of which are the main effects model and the stress-buffering model (Cohen \& Wills, 1985). The main effects model posits that structural aspects of social relationships, such as social networks and social integration, are beneficial regardless of the individual's perception of support. The stress-buffering model, on the other hand, suggests that functional aspects of social relationships counteract the negative effects of stress by enhancing an individual's coping abilities (Kawachi \& Berkman, 2001; Cohen \& Wills, 1985). Krause (2005) found that there was a reduced effect of financial strain on life satisfaction for older adults who received emotional support from family and friends, however there was no such stressbuffering effect seen in younger adults, which suggests that the stress-buffering effect of social support on financial strain may be moderated by age. The ability of social support to buffer the negative effects of depression has also been reported, such that it promotes abilities in daily living and life satisfaction in older adults who have increased levels of depressive symptoms (Hays, Steffens, Flint, Bosworth, \& George, 2001; Adams et al., 2016).

Although overall levels of social support are associated with improved cognitive functioning (Cohen \& Wills, 1985), findings suggest that emotional support may be particularly potent for enhancing resilience. For example, Seeman, Lusignolo, Albert, and Berkman (2001) found that emotional support is associated with the promotion of cognitive function over 7.5 years, and findings from a cross-sectional study found that emotional support was a better indicator of positive affect, executive functioning and processing speed scores than instrumental support (Zahodne et al., (2014). Furthermore, using the MOS-SSS, Pillemer and Holtzer (2016) 
also found that gender moderates these effects, such that females experienced a stronger beneficial effect of emotional support compared to males.

In addition to emotional support, the level of participation and satisfaction with social networks may be another protective factor against cognitive impairment. Longitudinal studies have found that after controlling for baseline health and cognitive status, participation in two-tothree social activities resulted in $13-33 \%$ less cognitive failures on five items from the Short Portable Mental Status Questionnaire (Pfeiffer, 1975) compared to those who did not participate in any social activities. Further, those who are satisfied with their social networks and receive more support have a $23 \%$ and $55 \%$ reduced risk of developing dementia 5 to 10 years later, respectively (Glei et al., 2005; Amieva et al., 2010). The findings that one's participation and satisfaction with social networks is protective against cognitive decline have been supported above and beyond the effects of depressive symptoms, health factors, and physical activity in a cross-sectional study (Krueger et al., 2009).

Social support may exert its beneficial effects by targeting feelings of loneliness (Pinquart et al., 2001). Loneliness has been associated with negative health outcomes and is found to increase older adults' vulnerability to stress, depression and cognitive impairment (Victor, 2012; Cacioppo, Hughes, Waite, Hawkley, \& Thisted, 2006; Ellwardt et al., 2013). When childhood intelligence, sex, education, and social class are statistically accounted for, loneliness was found to be most predictive of cognitive function at 70-79 years of age (Gow et al., 2007; Gow, Corley, Starr, \& Deary, 2013). Further, the rate of cognitive decline over 12 years is reportedly $20 \%$ quicker in those who endorse loneliness (Donovan et al., 2016). Again, the form of social support provided has implications for targeting loneliness, such that emotional support and socializing with friends rather than family members are most protective against 
feelings of loneliness (Ellwardt et al., 2013; Pinquart \& Sörensen, 2001). However, it is important to note that those with cognitive impairment have social networks that are dominated by family rather than friends due to the associated care needs (Aartsen, van Tilburg, Smits, \& Knipscheer, 2004).

The exact function that loneliness serves within the relationship between social support and cognition has been debated. It is possible that loneliness is the result of the deleterious effect that cognitive impairment has on social resources: as social resources decline so too does cognition, and the loneliness subsequently increases (Burhold et al., 2017). However, a longitudinal study found that loneliness mediates the positive relationship between emotional support and cognition (Ellwardt et al., 2013), and that this relationship is particularly powerful for those 65 years of age and older. Greater levels of loneliness have also been found to have a distinct association with decreased mood and wellbeing (Golden et al., 2009). Despite the undetermined direction and role of loneliness within the relationship, research suggests that loneliness and cognition have a meaningful and reciprocal relationship.

Increased satisfaction with one's social support network has also been found to have beneficial effects on autonomy and is a central component to older adults' perception of independence (Hillcoat-Nallétamby, 2014). Pin, Guilley, Spini, and d'Epinay (2005) found that in a sample of 340 participants 80 to 84 years old who were assessed annually over a five-year period, the existence of a close friend and contacts with family had a significant beneficial effect on the participants' self-rating of independence. Again, it is the perceived amount of social support that one receives through their social network that contributes to this increased sense of autonomy, rather than the amount of social contact (Hwang, Lin, Tung, \& Wu, 2006). Competence, defined as mobility and sensory ability and related to autonomy, is also negatively 
affected by loneliness; the effect of which is moderated by age, with stronger relations found for those over 70 years (Pinquart \& Sörensen, 2001).

The research above demonstrates how social support may be beneficial for cognitive functioning by buffering the negative effects of multiple mental health factors including depression, stress and loneliness. Additionally, social support has been found to improve feelings

of autonomy, independence and competence, which are all related to successful aging. Increasing social support within residential care could have far reaching beneficial effects for residents, which may promote cognitive health.

\section{Social Support Interventions within Residential Care}

In response to the extensive research supporting the protective qualities of social support on cognitive and psychosocial health, various group-based interventions have been developed and implemented within residential facilities. For example, Winningham \& Pike (2007) facilitated a cognitive training intervention in assisted living centers for three months that was designed to strengthen social relationships among persons with dementia in residential care. Although no improvement in global cognition was reported, the authors found a beneficial effect of cognitive training on self-reported social support and levels of loneliness, compared with the treatment as usual control group. In examining the benefits of reminiscence therapy for residential care participants, Haslam et al., (2010) compared a 6-month group-based and an individual-based reminiscence program, to a group-based control group that played social games together over a 6-month period. It was found that only individuals who participated in the groupbased interventions (i.e., group reminiscence or game playing) experienced improvements in health, wellbeing, social identity, and performance on a memory task (Haslam et al., 2010). 
Together, these studies suggest that there are potential psychosocial and cognitive benefits associated with group-based activities for persons living in residential care.

In a systematic review on randomized control trials (RCTs) investigating the beneficial effects of social support on cognition in dementia patients, it was reported that there were limited published RCTs investigating the beneficial effects of social support interventions for older adults with cognitive impairment (Leung, Orrell, \& Orgeta, 2015). However, the two studies that were included in the review suggest that social support programs have beneficial effects on depression, quality of life, and self-esteem (Leung et al., 2015). Survey research has found that within samples of persons with mild cognitive decline, friendship and socialization are strong motivators to attend group-based activities (Snyder, Jenkins, \& Joosten, 2007). In contrast, for those with more severe cognitive impairment, such as Alzheimer's Disease, learning more about the disease and ways to cope are strong motivators for taking part in such groups.

Although much of the research is in favour of social support, contradictory findings have also been reported. For example, within a cross-sectional, correlational study, Sims et al. (2014) found that belonging, tangible, and self-esteem social support were associated with decline in nonverbal memory and response inhibition. Potentially this is due to the receipt of social support being interpreted as a burden (Reinhardt, Boerner, \& Horowitz, 2006), or, that not being able to reciprocate social support causes distress (Uehara, 1995). In light of this, it is important that effective social support is provided to those who may need it. Furthermore, although social support is significantly implicated in cognitive health, this is a bi-directional relationship. This means that although social support affects cognition, cognition also affects social support. As one experiences increasing cognitive decline, their social network may change as well, such that it becomes smaller due to loss of relationships, with the majority of social support being focused 
on family members (Aartsen et al., 2004). These considerations provide further support for social support interventions within residential care, such that social networks can be preserved and developed for those who may experience increased cognitive decline and social isolation.

\section{Social Programming in Residential Facilities}

Despite the beneficial effects of social support and research suggesting that increased social support promotes positive transitions to residential care and decreased depressive symptoms during this time (Lee et al., 2013), social isolation is common during and after the transition to residential care, due in part to displacement, loss of former social networks, and increased functional dependency (Winstead, Yost, Cotton, Berkowsky, \& Anderson, 2014; McGregor \& Ronald, 2011). Residents often report lack of life purpose and meaning (Choi, Ransom, \& Wyllie, 2008; Knight \& Mellor, 2007), as well as limited chances to provide meaningful contributions so their social surroundings (Van Malderen, Mets, \& Gorus, 2013). These issues are exacerbated for residents with dementia who may find social interaction intimidating or stressful due to the gradual decline in their ability to understand information, communicate, and participate in social activities as the disease progresses (Alzheimer Disease International, 2013). This idea is supported by a study conducted by Burhold et al. (2017), that found cognitive functioning to significantly predict fewer social resources, above and beyond the impact of disability. Burhold et al. (2017) reasoned that older adults may internalize negative stereotypes of cognitive impairment which negatively impact their desired to engage in socially interactive behaviours.

Effort has been made to increase social interaction within residential care; however, there are a number of concerns regarding the current psychosocial approaches that have been employed (Theurer et al., 2015). Theurer et al., (2015) labels the current climate of programming 
within residential care as "institutionalized recreation"; which describes the current focus on providing residents with recreational activities that may be enjoyable, but that do not provide adequate opportunity for receiving and providing meaningful social support (Wiersma \& Dupuis, 2010; Theurer et al., 2015). Recreation calendars typically offer a variety of social events and entertainment; however, based on a 2011-2012 assessment, 44\% of residential care residents in Ontario report having little to no social engagement (Canadian Institute for Health Information, 2013). In this form of programming, residents may become used to passively receiving services, which results in superficial social interactions (Knight \& Mellor, 2007) lacking in the social reciprocity that is significantly related to perceived happiness and life satisfaction (Theurer and Wister, 2010). This issue is found throughout senior living (Katz, 2000; Knight \& Mellor, 2007), indicating that current programing in many residential care settings does not reflect the current body of literature on the beneficial effects of meaningful social support, which highlights perceived emotional support, having a close friend to talk to, and reciprocal engagement as optimally beneficial.

\section{The Java Music Club}

In an attempt to address the disconnect between research and practice in LTC, the Java Music Club was developed (Theurer et al., 2012). The Java Music Club is a standardized peer support group that is facilitated by staff or volunteers across the continuum of care. The Java Music Club comes with facilitator materials that include an instruction manual, a session guide, and a video that outlines group formation and a step-by-step approach for the sessions. The manual also includes 52 themes that can be used to prompt discussion within a given session, as well as photographs and 142 popular recorded songs, sensory suggestions, and short quotes that correspond to each theme. Discussion is promoted through the use of discussion 
questions that are intended to illicit information related to the theme of the week. Residents are encouraged to support one another throughout the discussion process, and to reach out to fellow residents who are lonely or isolated and invite them to the group. The Java Music Club provides weekly opportunities for participants to experience social interaction, feelings of belonging, purpose through helping others, and learning new ways of coping by identifying with other group members who may be going through similar circumstances. The Java Music Club also incorporates themed singing and wind chimes. This musical aspect of the Java Music Club is important to note, as social interventions that incorporate music have been shown to have greater beneficial effects on life satisfaction, interest and emotion in older adults (Ysseldyk, Paric, \& Luciani, 2016).

To date, implementation of the Java Music Club within residential care has been well received, with participants and facilitators reporting that they enjoy the group and that participants enjoy the various elements including the discussion, music, and photos (Theurer et al., 2012). Qualitative research findings have elucidated several positive benefits of the group, including spending time together, building deeper relationships, gaining new respect and understanding for one another, giving and receiving support, sharing fears and burdens, and learning new coping skills (Theurer et al. 2012). Group observations have corroborated these reports and staff have also shared positive experiences with the group and described how the program structure and content fostered empowerment and sharing, including those with moderate to severe cognitive impairment (Theurer et al., 2012). Observations of the facial expressions and body language of six participants with severe cognitive impairment showed that they were focused on the group, although their verbal communication abilities were limited. A further pilot study that was conducted in a community sample of older adults without dementia $(n=16)$ found 
that participants experienced less global cognitive decline, as measured by the MMSE, and depression following a 26-week Java Music Club intervention compared to those who did not participate in the group (Cunningham, 2016). A few limitations of this study should be noted, including irregular attendance that was not precisely quantified in the publication, and a break of two months within the 26-week period in which the group was not facilitated due to staffing shortages. Furthermore, a community sample was used leaving open the question of the relative benefits of the Java Music Club for inhabitants of residential care homes, who may present with a range of cognitive abilities. Additionally, only global cognition was assessed, which means that the beneficial effect of the Java Music Club on specific cognitive domains (VonDras et al., 2005; Aggarwal et al., 2014; Dotson, Resnick, \& Zonderman, 2008) remains to be addressed.

As described in the research above, social support may be able to improve cognitive function, likely by buffering the negative effects of stress, depression, loneliness, and reduced autonomy (Amieva et al., 2010; Pillemer \& Holtzer, 2016; Cohen \& Willis, 1985). Therefore, an intervention that has been empirically proven to promote perceived social and emotional support would be extremely beneficial for the aging community in residential care. Prior research has been conducted using the Java Music Club, however its specific effects on cognition based on regular attendance of the Java Music Club must be further elucidated.

\section{Current Study}

The objectives of the current study were four-fold: 1) to determine whether participation in the Java Music Club has beneficial effects on cognitive function, with a primary focus on executive function inhibition (i.e., primary cognitive outcome of interest). It was hypothesized that participants who took part in the Java Music Club would display improved performance on the Colour-Word Stroop test, evidenced by increased inhibition capacity at post-intervention. 
Tasks that tapped into set-shifting, global cognition and verbal memory were also assessed as secondary cognitive outcomes; 2) to determine whether participation in the Java Music Club has beneficial effects on psychosocial health, with a primary focus on social support and loneliness. It was hypothesized that participants who took part in the Java Music Club would display improved psychosocial functioning post-intervention, evidenced by increased perceived social support and decreased loneliness. Additional measures of psychosocial wellbeing that were assessed included perceived stress, depression and autonomy; 3) to determine whether benefits follow Java Music Club are maintained at a 3-month follow-up period. It was hypothesized that benefits observed at post-intervention would be maintained at follow-up; and 4) to examine the perceptions of the program from the perspective of participants and recreation coordinators to explore acceptability of the program and aspects of the program that promote positive health outcomes.

\section{Methods}

\section{Participants and Participant Recruitment}

Participants were residential care users residing in Toronto, Ontario. For the current study, a power calculation was conducted based on the primary study outcome (executive function inhibition) using G*Power (Faul, Erdfelder, Lang \& Chuner, 2007; with medium effect size, a priori $\alpha=.05 . \beta=.80$, two-tailed), which resulted in a recommended sample size of 34 participants. Due to high attrition rates when working with older adults living in residential care, and for the purpose of this project as a feasibility study, the research team decided a priori to recruit until there was a minimum sample size of 20 participants at post-testing. Through communication with the developer of the Java Music Club, it was decided that each group must include a minimum of five participants. Therefore, four cycles of the 12-week Java Music Club 
intervention were facilitated by the primary investigator (PI, Geneva Millett) at separate residential care centers, with a minimum of five participants in each group (smallest group: $\mathrm{n}=$ 5, largest group: $n=9$ ). The final sample size consisted of 24 participants.

The PI was the first point of contact with the residential care homes via a phone call or email to the center's recreation coordinator. This phone call and email included a brief summary of the Java Music Club and the proposed study. The PI then conducted a recruitment presentation for interested participants at each centre that expressed interest in being involved in the study ( $\mathrm{n}$ =4). During this time, the Java Music Club was described, and details of study participation was explained. Residents who were interested in participating in the study then had the opportunity to register after the presentation or later by contacting the research team or through their recreation coordinator. Recruitment flyers containing information about the study and the Stress and Healthy Aging Research Lab's contact information were also left at each facility in case residents missed the presentation or decided at a later date that they would like to participate.

All residents who voiced interest in participating in the Java Music Club were eligible for inclusion. Those with cognitive impairment or dementia were not excluded from the study, as they are part of the population intended to benefit from social support interventions. For those who presented with advanced dementia or had an acting power of attorney, an assent process was available and was used for five participants.

\section{Study Design and Procedures}

This pilot study followed a pre-post mixed methods study design to investigate the effect of the Java Music Club on measures of cognitive and psychosocial wellbeing. Participants were evaluated at three time-points over a six-month period.

Each testing session was conducted by a trained research assistant (RA) at T1 (baseline), 
T2 (after 3-months of the Java Music Club intervention), and T3 (follow up, 3-months postintervention). The PI was not privy to the data until the end of T3. Each testing session took approximately two hours. To address the risk of participant fatigue, each round of data collection was administered during two visits if necessary (i.e., Pre T1/T1, PreT2/T2, PreT3/T3) and participants were urged to request breaks as needed.

All participants provided written informed consent/assent prior to commencing the study (see Appendix A). The participant testing session at $\mathrm{T} 1$ consisted of: a demographics questionnaire, self-report measures of depression, stress, loneliness, social support and autonomy, and a cognitive test battery. The cognitive test battery measured global cognition, executive function, learning and memory, and attention, as well as subjective memory complaints. This extensive cognitive test battery was administered to elucidate the potential effects of the Java Music Club on different cognitive domains that have been found to associate with mechanisms of social support in past literature (e.g., Pillemer \& Holzer, 2016; Krueger et al., 2009). At all three time points, cognitive measures were attempted first, followed by psychosocial questionnaires. However, due to the nature of the participant population, this pattern was not always achievable, as residents grew fatigued by multiple cognitive tasks and therefore psychosocial questionnaires were often used as a reprieve in between the cognitive tasks. The same procedure was followed at $\mathrm{T} 2$ and $\mathrm{T} 3$. To reduce the potential impact of practice effects at T2 and T3, alternate test forms were used, where available (i.e., Trail Making Test A and B, and the California Verbal Learning Test).

Following data collection at T1, the Java Music Club was administered for one hour, once a week, for 3-months. A 3-month intervention period was chosen based on previous research reporting the beneficial effects of social support over a 12-week period (Winningham \& 
Pike, 2007). Measures were administered at T2 to investigate the effects of the intervention, and then again at $\mathrm{T} 3$ to determine maintenance effects over time. At T2, participants and recreation coordinators had the opportunity to complete a 30-minute optional qualitative interview. Each qualitative interview was audio-recorded and subsequently transcribed verbatim. The interviews were conducted in order to elicit further information about residents' general experience participating in the group, including how they found the social element of the group, what they enjoyed most and least about the group, suggestions for improvement, whether they perceived any subjective benefits from participation and how the group was implemented.

\section{Measures and Questionnaires}

Cognitive test battery. Four cognitive tests and one subjective measure of cognition was administered to participants at three time points (T1, T2, and T3, see Appendix B). The cognitive battery included:

The Stroop Test (Primary study outcome). The Stroop test is used to assess cognitive control and the ability to inhibit a dominant response (Stroop, 1935). The Stroop test has been found to be sensitive to brain damage and is appropriate for use with older adults. The Stroop test starts with two practice trials. The first trial is composed of 40 exposures where the participant is required to press a keyboard key that corresponds with the colour of ink that a series of Xs is presented in on the screen. The second trial is a practice trial that requires the participant to press the key that corresponds with the colour of ink that either a series of Xs or a colour word is presented in on the screen and consists of 25 exposures. Once both practice trials have been completed, and the participant has voiced that they understand the task, they will then complete the test trial which is the same as the second practice trial but consists of 216 exposures. Test administration for the Stroop is 15 minutes on average. Typically, participants demonstrate 
slower reaction times for incongruent colour words compared to congruent colour words and therefore, the Stroop effect is calculated by subtracting the reaction time on the congruent trials from the incongruent trials.

Mini Mental State Examination (MMSE). The MMSE is used to assess global cognition by assessing five areas of cognitive functioning (i.e., orientation, attention, calculation, language, and immediate and delayed recall; Folstein, Folstein, \& McHugh, 1975). The MMSE is useful to screen for cognitive impairment in older adults, track cognitive changes over time and assess the effects of interventions on cognition. The test is scored out of 30 points, with 30 being the maximum, indicating high global cognitive function. Although cut off scores vary between studies, Folstein et al. (2001) suggest that scores $>27=$ normal, 21-25 = mild, 11-20= moderate, and $<10=$ severe cognitive impairment. The test takes approximately 10 minutes to administer and has been validated for use with those aged 18 to $85+$. The MMSE has a concurrent validity of .78 and a test-retest reliability of 0.89 .

The Trail Making Test $A$ and $B(T M T A$ and $B)$. The TMT is a neuropsychological test that measures attention, speed and mental flexibility (Reitan, 1958). Part A requires subjects to connect 25 encircled numbers in ascending order (i.e., 1, 2, 3, 4, etc.) and measures visual search and motor skills. Part B requires subjects to connect encircled number and letters in ascending alternating order (i.e., 1, A, 2, B, etc.) and in addition to visual search and motor skills it measures executive function, specifically set shifting (i.e., cognitive flexibility). Errors and response times are recorded, with longer response times corresponding with poorer attention (TMT A) and poorer set shifting (TMT B). This task takes approximately six minutes to administer. 
The California Verbal Learning Test-II (CVLT-II). The CVLT is used to assess episodic verbal learning and memory (Delis, Kramer, Kaplan, \& Ober, 2000). The task requires participants to recall a list of 16 words immediately after the list is read to them by the experimenter, for a total of five trials. Following a 20-minute delay, participants engage in a freerecall trial of the 16 words, followed by a recognition recall trail of the list. Items recalled correctly, intrusions and repetitions are recorded for each individual trial, with greater number of items recalled indicating better episodic memory. The CVLT-II has been validated in a sample of older adults and has an internal consistency of $0.78-0.94$ and a test-retest reliability of 0.80 0.84 (Delis et al., 2000). For the purpose of the current study, immediate recall (i.e. total number of words recalled over five trials, possible range from 0 to 80 ) and delayed recall (free recall of word list after 20 minutes, possible range from 0 to 16) were analyzed.

Prospective-Retrospective Memory Questionnaire (PRMQ). The PMRQ uses 16 items to measure subjective memory complaints. The questionnaire asks participants to rate how often certain memory occurrences happen on a 5-point scale that ranges from 1 (never) to 5 (very often). The minimum score that a participant can receive is 16 , and the maximum is 80 , with a higher score corresponding to greater subjective memory complaints. Reliabilities of the PRMQ range from .80-.89. (Smith et al., 2000, Crawford et al., 2003). In the current study, the PRMQ demonstrated acceptable to excellent internal reliability (i.e., Cronbach's $\alpha=.83, .90$ and .79 at T1, T2 and T3, respectively).

Psychosocial questionnaires. In addition to psychosocial outcomes of stress, depression, loneliness, social support and autonomy, participants also completed a demographics questionnaire at baseline to characterize the sample (e.g., age, sex, medical comorbidities). The following questionnaires were employed in the study (see Appendix C): 
Demographics questionnaire. The demographics questionnaire consists of 13 items. These items collected information about the participants age, marital status, education, and relevant medical history including visual or hearing concerns. The demographics questionnaire also asked how many years each participant had been living in residential care and what residential programs they took part in.

Revised UCLA Loneliness Scale. The UCLA loneliness scale was designed to measure subjective feelings of loneliness and social isolation. The revised version was used, which uses simplified wording and has 10 out of the 20 items reverse scored. The revised UCLA has been found to be both reliable and valid within a sample of older adults (Russell, 1996). Example items on the UCLA Loneliness scale are "There is no one I can turn to" and "People are around me but not with me" that are rated on a Likert scale from 1 (Never) to 4 (Often) with higher scores indicating greater perceived loneliness. Within the current sample, the UCLA-R Cronbach's $\alpha$ ranged from $.88-.90$, which suggests good internal reliability at all three time points.

Centre for Epidemiologic Studies Depression Scale (CES-D). The CES-D is a 20-item self-report tool that is used to screen for depression and measures sadness, loss of interest, appetite, sleep, thinking/concentration, guilt, fatigue, movement and suicidal ideation (Radloff, 1977). The CES-D has demonstrated high test-retest reliability (.45 to .70), internal consistency $(\alpha=.85-90)$ and validity within a general sample (Radloff, 1977), and the psychometrics are sustained with older adults (Beekman et al., 1997). The CES-D is composed of 20 items that are answered on a 4-point scale. Example items include "I thought my life had been a failure" and "I did not feel like eating, my appetite was poor." Higher scores on the CES-D corresponds with greater depressive symptoms. Within the given sample, Cronbach's $\alpha$ varied from good, to 
acceptable to questionable (ie., $\alpha=.82, .74, .66$ at $\mathrm{T} 1, \mathrm{~T} 2$ and $\mathrm{T} 3$, respectively) which suggest more dispersion in responding over time.

Perceived Stress Scale (PSS). The PSS is composed of 10 questions that aim to determine how unpredictable, uncontrollable, and overloaded respondents find their lives (Cohen, Kamarck, \& Mermelstein, 1983). The 10 items are answered on a 5-point likert scale from 0 (never) to 4 (very often). The PSS is the most widely used test to measure perceived stress. The PSS has high internal validity (Cronbach's alpha $>0.70$ ) and good test-retest reliability (Rho > 0.70) (Leung, Lam \& Chan, 2010; Mimura \& Griffiths, 2008). Example items include "In the last month, how often have you felt difficulties were piling up so high that you could not overcome them?" and "In the last month, how often have you felt nervous or 'stressed'?", and higher scores suggest greater perceived stress. Within this sample, internal reliability ranged between questionable to acceptable (i.e., $\alpha=.77, .76, .66$ at T1, T2 and T3, respectively).

The Medical Outcomes Study-Social Support Survey (MOS-SSS). The MOS-SSS is a brief multidimensional scale that was developed and validated for use with older adults and those with chronic conditions (Sherbourne \& Stewart, 1991). The 19 items of the MOS-SSS measure emotional support/informational support, tangible support, affectionate support, and positive social interaction (Sherbourn \& Stewart, 1991). Therefore, a total score and four subscores that correspond to the four hypothesized factors can be calculated with greater scores suggesting larger and more meaningful social networks. Cronbach's alpha ranges from .91-.97 for all of the sub scores and the overall measure (Sherbourn \& Stewart, 1991). Within the current study sample, Cronbach's $\alpha$ ranged from $.91-.97$ suggesting excellent internal reliability. Example items include "Someone to confide in or talk to about yourself or your problems" and "Someone 
to take you to the doctors if you needed it" that are rated on a Likert scale from 1 (None of the time) to 4 (All of the time).

Hertz Perceived Enactment of Autonomy Scale (HPEAS). The HPEAS is a self-report scale that measures participants perceived ability to make decisions to meet their needs for independence or dependence (Hertz \& Anschutz, 2002). The scale was developed for use with older adults and includes 31 items on a 4-point likert scale from "not at all true" to "completely true" (Hertz \& Anschutz, 2002). Nine items tap into the subscale for voluntariness and selfdirection, and 13 items are used to assess individuality. Scores range from 31 to 124, with higher scores indicating a higher level of perceived autonomy. Cronbach's $\alpha$ for the total scale was 0.87, the subscale alphas with $0.71,0.76$, and 0.74 (Hertz \& Anschutz, 2002). Within this sample, Cronbach's $\alpha$ was $.85, .85$, and .92 at T1, T2 and T3, respectively, suggesting good to excellent internal reliability. Example items include "I do what I think is best for me in my life" and "other people act for me when I do not want them to".

Qualitative interview. In order to explore the perceptions of participants with the Java Music Club, semi-structured interviews were conducted by trained research assistants and analyzed using thematic analysis as outlined by Braun \& Clark (2012). Qualitative interviews were conducted with all participants who volunteered to participate in this qualitative aspect of the study at $\mathrm{T} 2$, as well as with recreation coordinators from three of the four participating sites (See Appendix D). Those who wished to participate signed an additional consent form (see Appendix A). Parallel interview guides were developed for residents and recreation coordinators. The interviews consisted of open-ended questions that elicit information about the five prominent domains that are important for implementation including: Java Music Club characteristics, the setting within the Java Music Club itself and the setting within which it is 
conducted, information about the experience of the individuals who participated, and how the group was implemented (Damschroder et al., 2009). Additional information collected during the interview was the participant's experience with the Java Music Club; particularly, whether they felt that group effected their social engagement in any way, and if they experienced any unique benefits from participating in the group. Interviews were piloted with five residents, at which time additional prompts were added in order to encourage detailed data collection.

\section{Data Analyses}

Quantitative. Data were analyzed using SPSS version 23 (IBM, 2015). All data were checked for normality violations by investigating skew, kurtosis, Kolmogorov-Smirnov statistic, significant outliers, and visual analysis of histograms. Based on best practices for small sample sizes (i.e., $\mathrm{N}<50$ ), data were found to violate normality assumptions when: 1) skew and kurtosis $\mathrm{z}$ scores were $\geq 1.96,2$ ) there was evidence of a significant Kolmogorov-Smirnov test (i.e., $\mathrm{p}<$ $.05)$, and 3) histograms displayed visibly abnormal distributions of data (Kim, 2013). Differences between participants who completed testing at T1 and T2 were compared to those who only completed testing at T1 using independent samples t-tests (for interval dependent variables), Wilcoxon Mann-Whitney tests (for ordinal dependent variables) and Chi-Square tests (for dichotomous dependent variables).

In order to preserve power given the small sample sizes, the primary and secondary objectives were assessed using paired t-tests, to determine immediate benefits following the 3month intervention program. The third objective was assessed using a repeated measures analysis of variance over three time points (RM ANOVA). Data that were found to violate assumptions of normality were analyzed using the Wilcoxon signed-rank test and Friedman's test in replacement of the paired-sample t-test and RM ANOVA, respectively. 
Qualitative. Qualitative interview audio-recordings were transcribed verbatim. Transcriptions were analyzed by the PI using thematic analysis in order to make inferences from the data and provide insight into the Java Music Club and how it is experienced in residential care (Braun \& Clark, 2012). The inductive approach to thematic analysis was used such that the categories were generated from the data itself through open coding (Braun \& Clark, 2012). The preparation, organization and reporting of the interview data were conducted according to the phases outlined by Braun \& Clark (2012). First, the hard copies of transcribed interviews were reviewed several times and notes were taken in order to become familiar with the data. During the second phase, semantic and latent codes were generated in order to label recurring features of the data that was relevant to residents' perceptions of the Java Music Club. During the third phase, codes were clustered into themes and subthemes based on similarities and overlap between codes in order to identify significant patterns in the data. This was done using Microsoft word and placing similar quotes together based on themes and sub-themes. The themes were then reviewed during a recursive process with the coded data, defined and named, and particularly salient extracts were selected.

During the thematic analysis, steps were taken to promote recommended reliability procedures for qualitative analyses. Specifically, based on an article by Morse, Barrett, Mayan, Olson, and Spiers (2002), techniques for reliability of qualitative research were incorporated including an audit trail to reflect the thematic analysis process through documentation of interpretations, category selection and decisions for inclusions (Morse et al., 2002). It is important to note that the PI was both the facilitator of the Java Music Club, and the primary coder for the qualitative analysis. Acknowledging this fact, a second reader (i.e., trained research assistant) who did not take part in Java Music Club facilitation or qualitative interviews, 
participated in all stages of the analysis, such that themes, sub-themes, and interpretations were discussed with this research assistant as they were being developed. This allowed for investigator triangulation, such that interview content was investigated by two researchers, thereby supporting the reliability of themes derived and reducing possible bias.

\section{Results}

\section{Participants}

Baseline characteristics of the 24 participants are presented in Table 1. Small sample size precluded the ability to account for covariates in any analyses, however a correlation table suggests that age, ethnicity and hearing concerns could be possible covariates (see Table 2) as there are significant correlations between age and PRMQ, ethnicity and TMT A, UCLA, and HPEAS, and hearing concerns with MOS-SSS. Mean age of the sample was 83.33 (7.76) and $91.7 \%$ were women. The mean number of years living in residential care was 2.91 (2.4).

On average, participants attended $10.33(\mathrm{SD}=1.9)$ of the twelve Java Music Club sessions, with $37.5 \%$ attending all 12 sessions. Participant drop out $(n=5)$ was due to a change in schedule $(\mathrm{n}=2)$, death $(\mathrm{n}=1)$, and unknown reasons $(\mathrm{n}=2)$. Those who dropped out before $\mathrm{T} 2$ were not significantly different from those who participated in $\mathrm{T} 2$ testing in terms of gender, age, self-rated health, years in residential care, level of education or MMSE score.

\section{Table 1}

Demographics information for all participants who completed testing session at $T 1$ and $T 2$

\begin{tabular}{llll}
\hline Variable & $\mathrm{N}$ & Mean (SD) & Frequency (\%) \\
\hline Age & 24 & $83.33(7.76)$ & \\
Years in residential care & 18 & $2.91(2.4)$ & \\
Sex (female) & 24 & & $22(91.7)$ \\
Marital status & 24 & & \\
$\quad$ Married & & & $4(16.7)$ \\
$\quad$ Widowed & & & $14(58.3)$ \\
$\quad$ Divorced/Single & & & $6(25)$
\end{tabular}


Level of education

Completed highschool

Some graduate education

Completed college/university

Other

Region of Origin

Canada

Europe/United Kingdom

Other

Ethnicity

Aboriginal/First Nations/Metis

White/European

Black/African/Caribbean

Southeast Asian

South Asian

Hearing Concerns

Yes

Hearing Aids

No

Mobility Concerns

Yes

Walking Aids

No

Hypertension

Yes

Treated

No

Neurological Concerns

Yes

Treated

No

Cardiovascular Disorders

Yes

Treated

No

Cancer

Yes

Treated

No

Prior Mental Health Concerns

Depression

Treated

Anxiety

24

7 (29.2)

7 (29.2)

$7(29.2)$

3 (12.6)

24

$15(62.5)$

$5(20.9)$

4 (16.8)

23

$1(4.2)$

$18(75)$

$2(8.3)$

$1(4.2)$

$1(4.2)$

23

$6(25)$

$6(100)$

$17(70.8)$

24

$12(50)$

12 (100)

$12(50)$

23

7 (28)

7 (100)

16 (64)

24

4 (16.6)

4 (100)

$20(83.3)$

24

$8(33.3)$

$6(75 \%)$

24

6 (24)

4 (66.6)

$18(75)$

24

$2(8.3)$

2 (100)

6 (25)

$3(50)$ 
Table 2

Correlations between predictor variables, outcome variable, and possible covariates

\begin{tabular}{|c|c|c|c|c|c|c|c|c|c|c|c|c|c|c|c|c|c|c|c|}
\hline Variables & 1 & 2 & 3 & 4 & 5 & 6 & 7 & 8 & 9 & 10 & 11 & 12 & 13 & 14 & 15 & 16 & 17 & 18 & 19 \\
\hline 1. Age & - & - & - & - & - & - & - & - & - & - & - & - & - & - & - & - & - & - & - \\
\hline 2. Gender & -.22 & - & - & - & - & - & - & - & - & - & - & - & - & - & - & - & - & - & - \\
\hline $\begin{array}{l}\text { 3. Level of } \\
\text { education }\end{array}$ & -.26 & .23 & - & - & - & - & - & - & - & - & - & - & - & - & - & - & - & - & - \\
\hline $\begin{array}{l}\text { 4. Marital } \\
\text { status }\end{array}$ & -.12 & .08 & .02 & - & - & - & - & - & - & - & - & - & - & - & - & - & - & - & - \\
\hline 5. Ethnicity & -.04 & -.35 & .03 & .09 & - & - & - & - & - & - & - & - & - & - & - & - & - & - & - \\
\hline $\begin{array}{l}\text { 6. Mobility } \\
\text { concerns }\end{array}$ & -.22 & -.12 & .34 & -.27 & -.01 & - & - & - & - & - & - & - & - & - & - & - & - & - & - \\
\hline $\begin{array}{l}\text { 7. Hearing } \\
\text { concerns }\end{array}$ & -.15 & .00 & -.07 & .10 & .25 & .37 & - & - & - & - & - & - & - & - & - & - & - & - & - \\
\hline 8. MMSE & .01 & -.02 & -.01 & .15 & -.36 & -.19 & -.40 & - & - & - & - & - & - & - & - & - & - & - & - \\
\hline $\begin{array}{l}\text { 9. TMT A } \\
\text { Time }\end{array}$ & .19 & -.20 & -.31 & -.20 & $.43 *$ & .13 & .25 & $\begin{array}{l}-.77 \\
* *\end{array}$ & - & - & - & - & - & - & - & - & - & - & - \\
\hline $\begin{array}{l}\text { 10. TMT B } \\
\text { Time }\end{array}$ & .41 & -.40 & -.27 & -.03 & .14 & -.28 & -.21 & $\begin{array}{c}-.64 \\
*\end{array}$ & .45 & - & - & - & - & - & - & - & - & - & - \\
\hline $\begin{array}{l}11 . \\
\text { Immediate } \\
\text { recall }\end{array}$ & .07 & .19 & .11 & -.16 & $\begin{array}{l}-.40 \\
*\end{array}$ & .16 & -.00 & $\begin{array}{l}.76 \\
* *\end{array}$ & $\begin{array}{l}-.52 \\
* *\end{array}$ & -.27 & - & - & - & - & - & - & - & - & - \\
\hline $\begin{array}{l}\text { 12. Long } \\
\text { delay free } \\
\text { recall }\end{array}$ & .11 & .17 & .12 & -.14 & .38 & .07 & -.02 & $.77 *$ & $\begin{array}{c}-.52 \\
* *\end{array}$ & -.36 & $\begin{array}{l}.97 \\
* *\end{array}$ & - & - & - & - & - & - & - & - \\
\hline
\end{tabular}




\begin{tabular}{|c|c|c|c|c|c|c|c|c|c|c|c|c|c|c|c|c|c|c|c|}
\hline $\begin{array}{l}\text { 13. Stroop } \\
\text { effect }\end{array}$ & .30 & .27 & -.13 & .16 & -.11 & -.11 & .20 & .39 & $\begin{array}{c}-.46 \\
*\end{array}$ & .12 & .36 & .34 & - & - & - & - & - & - & - \\
\hline $\begin{array}{l}\text { 14. MOS- } \\
\text { SSS }\end{array}$ & .19 & .24 & -.05 & -.16 & -.02 & -.20 & $\begin{array}{c}-.49 \\
*\end{array}$ & $.45^{*}$ & -.37 & -.01 & .14 & .15 & .09 & - & - & - & - & - & - \\
\hline 15. PSS & .04 & -.09 & -.20 & -.08 & .28 & .08 & .31 & -.06 & .07 & .54 & .03 & -.01 & .11 & -.11 & - & - & - & - & - \\
\hline 16. UCLA & .05 & -.13 & -.17 & -.21 & $\begin{array}{c}-.41 \\
*\end{array}$ & .13 & -.30 & .12 & .20 & .08 & .08 & .09 & -.01 & .22 & -.30 & - & - & - & - \\
\hline 17. CES-D & .10 & .08 & -.06 & .01 & .03 & -.16 & .07 & -.10 & .04 & .44 & -.08 & -.08 & -.02 & -.26 & $\begin{array}{l}.61 \\
* *\end{array}$ & $\begin{array}{c}-.62 \\
* *\end{array}$ & - & - & - \\
\hline 18. HPEAS & -.04 & .26 & .15 & -.17 & $\begin{array}{c}-.47 \\
*\end{array}$ & .06 & -.20 & $.42 *$ & -.34 &. & $.39 *$ & $.45^{*}$ & .30 & .18 & $\begin{array}{c}-.64 \\
* *\end{array}$ & $.40 *$ & $\begin{array}{c}-.58 \\
* *\end{array}$ & - & - \\
\hline 19. PRMQ & $.41^{*}$ & -.14 & -.35 & -.13 & .20 & -.21 & .01 & -.09 & .21 & $.66^{*}$ & -.19 & -.14 & .04 & .31 & $.39 *$ & .04 & .21 & $\begin{array}{l}-.43 \\
*\end{array}$ & - \\
\hline
\end{tabular}

* Correlation is significant at the $p<.05$ level

** Correlation is significant at the $p<.01$ level

Note: Spearman's Rho is reported for correlations including monotonic variables (i.e., gender, level of education, marital status, ethnicity, mobility concerns, hearing concerns) and Pearson's $r$ is reported for correlations for linear relationships (i.e., age, MMSE, TMT A, TMT B, immediate recall, long delay free recall, Stroop effect, MOS-SSS, PSS, UCLA, CES-D, HPEAS, PRMQ). 


\section{Objective 1: Effects of the Java Music Club on Cognitive Function from T1 to T2}

Paired t-tests were conducted for normally distributed variables (i.e., MMSE, Stroop

Effect and PRMQ) and Wilcoxon signed-rank tests were conducted for non-normally distributed variables (i.e., TMT, CVLT short and long delay free recall). The primary outcome of interest was executive function inhibition, as measured by the Colour-Word Stroop test. Paired t-test indicated no statistically significant difference in the Stroop effect between $\mathrm{T} 1$ and $\mathrm{T} 2 ; t(12)=-$ 1.93, $p=.079($ see Table 3$)$.

As shown in Table 2, the Java Music Club did not significantly change scores on the MMSE, $t(23)=-.38, p=.709$, TMT A, $Z=-.37, p=.709$, or TMT B, $Z=-.97, p=.333$.

Furthermore, the Java Music Club did not significantly change performance on immediate recall, $Z=-1.02, p=.308$, or long-delay recall of the CVLT, $Z=-1.03, p=.305$. Finally, no significant change was observed for subjective memory complaints, $t(19)=1.04, p=.311$.

Table 3

Mean (standard deviation) performance on cognitive tests across testing sessions

\begin{tabular}{llll}
\hline & T1 & T2 & T3 \\
& M (SD) & M (SD) & M (SD) \\
\hline Stroop & $206.50(248.08)$ & $360.1453(241.23)$ & $312.29(234.3)$ \\
MMSE & $21.42(6.25)$ & $21.63(5.96)$ & $23.20(4.97)$ \\
TMT-A & $109.83(85.65)$ & $95.24(72.36)$ & $84.33(65.44)$ \\
TMT-B & $157.36(46.45)$ & $178.82(77.71)$ & $118.89(39.25)$ \\
CVLT Immediate Recall & $3.74(3.90)$ & $3.75(4.24)$ & $4.06(3.93)$ \\
CVLT Long-delay Recall & $3.83(4.29)$ & $3.58(4.45)$ & $4.69(4.22)$ \\
PRMQ & $34.43(7.95)$ & $32.10(9.51)$ & $29.50(5.50)$ \\
\hline
\end{tabular}

${ }^{a}$ Values obtained from t-test and Wilcoxon signed-rank tests

b Values obtained from RM ANOVAs and Friedman's test Note: Stroop T1 and T2 $n=13, \mathrm{~T} 3 \mathrm{n}=11$; MMSE T1 and T2 $\mathrm{n}=24$, T3 = 20; TMT A T1 and T2 $\mathrm{n}=21$, T3 = 17; TMT B T1 and T2 $\mathrm{n}=18$, T3 $\mathrm{n}=9$; CVLT Immediate recall and long-delay recall)T1 and T2 $\mathrm{n}=20, \mathrm{~T} 3 \mathrm{n}=17$; PRMQ T1 and T2 $\mathrm{n}=20, \mathrm{~T} 3=18$

\section{Objective 2: Effects of the Java Music Club on Psychosocial Health from T1 to T2}

The secondary objective of this pilot study was to investigate the effects of the Java Music Club on psychosocial health, including social support, loneliness, depression, perceived 
stress and autonomy. Paired t-tests were used for comparing means between $\mathrm{T} 1$ and $\mathrm{T} 2$ for

UCLA, CES-D, PSS, HPEAS. Wilcoxon signed-rank tests were used to investigate mean difference for MOS-SSS.

As shown in Table 4, Java Music Club was associated with significant reductions in selfreport loneliness, $t(20)=3.31, p=.003$. However, there was no significant change in MOS-SSS scores from $\mathrm{T} 1$ to $\mathrm{T} 2, Z=-.63, p=.532$, depressive symptoms, $t(19)=.07, p=.948$, perceived stress, $t(20)=.24, p=.816$, or autonomy, $t(19)=-1.15, p=.265$.

Table 4 Mean (standard deviation) self-reported psychosocial wellbeing across testing sessions

\begin{tabular}{llll}
\hline & T1 & T2 & T3 \\
& M $(\mathrm{SD})^{\mathrm{a}}$ & $\mathrm{M}(\mathrm{SD})^{\mathrm{a}}$ & $\mathrm{M}(\mathrm{SD})$ \\
\hline MOS-SSS & $3.17(.59)$ & $2.99(.82)$ & $3.18(.64)$ \\
UCLA & $41.71(9.21)$ & $38.95(9.05)$ & $39.05(9.50)$ \\
CES-D & $14.15(9.23)$ & $14.05(7.39)$ & $10.72(5.96)$ \\
PSS & $13.57(7.15)$ & $13.19(6.21)$ & $15.33(5.48)^{\mathrm{a}}$ \\
HPEAS & $99.35(14.52)$ & $102.20(12.93)$ & $98.11(17.29)$ \\
\hline
\end{tabular}

${ }^{a}$ Values obtained from t-test and Wilcoxon signed-rank tests

b Values obtained from RM ANOVAs and Friedman's test

Note: UCLA T1 and T2 $\mathrm{n}=21$, T3 $\mathrm{n}=19$; MOS-SSS T1 and T2 $\mathrm{n}=22$, T3 = 20; CES-D T1 and $\mathrm{T} 2 \mathrm{n}=20, \mathrm{~T} 3=19 ;$ PSS T1 and T2 $\mathrm{n}=21, \mathrm{~T} 3 \mathrm{n}=19 ;$ HPEAS T1 and T2 $\mathrm{n}=20, \mathrm{~T} 3=18$

\section{Objective 3: Effects of the Java Music Club at 3-month Follow Up}

RM ANOVA's were conducted for MMSE, Stroop effect, PMRQ, UCLA, CES-D, HPEAS. Friedman's tests were conducted to investigate TMT A, TMT B, CVLT, PSS and MOSSSS.

There was a significant difference for or TMT B, $\chi^{2}(2)=7.23, p=.027, Z=-.95, p=$ .05 , suggesting improvements in set-shifting at $\mathrm{T} 3$. There was also a significant change in PMRQ, $F(1.43,24.40)=3.84, p=.048$, such that subjective memory complaints decreased from $\mathrm{T} 2$ to $\mathrm{T} 3, t(17)=2.89, p=.010$. There was no significant difference over time for Stroop inhibition, $F(2,20)=.71, p=.50$, MMSE, $F(2,36)=.29, p=.748$, or TMT A, $\chi^{2}(2)=.35, p=$ 
.838. There was also no difference over the three time points for CVLT immediate free recall, $\chi^{2}(2)=2.00, p=.368$, and long delay free recall, $\chi^{2}(2)=3.85, p=.146$. See Table 3 for mean performance on cognitive tasks across testing sessions.

In terms of psychosocial questionnaires, there was a significant effect on depression, $F(2,34)=3.46, p=.043$, such that depressive symptoms decreased between $\mathrm{T} 2$ and $\mathrm{T} 3, t(17)=$ $2.80, p=.012$. There was also a significant omnibus effect for loneliness, $F(2,36)=3.94, p=$ .028 , however there was no significant difference between loneliness at $\mathrm{T} 2$ and $\mathrm{T} 3, t(18)=-.22$, $p=.828$. There was no significant difference between MOS-SSS at all three time points, $\chi^{2}(2)=$ $.35, p=.839$. There was no significant difference over the three time points for PSS, $\chi^{2}(2)=$ $1.25, p=.536$, or autonomy, $F(2,34)=.60, p=.556$. See Table 4 for mean scores on psychosocial questionnaires across testing sessions.

\section{Objective 4: Qualitative Investigation of the Java Music Club}

Nineteen residents and three recreation coordinators from the four residential care centres engaged in qualitative interviews conducted by trained research assistants. As per qualitative research methods standards, data saturation was achieved. There was evidence of data saturation after 15 interviews when interviews became predictable and no new information was being reported, supporting confidence in the representativeness of themes shared by participants. Interview data from residents and recreation coordinators was considered together given the overlap in themes identified.

Two main thematic areas emerged from the data: the personal experience of participating in the Java Music Club, and the observations and feedback related to implementation of the Java Music Club. Please see Table 5 for the themes and subthemes. 
Personal experience of participating in the Java Music Club. Three sub-themes were identified within this theme: the Java Music Club was an enjoyable and positive experience overall, the Java Music Club promoted social engagement, and the Java Music Club benefited the social emotional well-being of residents.

\section{The Java Music Club was an enjoyable and positive experience overall. When} reflecting upon the Java Music Club in general, participants reported that it was a "very positive" and "fun" experience, that they "enjoyed it", and that "it's a very pleasant way to spend the hour". These sentiments were also supported by recreation coordinators, who relayed that participants "really loved it", that "they seemed to enjoy it", and that participants would often discuss the group with residential staff. Recreation coordinators voiced that it seemed as though residents "felt extra special ...that they were part of a group".

One condition that appeared to contribute to the positive experience was the comfort and support that residents experienced while being part of the group. Residents reported that "we were all comfortable with each other and were happy to share our stories with each other". Participants reported that the Java Music Club was supportive and "not threatening in any way", which served to facilitate sharing between participants. Although not all residents reported needing support for current personal issues, one resident said: "I think that if I had a problem and so on, everyone would be very supportive. At this point I don't happen to have a particular problem that needs support...but I am sure that it would be there if I needed it". Interviews demonstrated that a reason why residents reporting feeling comfortable sharing with each other was because they felt that fellow group members could relate to what they were saying. For example, one resident reported "I was with people that I could talk with that were in the same situation as me", and another said "we are all experiencing the same daily routines". 
The Java Music Club promoted social engagement. All residents and recreation coordinators reported that social engagement was promoted in some capacity during their time in the Java Music Club. For example, residents noted that "it's good, good associating with other people taking part in the activities" and that "it's good to get out and talk- it's too easy to sit in your apartment suite, you know, and I think 'Oh, I have to go to that Java time, I better hurry up'...I think any activity you do at a place like this is beneficial."

One way in which the Java Music Club increased social engagement was though promoting listening, sharing and reminiscing. Residents reported that "the sharing was really good... we were given a topic to talk about and then each person did what they wanted to with that topic and that was good". Another resident said "what I liked was when the person was saying what they thought about the topic and somebody else chimed in...it was an open discussion sort of thing". Additionally, this sharing and storytelling provided the opportunity for residents to reminisce together when common experiences were recognized, for example one resident reported that "it was interesting hearing all the peoples' stories and reminiscing about our pasts. Yes, that was good" and another said "it was nice to hear other people's stories". Additionally, residents who were more shy and did not feel as comfortable sharing their own experiences still reported that they "enjoyed hearing about other people", for example "how they grew up". Furthermore, residents also reported that it was interesting to "learn more about different people", from "different walks of life".

Many residents reported that the Java Music Club increased initiation of social interactions outside of the Java Music Club. For some, this included becoming closer with acquaintances that they already had before participating; "just a couple of the people that I didn't know, I got to know a little bit better". For others, this included "making new friends" and 
having verbal interaction with residents who had previously been a familiar face. These verbal interactions were fostered in many different ways. For example, one resident reported that "people that you met in the elevator and waiting for lunch, and what not, you could talk a little bit more than you would have before", and a recreation coordinator noted that she observed residents "stopping at each other's tables at lunch and dinner. So instead of going straight from their table back upstairs, they will stop and say 'hey how are you?', 'You coming to this?', 'Yeah you coming for this?' So there was this bonding". Recreation coordinators also noted an increase in conversations between residents outside of the Java Music Club, sometimes about the group and other times just to chat. At one home where residents were recruited from two different units, the recreation coordinators said: "another good thing I noticed was social interaction with a resident from a different floor... So they don't normally see those residents on a daily basis so yeah I noticed more interaction and they got to know them better". Recreation coordinators also noted more interaction in communal spaces, such as "coming outside on the terrace, they would go like 'hi', and you know, they would chat for a little bit'.

The Java Music Club benefited the social emotional well-being of residents. The reported benefits varied between residents in degree and kind, from no benefit to supporting significant gains in social emotional well-being. A common perceived benefit included increasing social interaction (noted above). However, additional benefits that were reported by residents included: getting involved in programming, such that the program "allow[s] you to participate"; understanding other peoples" perspectives, such that "it brings up your spirit, you feel better when you come out and enjoy it with the other people"; and the opportunity to express oneself, such that the program allowed them to "get some things in discussion out of me that I hold inside, you know?". One resident remarked that the Java Music Club made her more 
outgoing within the home, such that she was "not afraid to speak to somebody now". Another resident said that "the affirmation helped [her]"; more specifically, the resident shared that "I thought it was difficult to feel good about yourself and that kind of thing...I changed my mind...I changed my mind and I said 'if you keep repeating something that's good, it happens'...eventually it sinks in and that's how you feel inside".

Participant Observations and Feedback Related to the Implementation and Core Elements of the Java Music Club. Regarding participants' and recreation coordinators' experience with the Java Music Club implementation, four important subthemes emerged: favourite content, important implementation factors, addresses an existing gap in services, and accessibility that promotes engagement.

Java Music Club Content. When participants were asked about their favourite parts of the Java Music Club, they either referred to the group as a whole (i.e., "I don't have a favourite part, I think, just the whole thing, you know?") or specified the social aspect or the music.

About half of the residents reported that they were "really glad when we start discussing things" and that it was interesting to "[give] stories of things that have happened in [their lives]" and that they "found it interesting... listening to someone else's attitude about something" and sharing stories. Residents reported that they enjoyed that there was a different topic every week. Additionally, socializing was reported as one of the most common reasons for joining the Java Music Club. Recreation coordinators also noted that social interaction with fellow residents was an important impetus for wanting to bring the Java Music Club to their residential facility. For example, one said "I think the predominant aspect of the group is social. The music is a catalyst to create belongingness and a sense of comfort, a sense of reminiscence. But really the social aspect, that's the biggest for me. I love any program that allows residents to get to know each 
other, that fosters friendships and connections that go beyond the program". Even residents who were "a bit on the nervous side" and "not used to speaking out about [themselves]" reported that they enjoyed "listening to others, what they have to say" and that they "enjoyed it all".

The music was also an often cited "favourite thing" about the Java Music Club. Residents reported that they "enjoy the music on a whole" and that "most of the music that was chosen was very relevant to the age group", as many residents, including those with cognitive impairment, recognized a majority of the songs. Although the majority of the residents enjoyed the music as is, one resident would have preferred the music to be more high-tempo. Several residents reported that they were "used to having music around [them]... and I just uh, you know, I appreciated it when I was a part of it here". In fact, when asked what interested residents about the Java Music Club, many reported that the word "music" in the title made them interested in seeing what the Java Music Club was all about. Although some residents were more confident singers than others, even residents who did not considered themselves as such reported enjoying singing or listening to others sing. For example, one resident said, "I like to sing, I am not a good singer, but I enjoy it, and I like to be in a group with the people around me", and another said "I'm not musical...I start singing, everybody runs. But uh I like to listen to music". Some residents also noted that the "music makes you happier", "if you're down you put music on", and that "anything to do with music I can benefit from". Additionally, recreation coordinators noted that singing was an activity that many residents enjoyed, and that "the fact that music was in the title, everyone on this floor loves music, so I thought it would be like a really good fit" and that this factored into their decision to conduct the Java Music Club at their residence.

Implementation factors. Important elements that residents often reported as impacting their experience with the Java Music Club included the facilitator and group composition. 
Throughout the interview or when prompted whether participants had anything to add at the end of the interview, many participants made reference to the Java Music Club facilitator. Participants noted the importance of the facilitator in promoting discussion and sharing, and making the Java Music Club a welcoming, comfortable, and non-threatening environment. For example, residents said that the facilitator was "great, very gentle, but very positive and easy to talk with so that was good", "friendly and outgoing and we found that very nice you know" and that for a "couple of women [the facilitator] got them opening up more". Another resident noted the importance of the facilitator being "the type of person that kinda draws you into the, you know, to talking and so on". Additionally, recreation coordinators noted that the Java Music Club facilitator was another person with which participants "share experiences" with and form new, or stronger relationships. Recreation coordinators noticed that "they bonded quite a bit with [the facilitator]" and that they had "seen the residents like adopt a relationship with her over time".

Java Music Club participants and recreation coordinators also described the importance of group composition. For example, for participants in the Java Music Club, it appeared to be important that there were residents of varying cognitive ability. Qualitative interviews demonstrated participation and enjoyment by residents with cognitive impairment and recreation coordinators noted the importance for "someone who has dementia to be positively impacted". However, some participants noted that it was difficult when a resident “couldn't remember anything...so I felt that I was doing all of the talking" and that it was difficult at times for these participants to contribute verbally to the discussion. Therefore, it was helpful and important to have "a mix of cognition in the same group". One recreation coordinator said "I like to have everyone together, and it becomes even a teaching moment for everybody. Whereas residents 
who are not cognitively impaired can learn how to therapeutically communicate with those who are". In light of this, recreation coordinators also noted that they had put considerable thought into group composition. They all reported considering cognitive ability, as well as social facilitation. For example, recreation coordinators noted that they believed it was important to include "those who were starting to exhibit signs of dementia, those who aren't coming to as any programs, those who don't have a lot of visitors, those who like to chat but haven't had an opportunity to really bond to people, and new residents... and then a couple of people who joined were just lovely chatterboxes so they kind of help the conversation".

The Java Music Club addresses an existing gap in services. Participants noted that the Java Music Club addresses an existing gap in services within their residential care centres and that it would be "valuable for people who are in seniors' homes with fewer activities". During the interviews, the majority of residents noted that the Java Music Club was unlike other activities at their residence. Other activities reported included singalongs, "bingo", "exercises and crafts". Although enjoyable, these groups did not promote social engagement directly as does the Java Music Club, nor did they incorporate both sharing and singing within one meeting. Participants reported that they were interested in joining the Java Music Club because of the music, socializing, and just "to go in and find out what it was like" and "to see what it was about". Recreation coordinators also noted that they "didn't have a similar program" and that although they may "have a lot of discussions here with the residents, like about current events ... and we do sing alongs, but it's never put together like Java music was". Although they try to promote social interaction between residents, current programming including bingo, presentations, entertainment, and exercise groups allow for passive social engagement, but not reciprocal sharing or the opportunity for reminiscence. Furthermore, the ability of the Java Music 
Club to promote initiation of social interactions directly addressed the need of one assisted living centre, where a recreation coordinator said they "wanted the residents to be a little more social...and maybe take initiative. Because I find initiative is not very strong here". Furthermore, recreation coordinators also noted that the Java Music Club "breaks up the monotony... it was something for them to look forward to and it was something different because even though we try to do different things here, sometimes we are not able".

Accessibility promotes engagement. All residents reported that the Java Music Club was very accessible in terms of location, time and content. There were no difficulties attending the Java Music Club weekly, even for those with mobility concerns, as it was held on site. Additionally, the content was appropriate for residents of varying levels of cognitive impairment, and one recreation coordinator said that "I just think it's a great program. It works for everyone". Furthermore, the fact that the Java Music Club was at "a consistent day and time...that's very very important when you are running a program. If it is kind of sporadic and all over the place, it's not going to work". This consistency promoted attendance as it was easy for residents to remember and could be included in their calendars, such that "everybody knew what was happening. So, the implementation was very very good because the residents did come, and they did show up every single week".

Although the Java Music Club was accessible to all participants who attended, both participants and recreation coordinators noted that there were some residents who could have benefited from the Java Music Club who did not attend. One reason was the discomfort with the testing sessions, as many residents did not understand the need for these sessions. The other limitation was that currently, recreation coordinators and residents voiced that many people who are already quite social attended the group, however it was difficult to attract the "socially 
isolated" residents to attend. One recreation coordinator noted that "you want them to do that but in fact it's not part of their character, it's not their personality, it's not an easy thing for them. And so you have these expectations and hopes but they don't necessarily always pan out".

Residents also noted that "it is a little more difficult, especially for introverted people" and that there may have been other residents at the home that would have benefited from the group but "they wouldn't take the interest".

Table 5

Themes and sub-themes developed using thematic analysis

Theme Sub-theme

Personal experience of participating in the Java Music Club

The Java Music Club was an enjoyable and positive experience overall

The Java Music Club promoted social engagement

The Java Music Club benefited the social emotional well-being of residents

Participant Observations and Feedback Related to Java Music Club Content the Implementation and Core Elements of the Java Music Club

Implementation factors

The Java Music Club addresses an existing gap in services

Accessibility promotes engagement 


\section{Discussion}

As our population ages and many older adults transition into residential care (Statistics Canada, 2011), the importance of maintaining and promoting psychosocial health within these settings continues to increase. Despite this importance, the rates of cognitive impairment within these settings is high and rising (CIHI, 2016). Additionally, older adults' self-reports suggest that stress, depression, and loneliness are experienced to a significant degree (Seitz et al., 2010; Pinquart \& Sörensen, 2001). In light of these findings, and the growing emphasis to promote successful aging, interventions that may increase the general wellbeing of older adults is receiving growing attention. Social support has been found in various studies to have a positive effect on cognitive functioning, potentially by buffering the negative effects of stress, depression and loneliness (Amieva et al., 2010; Pillemer \& Holtzer, 2016; Cohen \& Willis, 1985).

Therefore, this study investigated the ability of a manualized social support intervention to promote cognitive and psychosocial health in retirement and assisted living centres.

There are many important findings of this study. In terms of changes immediately following participation in the Java Music Club, there was a significant reduction in perceived loneliness between T1 and T2. Follow-up effects demonstrated benefits for both cognitive and psychosocial measures. In terms of cognitive benefits, improved abilities in set shifting, as well as subjective cognition were evident three months following participation in the Java Music

Club. Beneficial follow-up effects for psychosocial health was also evident by a significant decrease in depressive symptoms. Regarding the qualitative data, key processes were elucidated including the promotion of social engagement, opportunity for reminiscence, and the ability of both social interaction and singing to benefit residents and lift their "spirits". Important 
information was also outlined regarding implementation of the Java Music Club, including the important role of the group facilitator and group composition.

As noted above, there was a significant reduction in loneliness after participating in the Java Music Club for three months. This finding is in line with previous research highlighting the effect of social support intervention in decreasing loneliness. In a comprehensive literature review of 38 studies, including both quantitative and qualitative findings, Gardiner et al., (2018) reported that while a majority of studies reported some evidence of improvement in social isolation and loneliness following intervention implementation, the quality of the evidence was relatively weak. Of the 38 studies reviewed, only 10 studies focused on the promotion of social facilitation and exchange; eight of which showed a degree of support for decreasing loneliness and three of which solely provided qualitative evidence to support this claim. Review of the qualitative intervention studies identified three common characteristics of effective interventions, which were: 1) the adaptability of the program to the context in which it is being applied, 2) the use of an approach in which the service users are involved in how the intervention is designed and implemented, and 3) the ability of the intervention to support active and productive social engagement between participants (Gardiner et al., 2018). The current study findings suggest that the Java Music club incorporates many of these elements. In regard to characteristic three, productive social engagement is promoted throughout the Java Music Club sessions. Qualitative interviews clearly indicate that participants enjoyed their experience in the group, and that the most commonly reported "favourite" part of the group was the ability to share with, and listen to, others. This form of social interaction may be important, as traditionally implemented "institutionalized recreation" within these settings does not foster this form of reciprocal social interaction (Theurer et al., 2015). Additionally, this active rather than passive social engagement 
has shown promising benefits for cognitive and psychosocial health (Theurer and Wister, 2010; Pfeiffer, 1975; Amieva et al., 2010).

Throughout development of the Java Music club, program feedback has been collected from participants and residential staff to inform the intervention guidelines, which addresses the second important characteristic from Gardiner et al.'s (2018) review. Although the Java Music Club was led by an external facilitator for research purposes, the Java Music Club in its natural form is facilitated by recreation staff, so that it can be adapted to best suit the needs of the facility within which it is being implemented. This was also done to the best of our ability within the confines of this pilot study, in terms of location, set up, and participants. Although there are promising studies supporting interventions to reduce loneliness, many of the studies within the scoping review conducted by Gardiner et al. (2018) did not meet rigorous quality standards, which supports the importance of this study and the need for further, more controlled, intervention studies.

Although loneliness reduced immediately after the 12 Java Music Club sessions, changes in depression were not evident until the three-month follow-up period. This is contrary to the study by Cunningham et al. (2016) which found a significant decrease in depressive symptoms after participation in the Java Music Club despite comparable depressive scores to the current study sample at baseline (i.e., below the clinical cut-off). That being said, it is important to note that in the Cunningham study, the Java Music Club was conducted for 26 weeks rather than 12 weeks (despite there being a break in the middle), and therefore significant decreases in depressive symptoms were reported after a similar length of time in both studies. Therefore, we currently do not know if it is the passage of time after starting the Java Music Club that 
contributes to these effects on depression, or the implementation of this group over the entire time period.

It may be postulated that the reduction in loneliness post-treatment subsequently contributed to the significant decrease in depressive symptoms at follow up, as loneliness and depression have been found to correlate in the literature (Barg et al., 2006; Golden et al, 2009; Cacioppo et al., 2006). In order to further investigate the temporal relationship between loneliness and depression, Cacioppo, Hawkely \& Thisted (2010) conducted a 5-year follow-up study within 229 men and women which included a cross-lagged analysis at 1-year intervals. The findings suggest that increased loneliness is associated with increased depressive symptoms, however, the relationship does not work in the opposite direction. Further, the effect of loneliness on depressive symptoms was not attributable to other plausible factors including demographics, objective social isolation, social support, or perceived stress and significant life events. These findings support the possibility that decreased loneliness following the Java Music Club contributed to decreases in depressive symptoms, despite no significant changes in social support or perceived stress.

Despite the apparent contradiction in the findings, such that there were significant reductions in loneliness with no corresponding increase in perceived social support, this phenomenon has been found multiple times in the literature. Loneliness has been found to correlate with health outcomes above and beyond the effects of social network characteristics, including network size, frequency of contact, and quality of network connections (Rico-Uribe et al., 2015). Furthermore, loneliness only correlates $-0.11,-.25$ and -.24 with size, quality and frequency of social networks, respectively (Rico-Uribe et al., 2015), indicating small effect sizes. Taylor et al., (2018) also found that loneliness is predictive of mental and physical health, but 
that social support and engagement were not. This speaks to the true importance of the Java Music Club reducing perceived loneliness, despite no change in social support. That being said, the fact that there was no change in social support despite the qualitative reports of such an effect warrants further attention. It could be the validity of the scale itself, however, validity and reliability have been demonstrated in past literature, and internal reliability of the social support scale was excellent within the current study sample.

Despite limited changes in objective measures of cognitive functioning, there was evidence that subjective cognition improved three months after participating in the Java Music Club. This could be a result of the decrease in depressive symptoms (Zlatar et al., 2014; Reid et al., 2006). In fact, memory complaints are a criterion for major depressive disorder in the Diagnostic and Statistical Manual of Mental Disorders-5 (American Psychological Association, 2013). A review of this literature conducted by Reid et al. (2006) found that subjective cognitive complaints were consistently related to depressive symptoms, but are inconsistently related to objective cognitive impairment, despite being a criterion of various early-stage dementias including Mild Cognitive Impairment (Reid et al., 2006). Furthermore, Zlatar et al. (2018) found that after controlling for depressive symptoms, correlations between subjective and objective cognition are no longer significant, however correlations between subjective cognition and depression remain significant whether or not objective cognition and demographics are included in the model. Nevertheless, subjective cognitive complaints have also been found to be a risk factor for later development of objective cognitive impairment and dementia, and therefore the ability of the Java Music Club to decrease subjective cognitive complaints over time is clinically important for this population (Brigola et al., 2015). 
As noted above, there was only one statistically significant change in any of the objective measures of cognitive functioning, which was a significant reduction in TMT B from T2 to T3. TMT B measures set shifting, which is a component of executive function. Previous research has demonstrated that TMT B is a strong predictor of social support, such that as TMT B increases, social support decreases (Schnittger, Wherton, Prendergast, \& Lawlor, 2012). This could be for several possible reasons. For example, it could be that social engagement is cognitively stimulating, and therefore promotes executive functioning (Fratiglioni et al., 2004). Another possibility is that declines in executive functioning make it more difficult for older adults to engage in reciprocal social interactions and conversations, which subsequently causes a decrease in social network and social support (Alzheimer Disease International, 2013). Furthermore, research also suggests that TMT B is significantly associated with subjective memory impairment (Genziani et al., 2013), which supports the complimentary decrease and increase in TMT B and subjective cognition, respectively, at 3-months follow-up. However, it is important to note that the RM ANOVA for TMT B only included 9 participants, as the remaining participants were not able to complete the task in the allotted time (i.e., 300 seconds). Therefore, this finding should be interpreted with caution.

The fact that there were limited increases in objective measures of cognition does not necessarily preclude the possibility of the Java Music Club exerting beneficial effects. In the study by Cunningham et al. (2016), Java Music Club participants did not display an increase in global cognitive function following 26 weeks of the intervention; however, the control group significantly declined in cognitive functioning, suggesting a maintenance effect of the Java Music Club for community-living older adults. As such, future research is needed to determine whether cognitive function is maintained in residential care users who participate in the Java 
Music Club, relative to a randomized wait-list control group. Furthermore, the current study was underpowered. Therefore, a future RCT must include a larger sample size in order to detect significant differences.

The qualitative findings from this pilot study support and build on past qualitative research on the Java Music Club and speak to the perceptions of residents and recreation coordinators. The qualitative findings allowed for process evaluation by gathering information pertaining to the implementation of an intervention including receipt of the intervention and its components, the setting within which it is implemented, and the experience of the intervention for the users and other important stakeholders (Oakley et al., 2005).

To start, the qualitative findings spoke to three important process elements that may be important in mediating the beneficial quantitative health outcomes seen, including: the development of new social connections (both with fellow residents and the facilitator) and promoting social initiation outside of the Java Music Club, reminiscing, and improved mood through social interaction and music.

As outlined above, the development of new social connections has important implications for both cognitive and psychosocial health, through intellectual stimulation, buffering other negative psychosocial health outcomes, and decreasing loneliness (Cohen \& Wills, 1985; Pinquart et al., 2001). Qualitative interviews support that the ability to share stories, listen to others, and be supported were meaningful outcomes of participating in the Java Music Club, and quantitative findings support that the group had beneficial effects on loneliness immediately post intervention. Recreation coordinators and residents also noted that the Java Music Club increased social initiation outside of group. If this behaviour was maintained during the follow-up period it 
may have impacted the benefits of participating in the group and contributed to the beneficial effects on depressive symptoms, subjective cognition, and set shifting at follow-up.

Reminiscing was also repeatedly identified as an important element for change in the Java Music Club. This supports findings in the literature supporting the process of reminiscing in promoting therapeutic change, emotional well-being (Bohlmeijer et al., 2006) and cognition (Subramaniam \& Woods, 2012) in older adults, possibly by promoting meaning in life, and focusing on past successful coping experiences (Bohlmeijer et al., 2007). Furthermore, group reminiscence has been found to have increased beneficial effects on cognition compared to individual reminiscence, which may be due to increased cognitive engagement and resources when recollection is facilitated within a social environment (Haslam et al., 2010).

Participants also noted the ability of both socializing and music to improve their mood. The musical aspect of the Java Music Club is important, as social interventions that incorporate music have been shown to stimulate social cohesion, positive affect (Pearce et al., 2015), and attentional processes in older adults with Alzheimer's disease (Thompson et al., 2005). It could be that social support and music effect social support in different ways, with social support promoting connection with discussion and sharing, and music promoting social support through feelings of closeness and group cohesion by focusing on a common task (Pearce et al., 2015).

The qualitative analysis clearly elucidated the important social aspect of the group. However, participant and recreation coordinator qualitative interviews also noted that those with severe cognitive impairment found it difficult to actively contribute to some of the social exchanges (i.e., findings the right words, telling a story, asking questions). This speaks to the importance of group composition, such that to be optimally engaging and effective for all in attendance, there should be a wide variety of cognitive ability reflected in the group composition. Qualitative 
reports further suggest that residents who are more cognitively able may further develop their communication skills through interacting with residents who present with impairments in cognitive function, which in turn may promote social support for those who are severely cognitively impaired. Alternatively, research suggests that declines in comprehension and communication (Alzheimer Disease International, 2013), internalized negative stereotypes, or social discrimination based on cognitive impairment could make it difficult or threatening for these residents to engage in group settings (Burhold et al. (2017). As such, it is possible that a peer-mentorship relationship, where social support is fostered between one peer-mentor and a resident with severe cognitive impairment could be beneficial for these residents. Evidently, it is important for social programming to be modified in ways that accommodate the needs of residential care users with cognitive impairment. Tak et al., (2015) developed a checklist for individualizing activities for older adults with cognitive impairment, however further research is needed on accommodation in order to enhance more universal engagement from all residential care users, including those with more severe cognitive impairment.

Qualitative findings also spoke to important future directions of the Java Music Club. For example, recreation staff and residents spoke to the fact that within the study parameters, the Java Music Club was more likely to attract the involvement of those who are socially oriented, rather than the most socially isolated residents. This finding is consistent with existing qualitative research which suggests older adults who are experiencing the highest levels of social isolation and loneliness are not using social programming that is currently available (Goll et al., 2015). Therefore, it will be important to address this current hurdle through future research.

Gaining information on process facilitates further implementation of the intervention. Research incorporating these two elements is growing, however currently the quality of process 
evaluation research is highly variable (Lewin et al., 2009). Overall, the qualitative findings suggest that the Java Music Club is a very enjoyable way for residents to spend their time, and that it currently addresses a gap in widely available programming within these settings. Furthermore, the Java Music Club promotes social engagement, reminiscence, and lifts moods through this engagement and music. Furthermore, as the Java Music Club is conducted on site, at the same time every week, it is easy for residents to get to (including those with mobility concerns) and was relatively straightforward to incorporate into weekly residential programming.

\section{Limitations and Future Directions}

The findings from this pilot study have important implications for the elucidation of how social support benefits psychosocial wellbeing and cognitive functioning within residential care. However, there were several challenges and limitations of this study that must be clearly noted.

First, this study included a small sample size. Although power calculations indicated a minimum of 34 to detect a significant change in Stroop performance, this study was meant to be a pilot study, to detect trends within the data, which would then be followed by a larger RCT study.

Second, the current study did not include cognition in the exclusion criteria because the Java Music Club was designed to be implemented with residents along the spectrum of cognitive health and the research team did not want to exclude any residents who could benefit from the program. As such, not all participants were able to complete the entire test battery but were still included in the analyses, and the average MMSE score at T1 $(M=21.42)$ is indicative of possible mild cognitive impairment (Folstein et al., 1975). Despite the difficulties collecting data from residents with cognitive impairment, qualitative and observational data supported the ability of these residents to participate in the group. Additionally, Cronbach's $\alpha$ suggests reliable 
responding on the psychosocial measures within the study sample, and despite many questionnaires not having undergone validation in older adults with cognitive impairment, Beekman, van Limbeek, de Vries, \& Tilburg (1997) fund that the presence of cognitive impairment did not affect past false positive rates of depression diagnoses using the CES-D.

Additionally, as a consequence of the PI facilitating the Java Music Club as well as analysing the qualitative data, there is inherent possibility of investigator bias. A way to account for this in future qualitative studies is to implement a quality control process common to qualitative research called member checking (Harper \& Cole, 2012). Member checking can be completed in various ways, including debriefing interviews, and making study results available to research participants in order to confirm accuracy and completeness of the analysis. Within the current study, reliability standards including maintaining an audit trail and investigator triangulation, were used in order to minimize risk of bias in developing themes and sub-themes.

Finally, there were some limitations in terms of ecological validity. For example, the Java Music Club was conducted by the PI, rather than a recreation coordinator due to limited study materials. In its natural form outside of research, a member of the residential staff would be conducting the group so that there can be more flexibility in terms of how it is implemented within the current programming and more organic program membership, such that residents can invite others to the group on a rolling basis. Furthermore, as this study was conducted for research purposes, the Java Music Club was no longer facilitated after the initial 3-month period. This may have effected participants self-report ratings, as they were asked to complete measures on perceived social support, loneliness, stress and depression the week following the termination of a group that they enjoyed. 
There are important future directions that can build on the findings from this pilot study. First, it will be important to conduct further qualitative research to investigate the experience of the most socially isolated residents within residential care. Through qualitative means, it will be important to investigate ways that interventions can effectively engage these residents, who are not currently being engaged with available social programming, as lonely older adults may be able to benefit most from interventions like the Java Music Club (Newall \& Menec, 2017). Furthermore, an RCT must be conducted that compares the Java Music Club to care as usual. This will provide important information in terms of maintenance and beneficial effects of the Java Music Club that are not able to be investigated with a single sample pilot study. Furthermore, further analyses should investigate the relationship between depressive symptoms and subjective cognition within a larger sample. Additionally, an RCT with an adequate sample size would be able to support causal claims concerning the beneficial effects of a social support intervention on cognitive and psychosocial heath by controlling for confounding variables.

\section{Conclusion}

Despite the impetus for promoting successful aging of older adults living in residential care, there remains high rates of cognitive impairment, stress, depression and loneliness. The current study investigated the ability of a social support intervention to promote cognition, by reducing certain negative mental health constructs including loneliness, stress and depression. Quantitative findings suggest a beneficial effect of the Java Music Club on loneliness, depression, subjective memory, and set shifting. Qualitative findings suggest important process elements of the Java Music Club including the development of new social connections and social initiation outside of the club, reminiscing, and improved mood through social interaction and music. Furthermore, the Java Music Club can be easily implemented, and addresses a need 
within residential care settings. Further research is needed that compares the effects of the Java Music Club to a wait-list control, as well as investigate how we can promote the participation of the loneliest and socially isolated older adults. 


\section{Appendices}

Appendix A

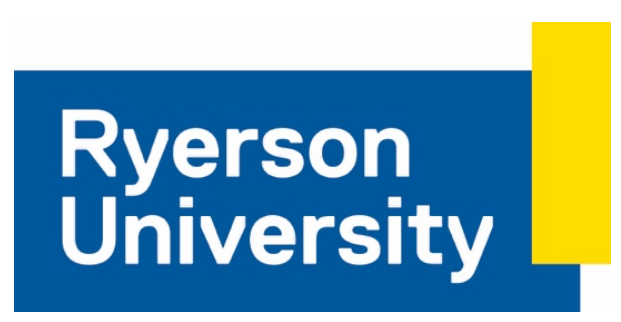

\section{Consent Agreement}

\section{Implementing the JAVA Music Club in Retirement Homes: Impact on Cognitive and Psychosocial Wellbeing}

You are being asked to participate in a research study. Before you give your consent to be a volunteer, it is important that you read the following information and ask as many questions as necessary to be sure you understand what you will be asked to do.

\section{Investigators:}

Principal Investigator: Geneva Millett, Master's of Arts candidate, Department of Psychology, Ryerson University

Supervisor: Dr. Alexandra J. Fiocco, Associate Professor, Department of Psychology, Ryerson University

\section{Purpose of the study:}

The purpose of this study is to investigate whether the JAVA Music Club is a beneficial program for retirement home residents. The primary aim of the JAVA Music Group is to foster social support and interaction between group members through discussion points and music. This study is part of Geneva Millett's Master's of Arts thesis. In total, we will be recruiting 30 retirement home residents to take part in this study.

\section{What you will be asked to do as a participant:}

a) Participate in the JAVA Music Club for 1-hour a week over 12 weeks

b) Complete a set of questionnaires and tasks at three separate time points:

1. Before starting the JAVA Music Club

2. After 12 weeks of participating in the JAVA Music Club

3. 3-months after participating in the JAVA Music Club

4. Please note that each of these three interview sessions will take approximately 1 hour of your time

\section{Risks or Discomforts:}

Any risk or discomfort associated with participating in this study is minimal. It is possible that you may feel some discomfort from completing study tasks and when answering questions about your health and emotional wellbeing. If any discomfort occurs, you are free to skip any 
questions, to take a break, and/or to stop participating completely. Also, some emotional discomfort may be experienced during participation in the JAVA Music Club. Please remember that participation in the JAVA Music Club is voluntary. That is, you can choose whether or not you want to share with the group or simply observe the group - this depends on your own comfort level. Also, remember that you are free to withdraw from the study completely and not attend the weekly group. You can also choose to temporarily or permanently stop your participation at any time.

Whether you remain in the study or not, remember that it is important to keep all conversations during each meeting with the JAVA Music Club confidential.

\section{Benefits of the Study:}

While we cannot guarantee that you will directly benefit by taking part in this study, you will be contributing to important research that investigates the benefits of JAVA Music Club on the wellbeing of retirement home residents. However, it is possible that you will enjoy your time in the JAVA Music Club.

\section{Dissemination of Research Results:}

All data collected from this study will be presented in aggregate form - that is, the group average will be presented and your data will not be examined on its own. As mentioned above, data gathered from this study will contribute to Geneva Millett's Master's of Arts Thesis in the Department of Psychology. This data will also be presented at community talks and scientific conferences, and published in a peer-reviewed journal. Finally, as a token of our appreciation, a final report will be created for your retirement home, to share the study results with you and the retirement community.

\section{Confidentiality and Data Storage:}

Although your involvement in the JAVA Music Club will be known to other members in your retirement community, all information and data that you provide us with during the three interview sessions will remain confidential.

It is important to emphasize that what happens in JAVA, stays in JAVA. Please do not share others' stories with persons outside of the JAVA Music Club. This level of confidentiality is important, as it is a sign of respect for other members in the group. As the researcher cannot guarantee confidentiality of information shared during group sessions, it is up to you and your JAVA peers to do so.

Your name or any other identifying information will not be linked to the data that you provide us with during each testing session. Instead, you will be assigned a unique study code, which will link your de-identified information. Research data will be kept in a secure cabinet file to which only the research team will possess the key. Any electronic data will be stored in a passwordprotected file on a secure laboratory server. Any documents that contain identifying information, including this consent form, will be stored separately from your data. All data will be securely stored up to 5 years after publication of study results, after which all electronic and hard copies of the data will be destroyed. 


\section{Costs and/or Compensation for Participation:}

There is no cost to you by participating in this study. The research team will visit your facility to conduct this research at a time that is convenient for you. No individual compensation is offered to participate in this study.

\section{Voluntary Nature of Participation:}

Participation is completely voluntary. Your choice of whether or not to participate will not influence your future relations with Ryerson University, the research team, or your retirement residence. At any particular point in the study, you may refuse to answer any particular question or stop participation altogether. If you decide to participate, you are free to withdraw your consent and stop your participation at any time without penalty. If you decide to stop participating, all information that you provided before stopping will be securely stored. This data may help us understand for whom the JAVA Music Group is best suited. Withdrawing from the study will not affect your relations with Ryerson University, the research team, or your retirement home.

\section{Questions about the Study:}

If you have any questions about the research now, please ask. If you have questions later about the research, you may contact the principal investigator: Geneva Millett via phone (416-9795000 ext 3233) or email (gmillett@psych.ryerson.ca). Or, you may contact her supervisor Dr. Alexandra J. Fiocco via phone (416-979-5000 ext 3008) or email (afiocco@psych.ryerson.ca).

If you have questions regarding your rights as a human subject and participant in this study, you may contact the Chair of the Research Ethics Board at Ryerson University via phone (416-9795042) or email (rebchair@ryerson.ca). You may also write them at:

Research Ethics Board c/o Office of the Vice President, Research and Innovation Ryerson University 350 Victoria Street Toronto, ON M5B 2K3 


\section{Implementing the JAVA Music Club in Retirement Homes: Impact on Cognitive and Psychosocial Wellbeing}

\section{Agreement:}

Your signature below indicates that you have read the information in this agreement and have had a chance to ask any questions you have about the study. Your signature also indicates that you agree to be in the study and have been told that you can change your mind and withdraw your consent to participate at any time. You have been given a copy of this agreement.

You have been told that by signing this consent agreement you are not giving up any of your legal rights.

Name of Participant (please print)

Signature of Participant

Date

\section{ASSENT: (If participant is unable to provide consent)}

Name of Legal Guardian:

Signature of Legal Guardian:

Date: 


\section{Ryerson
University}

\section{Consent Agreement \\ JAVA Music Club: A Qualitative Perspective}

As a participant in the JAVA Music Club Study, we are inviting you to participate in a side study that includes a 30-minute interview. This study is separate from the other study and therefore requires its own consent process. The format is also very different; it is a 30-minute semistructured interview with no questionnaires or tasks. Before you give your consent to be a volunteer, it is important that you read the following information and ask as many questions as necessary to be sure you understand what you will be asked to do.

\section{Investigators:}

Principal Investigator: Geneva Millett, Master's of Arts candidate, Department of Psychology, Ryerson University

Supervisor: Dr. Alexandra J. Fiocco, Associate Professor, Department of Psychology, Ryerson University

\section{Purpose of the Study:}

The purpose of this qualitative interview is to better understand the impact of JAVA Music, from the participants' point of view. Although questionnaires can answer some questions about the impact of the program, it does not capture the individual experience, in their own words. As such, we are inviting participants from the JAVA Music Club Study to participate in a one-onone 30-minute interview where you can freely talk about your experience in the 12-week JAVA Music Club.

This research will contribute to Geneva Millett's Master's of Arts Thesis and will further be presented to the community, including scientific and none scientific venues.

\section{What you will be asked to do:}

If you decide to take part in the one-on-one 30-minute interview, you will be asked to answer questions about the following aspects of the JAVA Music Club:

1. Your general experience in the group

2. Ways in which you felt the program benefited you or did not benefit you

3. Provide any feedback you would like to share regarding your personal experience

- In order to ensure that your words are captured and to ensure that the interviewer is able to focus on you and your story, this session will be audio recorded.

- Once you have completed the interview, the recording will be transcribed and the researcher will arrange to share the transcripts with you to get your final consent. At this point, you may choose to withdraw your interview or to delete any information that you feel would identify you. 


\section{Risks or Discomforts:}

Any risk or discomfort associated with participating in this interview is minimal. You may feel some discomfort from talking about your personal experience with the JAVA Music Club. However, remember that participating is completely voluntary and that there are no "right" or "wrong" ways to tell your story. If any discomfort occurs, you are free to skip any questions, to take a break, and/or to stop participating completely. All information that you share during the interview will be kept confidential. Also, once the interview is over and the audio recording has been transcribed, we will share the transcriptions will you, to make sure that there is nothing that you would like to retract, or delete from the transcript.

\section{Benefits of the Study:}

While we cannot guarantee that you will directly benefit by taking part in this study, you will be contributing to important research that investigates the benefits of JAVA Music Club on the wellbeing of retirement home residents.

\section{Confidentiality and Data Storage:}

The information that you provide us with during the interview will be kept in strict confidence. Your name will not be recorded, and any identifying information that is mentioned during the interview will be deleted from the interview transcripts. All recordings will be labeled with a unique study code.

All audio files and electronic transcripts will be stored in a password-protected file on a secure server in the Stress and Healthy Aging Research Lab. This consent form will be stored in a secure locked cabinet to which only the research team will possess the key. Audio files will be destroyed once transcribed. Transcribed data and consent forms will be stored up to 5 years after publication of study results, after which all data will be destroyed.

\section{Costs and/or Compensation for Participation:}

There is no cost to you by participating in this study. The research team will visit your facility to conduct the interview at a time that is convenient for you. No compensation is offered.

\section{Voluntary Nature of Participation:}

Participation is voluntary. Your choice of whether or not to participate will not influence your future relations with Ryerson University, the research team, or your retirement residence. At any particular point in the study, you may refuse to answer any particular question or stop participation altogether. If you decide to participate, you are free to withdraw your consent and stop your participation at any time without penalty. You may also choose to withdraw your data after viewing the interview transcript.

\section{Questions about the Study:}

If you have any questions about the research now, please ask. If you have questions later about the research, you may contact the principal investigator: Geneva Millett via phone (416-9795000 ext 3233) or email (gmillett@psych.ryerson.ca). Or, you may contact her supervisor Dr. Alexandra J. Fiocco via phone (416-979-5000 ext 3008) or email (afiocco@psych.ryerson.ca). 
If you have questions regarding your rights as a participant in this study, you may contact the Chair of the Research Ethics Board at Ryerson University via phone (416-979-5042) or email (rebchair@ryerson.ca). You may also write them at:

Research Ethics Board

c/o Office of the Vice President, Research and Innovation

Ryerson University

350 Victoria Street, Toronto, ON M5B 2K3

\section{Agreement:}

\section{JAVA Music Club : A Qualitative Perspective}

Your signature below indicates that you have read the information in this agreement and have had a chance to ask any questions you have about the study. Your signature also indicates that you agree to be in the study and have been told that you can change your mind and withdraw your consent to participate at any time. You have been given a copy of this agreement.

You have been told that by signing this consent agreement you are not giving up any of your legal rights.

Name of Participant (please print)

$\overline{\text { Signature of Participant }} \quad$ Date

\section{ASSENT: (If participant is unable to provide consent)}

Name of Legal Guardian:

Signature of Legal Guardian:

Date:

You have been told that the interview will be audio recorded and how it will be stored: YES $\mathrm{NO}$

Please provide your signature to acknowledge that you consent to the interview being audio recorded.

Name of Participant (please print) 


\section{Ryerson University}

\section{Consent Agreement JAVA Music Club: A Qualitative Perspective}

As a staff member of a residential care centre participating in the JAVA Music Club Study, we are inviting you to participate in a side study that includes a 30-minute interview. This study is separate from the other study and therefore requires its own consent process. This study is a $30-$ minute semi-structured interview with no questionnaires or tasks. Before you give your consent to be a volunteer, it is important that you read the following information and ask as many questions as necessary to be sure you understand what you will be asked to do.

\section{Investigators:}

Principal Investigator: Geneva Millett, Master's of Arts candidate, Department of Psychology, Ryerson University Supervisor: Dr. Alexandra J. Fiocco, Associate Professor, Department of Psychology, Ryerson University

\section{Purpose of the Study:}

The purpose of this qualitative interview is to better understand the impact of the JAVA Music Club, from the staffs' point of view. Although questionnaires can answer some questions about the impact of the program, it does not capture the individual experience within each residence. As such, we are inviting staff members from collective dwellings that are participating the JAVA Music Club Study to complete a one-on-one 30-minute interview where you can freely talk about your residence's experience in the 12-week JAVA Music Club.

This research will contribute to Geneva Millett's Master's of Arts Thesis and will further be presented to the community, including scientific and none scientific venues.

\section{What you will be asked to do:}

If you decide to take part in the one-on-one 30-minute interview, you will be asked to answer questions about the following aspects of the JAVA Music Club:

4. Your general experience with the implementation of the group

5. Ways in which you felt the program benefited your residence and the residents

6. Provide any feedback you would like to share regarding your personal experience

- In order to ensure that your words are captured and to ensure that the interviewer is able to focus on you and your story, this session will be audio recorded.

- Once you have completed the interview, the recording will be transcribed and the researcher will arrange to share the transcripts with you to get your final consent. At this point, you may choose to withdraw your interview or to delete any information that you feel would identify you.

\section{Risks or Discomforts:}


Any risk or discomfort associated with participating in this interview is minimal. You may feel some discomfort from talking about your personal experience with the JAVA Music Club.

However, remember that participating is completely voluntary and that there are no "right" or "wrong" ways to tell your story. If any discomfort occurs, you are free to skip any questions, to take a break, and/or to stop participating completely. All information that you share during the interview will be kept confidential. Also, once the interview is over and the audio recording has been transcribed, we will share the transcriptions will you, to make sure that there is nothing that you would like to retract, or delete from the transcript.

\section{Benefits of the Study:}

While we cannot guarantee that you will directly benefit by taking part in this study, you will be contributing to important research that investigates the benefits of JAVA Music Club on the wellbeing of retirement home residents.

\section{Confidentiality and Data Storage:}

The information that you provide us with during the interview will be kept in strict confidence. Your name will not be recorded, and any identifying information that is mentioned during the interview will be deleted from the interview transcripts. All recordings will be labeled with a unique study code.

All audio files and electronic transcripts will be stored in a password-protected file on a secure server in the Stress and Healthy Aging Research Lab. This consent form will be stored in a secure locked cabinet to which only the research team will possess the key. Audio files will be destroyed once transcribed. Transcribed data and consent forms will be stored up to 5 years after publication of study results, after which all data will be destroyed.

\section{Costs and/or Compensation for Participation:}

There is no cost to you by participating in this study. The research team will visit your facility to conduct the interview at a time that is convenient for you. No compensation is offered.

\section{Voluntary Nature of Participation:}

Participation is voluntary. Your choice of whether or not to participate will not influence your future relations with Ryerson University, the research team, or your retirement residence. At any particular point in the study, you may refuse to answer any particular question or stop participation altogether. If you decide to participate, you are free to withdraw your consent and stop your participation at any time without penalty. You may also choose to withdraw your data after viewing the interview transcript.

\section{Questions about the Study:}

If you have any questions about the research now, please ask. If you have questions later about the research, you may contact the principal investigator: Geneva Millett via phone (416-9795000 ext 3233) or email (gmillett@psych.ryerson.ca). Or, you may contact her supervisor Dr. Alexandra J. Fiocco via phone (416-979-5000 ext 3008) or email (afiocco@psych.ryerson.ca).

If you have questions regarding your rights as a participant in this study, you may contact the Chair of the Research Ethics Board at Ryerson University via phone (416-979-5042) or email (rebchair@ryerson.ca). You may also write them at: 
Research Ethics Board

c/o Office of the Vice President, Research and Innovation

Ryerson University

350 Victoria Street, Toronto, ON M5B 2K3

\section{Agreement:}

JAVA Music Club : A Qualitative Perspective

Your signature below indicates that you have read the information in this agreement and have had a chance to ask any questions you have about the study. Your signature also indicates that you agree to be in the study and have been told that you can change your mind and withdraw your consent to participate at any time. You have been given a copy of this agreement.

You have been told that by signing this consent agreement you are not giving up any of your legal rights.

Name of Participant (please print)

Signature of Participant

Date

\section{ASSENT: (If participant is unable to provide consent)}

Name of Legal Guardian:

Signature of Legal Guardian:

Date:

You have been told that the interview will be audio recorded and how it will be stored: YES NO

Please provide your signature to acknowledge that you consent to the interview being audio recorded.

Name of Participant (please print)

Signature of Participant

Date 


\section{Appendix B}

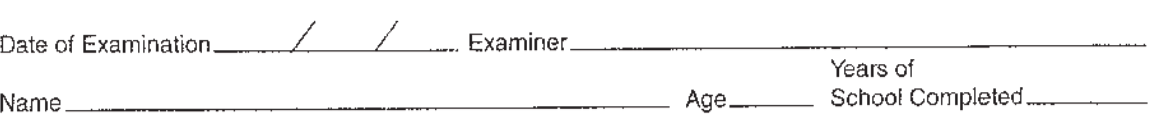

- Instructions: Words in boldface type should be read aloud clearly and slowly to the examinee. Item substitutions appear in parentheses. Administration should be conducted privately and in the examinee's primary language. Circle 0 if the response is incorrect, or 1 if the response is correct. Begin by asking the following two questions:

Do you have any trouble with your memory?

May I ask you some questions about your memory?

ORIENTATION TOTIME

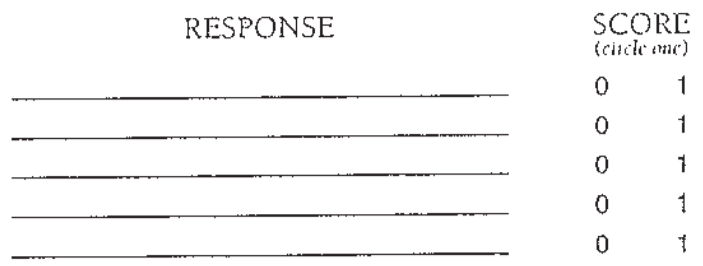

ORIENTATION TO PLACE*

Where are we now? What is the... state (province)?

county (or city/town)?

city/town (or part of city/neighborhood)?

building (name or type)?

floor of the building

(room number or address)?

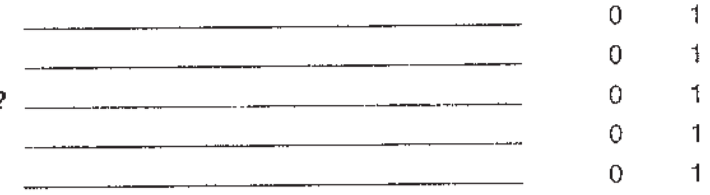

* Alernative place words that are appropriatc for the setting and increasingly precise may be substituted and noted.

REGISTRATION*

Listen carefully. I am going to say three words. You say them back after I stop. Ready?

Here they are... APPLE [pause], PENNY [pause], TABLE [pause]. Now repeat those words back to me.

[Repeat up to 5 times, but score only the first trial.]
APPLE
PENNY
TABLE

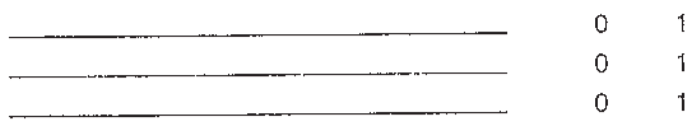

Now keep those words in mind. I am going to ask you to say them again in a few minutes.

*Alternative word sets (c.g., PONY, QUARTER, ORANGE) may be substituted and noted when retesting an examince.

\section{ATTENTION AND CALCULATION [Serial $7 \mathrm{~s}$ ] *}

Now l'd like you to subtract 7 from f00. Then keep subtracting 7 from each answer until l tell you to stop.

What is 100 take away 7 ?

[93]

If needed, say: Keep going.

If needed, say: Keep going.

[79]

If needed, say: Keep going.

If needed, say: Keep going.

[65]

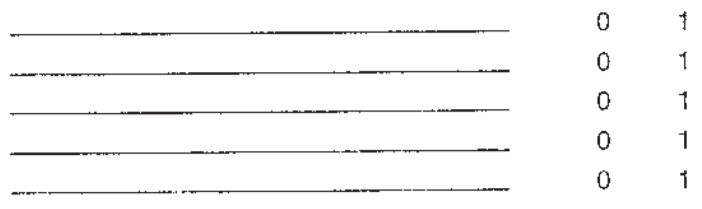

*Alternative item (WORJ. D) backward) should only be administered if the examinee refuses to perform the serial $7 \$$ task.

PAR Psychological Assessment Resources, Inc. • 16204 N. Florida Avenue • Lutz, FL 33549 - 1.800.331.8378 • www parinc.com MMSE Cupyright (1975, 1998, 2001 lsy MiniMcntal, LIC. All rights reserved. Published 2001 by Psyclological Assessment Resources, Inc. May not be reproduced whole or in part in any form or by any means without written permission of Psychological Assessment Resources, Inc. This form is printed in red and talue ink. Any - vher version is unauthorized.

9876543

Reorder $\sharp \mathrm{RO}-4740$

Printed in the U.S.A 
Substitute and score this item only if the examince retuses to perform the Serial 7s task.

Spell WORLD forward, then backward.

"arrect forwaret spelling if misspelled,

ant score only the hackward spelling.

$$
\begin{array}{lllll}
(\mathrm{D}=1) & \overline{(\mathrm{I}=1)} \quad \overline{(\mathrm{R}=1)} \quad \overline{(\mathrm{O}=1)}(\mathrm{W}=\mathrm{I}) & (0+15)
\end{array}
$$

RECALL

RESPONSE

SCORE

What were those three words I asked you to remember? [Do not offer any hints.]

$$
\begin{aligned}
& \text { APPLE } \\
& \text { PENNY } \\
& \text { TABLE }
\end{aligned}
$$

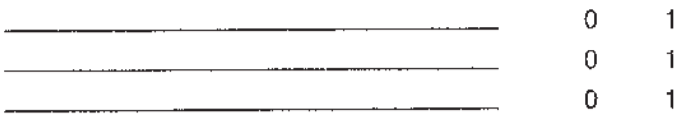

NAMING*

What is this? [Point to a pencil or pen.]

What is this? [Point to a watch.]

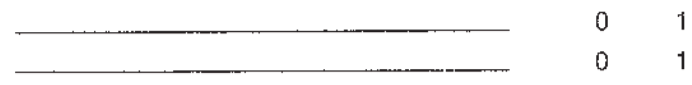

"Alternative common objects (e.g., eycglasses, chair, keys) may be substituted and noted.

\section{REPETITION}

Now I am going to ask you to repeat what I say. Ready? "NO IFS, ANDS, OR BUTS." Now you say that. [Repeat up to 5 times, but score only the first trial.]

$$
\text { NO IFS, ANDS, OR BUTS. }
$$

Detach the next page along the lengthwise perforation, and then tear it in half along the horizontal perforation. Use the upper half of the page (blank) for the Comprehension, Writing, and Drawing items that follow. Use the lower hall

- of the page as a stimulus form for the Reading ("CLOSE YOUR EYES") and Drawing (intersecting pentagons) items.

\section{COMPREHENSION}

Listen carefully because I am going to ask you to do something.

Take this paper in your right hand [pause], fold it in half [pause], and put it on the floor (or table).

\section{TAKE IN RIGHT HAND \\ FOLD IN HALF \\ PUT ON FLOOR (Or TABLE)}

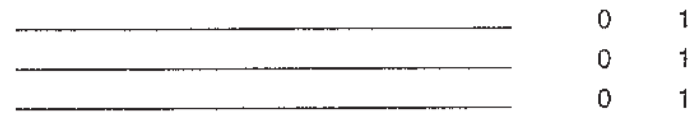

READING

Please read this and do what it says. [Show examinee the words on the stimulus form.]

CLOSE YOUR EYES

WRITING

Please write a sentence. [If examinee does not respond, say: Write about the weather.]

Place the blank piece of paper (unfolded) in front of the examinee and provide a pen or pencil. Score I point if

the sentence is comprehensible and contains a subject and a verb. Ignore errors in grammar or spelling.

\section{DRAWING}

Please copy this design. [Display the intersecting pentagons on the stimulus form.]

Score I point if the drawing consists of two 5-sided figures that intersect to form a t-sided figure. $-$

Assessment of level of consciousness

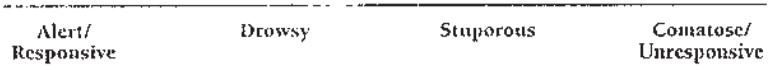


List A Immediate Free Recall Trial 1

I'm going to read a list of words to you. Listen carefully, because when I'm through I want you to tell me as many of the words as you can. You can say them in any order, just say as many of them as you can. Are you ready? Trial 2

I'm going to read the same list again Like before, tell me as many of the words as you can, in any order. Be sure to also say words from the list that you told me the first time.
Trials 3 and 4

I'm going to read the same list again.

Like before, tell me as many of the

words as you can, in any order,

including words from the list you've said before.
Trial 5

I'm going to read the same list

one more time. Like before, tell me as many of the words as you can, in any order, including words from the list you've said before.

Read List $A$ at an even pace, taking slightly longer than one second per word, so the entire list takes 18 to 20 seconds. Then say: Go ahead.

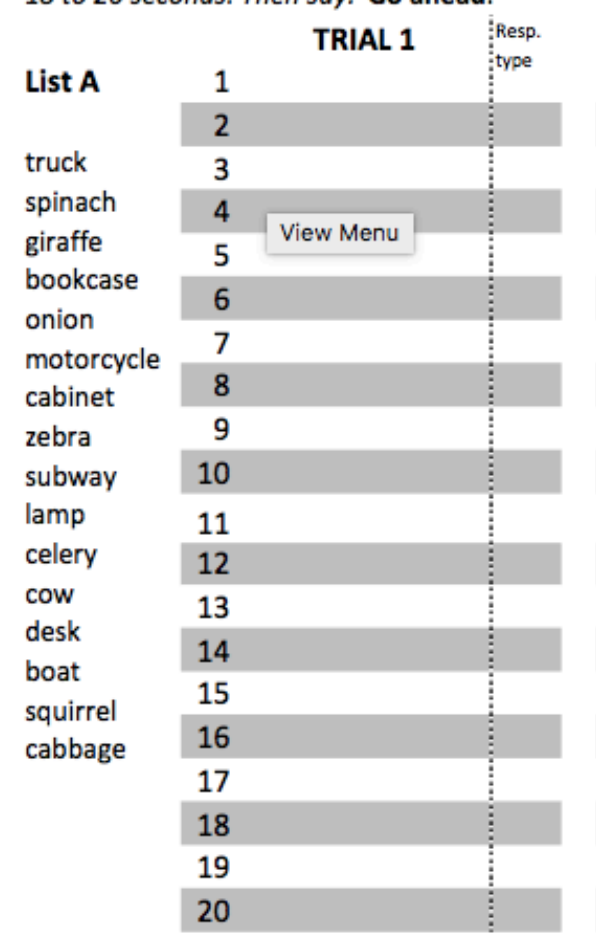

Total Correct

Total Repetitions Total Intrusions

Record all responses verbatim, in the order recalled. Prompt only once (e.g., Anything else?) at the end of each free and cued recall trial (i.e., after 15 seconds with no response or when the examinee says he/she cannot remember more words).

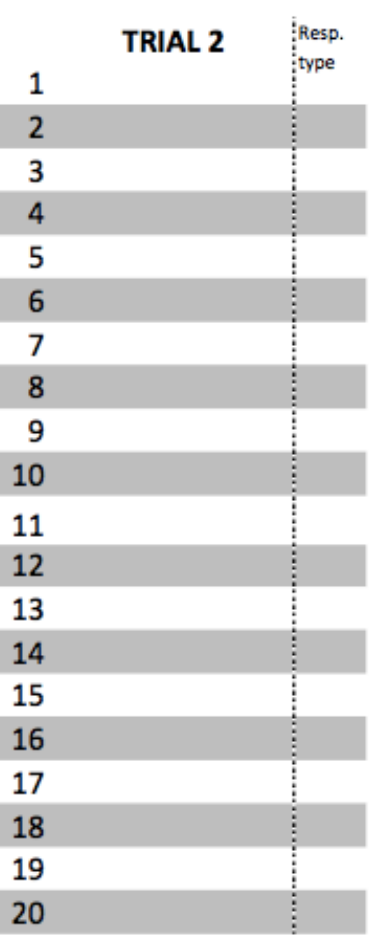

Total Correct

Total Repetitions Total Intrusions

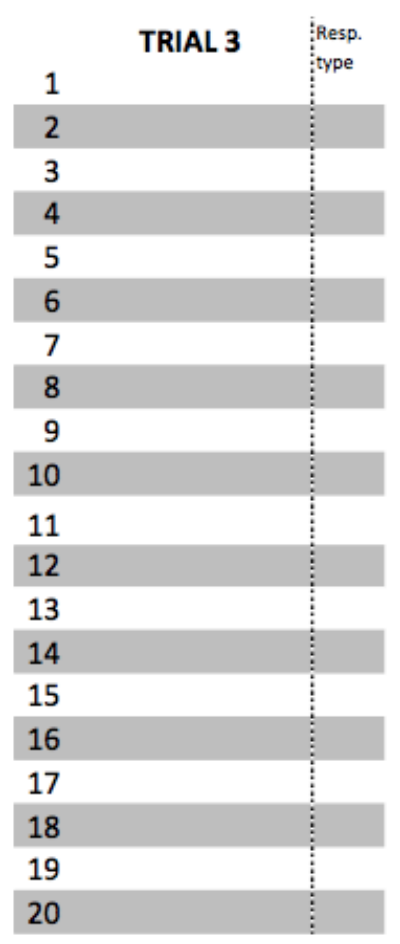

Total Correct

Total Repetition Total Intrusions

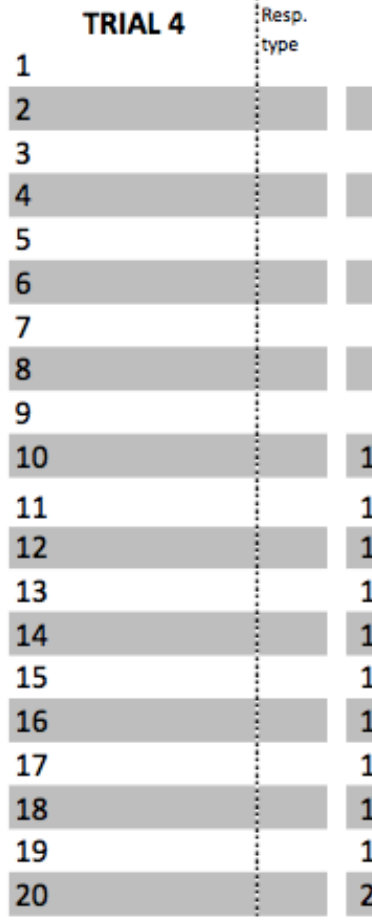

Total Correct

Total Repetition Total Intrusions

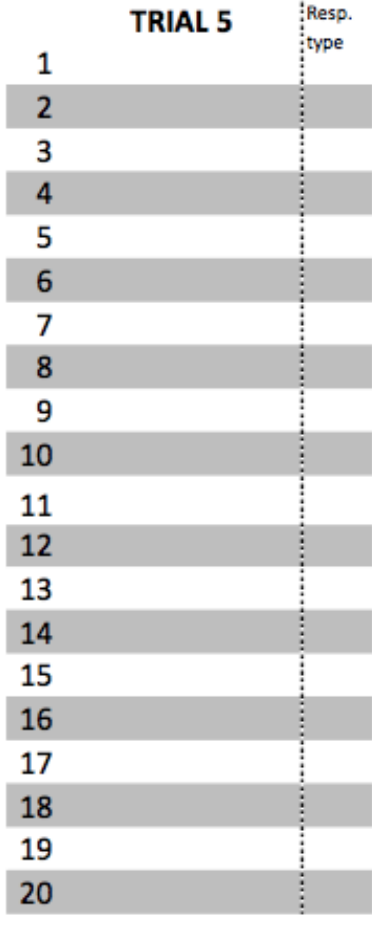

Total Correct Total Repetitions Total Intrusions 
List B Immediate Free Recall

Now I'm going to read a second list of words to you.

When I'm through, I want you to tell me as many

words from this second list as you can, in any order.

Don't tell me words from the first list, just this

second list.

Read List B at an even pace, taking slightly longer than one second per word, so the entire list takes 18 to 20 seconds. Then say: Go ahead.

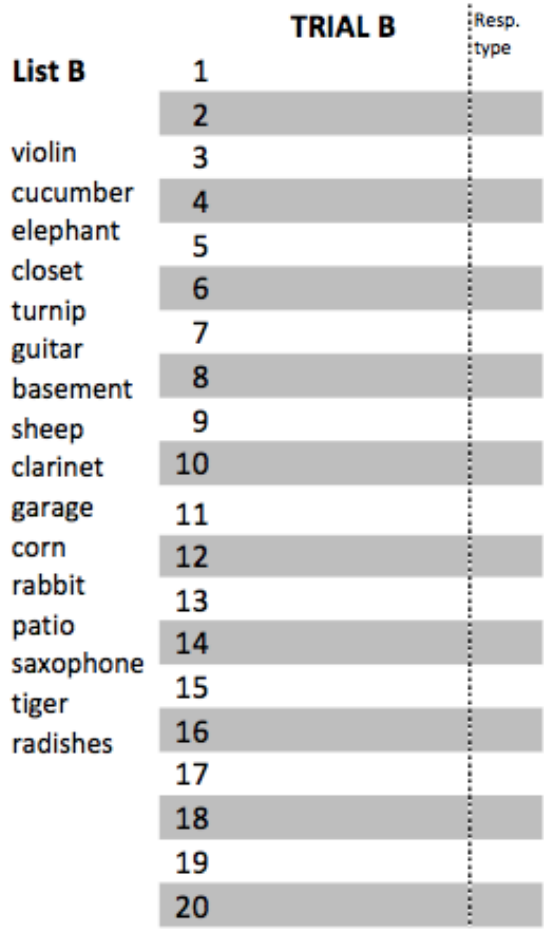

Total Correct

Total Repetitions

Total Intrusions
List A Short-Delay Free Recall Now I want you to tell me all the words you can from the first list, the one I read to you several times. Don't tell me words from the second list, just the first list. Go ahead.

Record all responses verbatim, in the order recalled. Prompt only once (e.g., Anything else?) at the end of each free and cued recall trial (i.e., after 15 seconds with no response or when the examinee says he/she cannot remember more words).

\begin{tabular}{|c|c|c|c|}
\hline $1 \quad$ List A & $\begin{array}{l}\text { IResp. } \\
\text { type }\end{array}$ & 1 & Furniture \\
\hline 2 & & 2 & \\
\hline 3 & & 3 & \\
\hline 4 & & 4 & \\
\hline 5 & & 5 & \\
\hline 6 & & 6 & \\
\hline 7 & & 7 & \\
\hline 8 & & 8 & \\
\hline
\end{tabular}

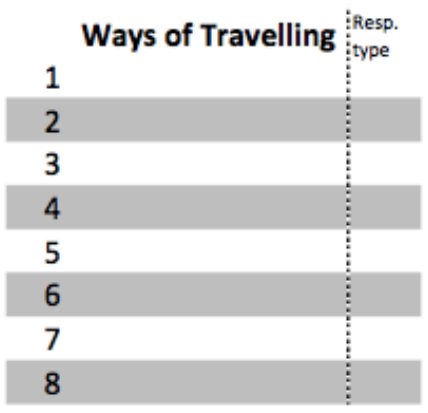

Total Correct
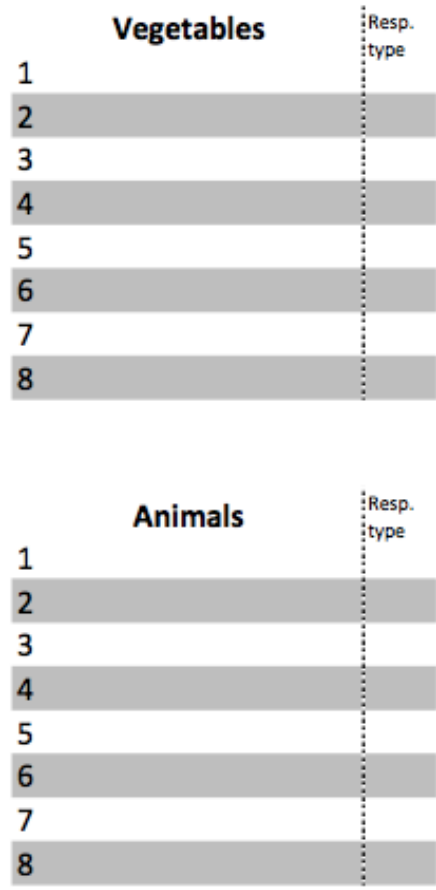

Total Repetitions
Total Correct

Total Repetitions Total Intrusions
List A Short-Delay Cued Recall

Tell me all the words from the first list that are furniture.

me all the words from the first list that are vegetables.

Tell me all the words from the first list that are ways of traveling.

Tell me all the words from the first list that are animals. sions

There should be approximately a 20-minute delay between the completion of

Short-Delay Cued Recall and the start of Long Delay Free Recall. Do not inform

the examinee that there will be later CVLT-II trials. 


\section{List A Long-Delay Free Recall}

$I$ read two different lists of words to you earlier:

a first list that I read to you several times, and a

second list that I read to you once. Tell me all the

words you can that were from the first list. Don't

tell me words from the second list, just the first list.

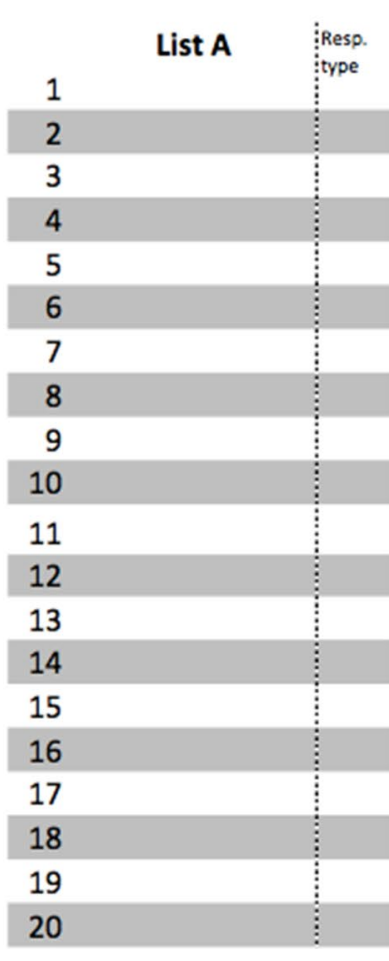

Total Correct

Total Repetitions Total Intrusions

\section{List A Long-Delay Cued Recall}

Tell me all the words from the first list that are furniture.

Tell me all the words from the first list that are vegetables.

Tell me all the words from the first list that are ways of traveling.

Tell me all the words from the first list that are animals.

Go ahead.

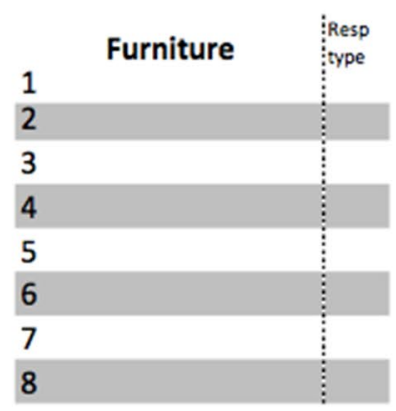

Total Correct

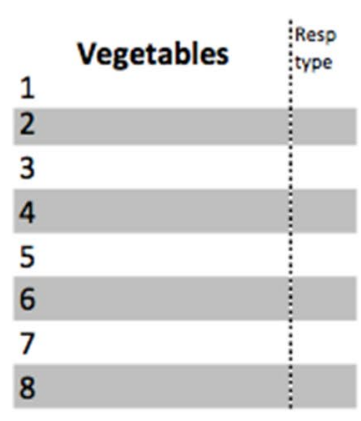

Total Repetitions

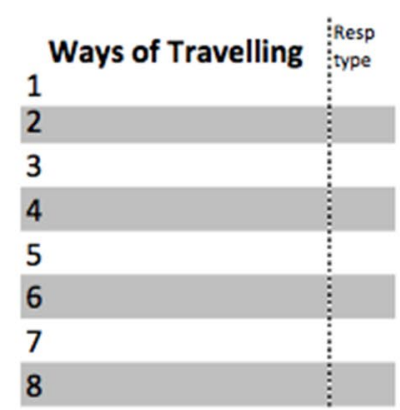

Total Intrusions

\section{List A Long-Delay Yes/No Recognition}

Now I'm going to read more words to you. After I read each one, say "Yes"

if that word was from the first list, or say "No" if it was not from the first list.

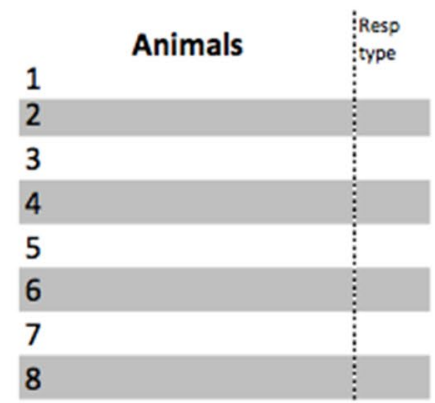

\begin{tabular}{|c|c|c|c|c|c|}
\hline wallet & $\begin{array}{l}\text { Y } \\
\text { Y }\end{array}$ & $\mathrm{N}$ & violin & :Y & $\mathrm{N}$ \\
\hline boat & Y & $\mathrm{N}$ & cow & Y & $\mathrm{N}$ \\
\hline saxophone & $\begin{array}{l}\text { : } \\
\text { Y }\end{array}$ & $\mathrm{N}$ & fork & $\begin{array}{l}\text { : } \\
Y\end{array}$ & $N$ \\
\hline cucumber & Y & $\mathrm{N}$ & bus & $Y$ & $\mathrm{~N}$ \\
\hline giraffe & $\begin{array}{l}Y \\
Y\end{array}$ & $\mathrm{~N}$ & celery & Y & $\mathrm{N}$ \\
\hline carrot & $Y$ & $\mathrm{~N}$ & lamp & $Y$ & $\mathrm{~N}$ \\
\hline patio & \begin{tabular}{l}
$Y$ \\
\hdashline
\end{tabular} & $\mathrm{N}$ & radishes & Y & $N$ \\
\hline cabbage & $Y$ & $\mathrm{~N}$ & table & Y & $\mathrm{N}$ \\
\hline desk & \begin{tabular}{|l}
$Y$ \\
$Y$
\end{tabular} & $\mathrm{~N}$ & rose & $\begin{array}{l}Y \\
Y\end{array}$ & $\mathrm{~N}$ \\
\hline bracelet & $Y$ & $\mathrm{~N}$ & motorcycle & $\mathbf{Y}$ & $\mathrm{N}$ \\
\hline car & $\begin{array}{c}\text { Y } \\
Y\end{array}$ & $\mathrm{~N}$ & sheep & Y & $\mathrm{N}$ \\
\hline elephant & $Y$ & $\mathrm{~N}$ & basement & Y & $\mathrm{N}$ \\
\hline
\end{tabular}

\begin{tabular}{l:cc} 
dog & Y & $\mathrm{N}$ \\
\hline bookcase & $\mathrm{Y}$ & $\mathrm{N}$ \\
\hline matches & $\mathrm{Y}$ & $\mathrm{N}$ \\
\hline spinach & $\mathrm{Y}$ & $\mathrm{N}$ \\
\hline clarinet & $\mathrm{Y}$ & $\mathrm{N}$ \\
\hline truck & $\mathrm{Y}$ & $\mathrm{N}$ \\
\hline rabbit & $\mathrm{Y}$ & $\mathrm{N}$ \\
\hline chair & $\mathrm{Y}$ & $\mathrm{N}$ \\
corn & $\mathrm{Y}$ & $\mathrm{N}$ \\
seashell & $\mathrm{Y}$ & $\mathrm{N}$ \\
garage & squirrel &
\end{tabular}

If the examinee responds "I don't know during Yes/No Recognition, say, "Tell me whether you

think was on the first list."

\begin{tabular}{l:cc:} 
turnip & Y & $\mathrm{N}$ \\
\hline cabinet & $\mathrm{Y}$ & $\mathrm{N}$ \\
onion & $\mathrm{Y}$ & $\mathrm{N}$ \\
\hline lion & $\mathrm{Y}$ & $\mathrm{N}$ \\
\hline camera & $\mathrm{Y}$ & $\mathrm{N}$ \\
guitar & $\mathrm{Y}$ & $\mathrm{N}$ \\
subway & $\mathrm{Y}$ & $\mathrm{N}$ \\
tiger & $\mathrm{Y}$ & $\mathrm{N}$ \\
coffee & $\mathrm{Y}$ & $\mathrm{N}$ \\
zebra & $\mathrm{Y}$ & $\mathrm{N}$ \\
lettuce & $\mathrm{Y}$ & $\mathrm{N}$ \\
closet & $\mathrm{Y}$ & $\mathrm{N}$ \\
TOTAL FALSE POSITIVES &
\end{tabular}




\section{$\underline{\text { Remembering To Do Things }}$}

Please provide the following details about yourself:

Age:

Gender:

How many years of formal education have you had?

Have you suffered from brain/head injury resulting in hospitalization? (Y/N)

Please give brief details:

Please answer all of the questions as accurately as possible.

\begin{tabular}{|l|l|l|l|}
\hline & $\begin{array}{l}\text { Very } \\
\text { Often }\end{array}$ & $\begin{array}{l}\text { Quite } \\
\text { Often }\end{array}$ & Sometimes \\
\hline $\begin{array}{l}\text { 1. Do you decide to do something in a } \\
\text { few minutes' time and then forget to do } \\
\text { it? }\end{array}$
\end{tabular}




\begin{tabular}{|l|l|}
\hline $\begin{array}{l}\text { 7. Do you forget to buy something you } \\
\text { planned to buy, like a birthday card, even } \\
\text { when you see the shop? }\end{array}$ \\
$\begin{array}{l}\text { 8. Do you fail to recall things that have } \\
\text { happened to you in the last few days? }\end{array}$ \\
$\begin{array}{l}\text { 9. Do you repeat the same story to the } \\
\text { same person on different occasions? }\end{array}$
\end{tabular}


Appendix C

\section{DEMOGRAPHICS QUESTIONNAIRE}

1. What is your age?

2. Please indicate your gender:

$\square$ Male

$\square$ Female

$\square$ Other

3. What is your marital status?

$\square$ Married

$\square$ Widowed

$\square$ Separated

$\square$ Divorced

$\square$ Single

$\square$ Common-law

$\square$ Other

4. Which of the following describes your HIGHEST level of education?

$\square$ Some high school

$\square$ Completed high school

$\square$ Some college/university

$\square$ Apprenticeship training and trades

$\square$ Completed college/university

$\square$ Some graduate education

$\square$ Completed graduate education

$\square$ Professional degrees

5. In what country were you born?

6. What is your native language?

$\square$ English

$\square$ French

$\square$ Other (Please specify): 
7. What language do you use most often?

$\square$ English

$\square$ French

$\square$ Other (Please specify):

8. Please indicate your ethnicity (check all that apply):

$\square$ Aboriginal/First Nations/Metis

$\square$ White/European

$\square$ Black/African/Caribbean

$\square$ Southeast Asian (e.g., Chinese, Japanese, Korean, Vietnamese, Cambodian, Filipino, etc.)

$\square$ Arab (Saudi Arabian, Palestinian, Iraqi, etc.)

$\square$ South Asian (East Indian, Sri Lankan, etc.)

$\square$ Latin American (Costa Rican, Guatemalan, Brazilian, Columbian, etc.)

$\square$ West Asian (Iranian, Afghani, etc.)

$\square$ Other (please specify):

9. How would you rate your general health on a scale of 1 "Very Poor" to 6 "Excellent"?

\begin{tabular}{|c|c|c|c|c|c|}
\hline Very Poor & Poor & Fair & Good & Very Good & Excellent \\
\hline 1 & 2 & 3 & 4 & 5 & 6 \\
\hline
\end{tabular}

10. Do you have any mobility concerns?

$\square$ Yes

$\square$ No

If yes, do you use any walking aids (e.g., cane, walker, wheel chair)?

$\square$ Yes

$\square$ No

11. Please check all medical conditions for which you have received a medical diagnosis.

11. a) Visual Impairment
$\square$ Cataract
$\square$ Glaucoma
$\square$ Macular degeneration
$\square$ Other (please specify): 
b) Hearing concerns

$\square$ Yes

$\square$ No

$\square$ Describe:

If checked yes, are hearing aids used? $\square$ Yes $\square$ No

c) Head Trauma
$\square$ Yes
If yes, please specify:
$\square$ No

d) Hypertension

$\square$ Yes

$\square$ No

If yes, is it being treated?

$\square$ Yes

If yes, please specify:

$\square$ No

e) Neurological Disorder (e.g., Parkinson's Disease, dementia, normal tension hydrocephalus, etc.)
$\square$ Yes
If yes, please specify:

$\square$ No

If yes, is it being treated?

$\square$ Yes

If yes, please specify:

$\square$ No

f) Cardiovascular

$\square$ Yes

$\square$ No

If yes, is it being treated?

$\square$ Yes If yes, please specify:

$\square$ No

g) Stroke

$\square$ Yes

$\square$ No 
If yes, is it being treated?

$\square$ Yes If yes, please specify:

$\square$ No

h) Diabetes

$\square$ Yes

$\square$ No

If yes, is it being treated?

$\square$ Yes If yes, please specify:

$\square$ No

i) Cancer

$\square$ Yes If yes, please specify what form:

$\square$ No

If yes, is it being treated?

$\square$ Yes If yes, please specify:

$\square$ No

Are you in remission?

$\square$ Yes

$\square$ No

j) Depression

$\square$ Yes

$\square$ No

If yes, is it being treated?

$\square$ Yes

If yes, please specify:

$\square$ No

k) Anxiety

$\square$ Yes

$\square$ No

If yes, is it being treated?

$\square$ Yes $\quad$ If yes, please specify:
$\square$ No


1) Other Medical Condition

$\square$ Yes If yes, please specify:

$\square$ No

12. How many years have you lived in residential care?

13. Please describe any residential programs that you take part in. 


\section{UCLA-R SCALE}

Instructions: Please indicate how often each of the statements below is descriptive of you.

1. I feel in tune with the people around me

Never Rarely Sometimes $\quad$ Often

2. I lack companionship

$\begin{array}{llll}\text { Never } & \text { Rarely } & \text { Sometimes }\end{array}$

3. There is no one I can turn to

Never Rarely $\quad$ Sometimes $\quad$ Often

4. I do not feel alone

Never Rarely Sometimes $\quad$ Often

5. I feel part of a group of friends

Never Rarely $\quad$ Sometimes $\quad$ Often

6. I have a lot in common with the people around me

Never Rarely Sometimes $\quad$ Often

7. I am no longer close to anyone

$\begin{array}{llll}\text { Never } & \text { Rarely } & \text { Sometimes }\end{array}$ 
8. My interests and ideas are not shared by those around me

Never

Rarely

Sometimes

Often

9. I am an outgoing person

Never Rarely Sometimes $\quad$ Often

10. There are people I feel close to

Never Rarely $\quad$ Sometimes $\quad$ Often

11. I feel left out

Never Rarely Sometimes $\quad$ Often

12. My social relationships are superficial

$\begin{array}{llll}\text { Never } & \text { Rarely } & \text { Sometimes }\end{array}$

13. No one really knows me well

Never Rarely Sometimes Often

14. I feel isolated from others

Never Rarely Sometimes $\quad$ Often 
15. I can find companionship when I want it

$\begin{array}{lll}\text { Never Rarely } & \text { Sometimes }\end{array}$

16. There are people who really understand me

Never Rarely Sometimes Often

17. I am unhappy being so withdrawn

Never Rarely Sometimes $\quad$ Often

18. People are around me but not with me

Never Rarely Sometimes Often

19. There are people I can talk to

Never Rarely Sometimes Often

20. There are people I can turn to

$\begin{array}{lll}\text { Never Rarely } & \text { Sometimes } & \text { Often }\end{array}$ 


\section{CESD}

Below is a list of the ways you might have felt or behaved. Please tell me how often you have felt this way during the past week.

\begin{tabular}{|c|c|c|c|c|}
\hline & $\begin{array}{l}\text { Rarely or } \\
\text { none of } \\
\text { the time } \\
\text { (less than } \\
1 \text { day) }\end{array}$ & $\begin{array}{l}\text { Some or a } \\
\text { little of the } \\
\text { time }(1-2 \\
\text { days) }\end{array}$ & $\begin{array}{c}\text { Occasionally } \\
\text { of a } \\
\text { moderate } \\
\text { amount of } \\
\text { time (3-4 } \\
\text { days) }\end{array}$ & $\begin{array}{l}\text { Most or all of the } \\
\text { time (5-7 days) }\end{array}$ \\
\hline $\begin{array}{l}\text { 1. I was bothered by things that } \\
\text { usually don't bother me. }\end{array}$ & & & & \\
\hline $\begin{array}{l}\text { 2. I did not feel like eating; my } \\
\text { appetite was poor. }\end{array}$ & & & & \\
\hline $\begin{array}{l}\text { 3. I felt that I could not shake off the } \\
\text { blues even with help from my family } \\
\text { or friends. }\end{array}$ & & & & \\
\hline $\begin{array}{l}\text { 4. I felt that I was just as good as } \\
\text { other people. }\end{array}$ & & & & \\
\hline $\begin{array}{l}\text { 5. I had trouble keeping my mind on } \\
\text { what I was doing. }\end{array}$ & & & & \\
\hline 6. I felt depressed. & & & & \\
\hline $\begin{array}{l}\text { 7. I felt that everything I did was an } \\
\text { effort. }\end{array}$ & & & & \\
\hline 8. I felt hopeful about the future. & & & & \\
\hline $\begin{array}{l}\text { 9. I thought my life had been a } \\
\text { failure. }\end{array}$ & & 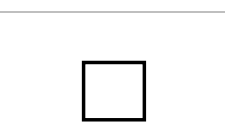 & & $\square$ \\
\hline
\end{tabular}




\begin{tabular}{|c|c|c|c|c|}
\hline & $\begin{array}{l}\text { Rarely or } \\
\text { none of } \\
\text { the time } \\
\text { (less than } \\
1 \text { day) }\end{array}$ & $\begin{array}{l}\text { Some or a } \\
\text { little of the } \\
\text { time (1-2 } \\
\text { days) }\end{array}$ & $\begin{array}{l}\text { Occasionally } \\
\text { of a } \\
\text { moderate } \\
\text { amount of } \\
\text { time (3-4 } \\
\text { days) }\end{array}$ & $\begin{array}{l}\text { Most or all of the } \\
\text { time (5-7 days) }\end{array}$ \\
\hline 10. I felt fearful. & & & & \\
\hline 11. My sleep was restless. & & & & \\
\hline 12. I was happy. & & & & \\
\hline 13. I talked less than usual. & & & & \\
\hline 14. I felt lonely. & & & & \\
\hline 15. People were unfriendly. & & & & \\
\hline 16. I enjoyed life. & & & & \\
\hline 17. I had crying spells. & & & & \\
\hline 18. I felt sad. & & & & \\
\hline 19. I felt that people dislike & & & & \\
\hline 20. I could not "get" going. & & & & \\
\hline
\end{tabular}




\section{PSS}

The questions in this scale ask you about your feelings and thoughts during the last month. In each case, you will be asked to indicate by circling how often you felt or thought a certain way.

Age __ Gender (Circle): $\quad \mathbf{M} \quad \mathbf{F}$

$$
\text { 0 = Never } 1 \text { =Almost Never } 2 \text { =Sometimes } 3 \text { = Fairly Often } 4=\text { Very Often }
$$

1. In the last month, how often have you been upset because of something that happened unexpectedly?

$\begin{array}{lllll}0 & 1 & 2 & 3 & 4\end{array}$

2. In the last month, how often have you felt that you were unable to control the important things in your life?
0
2
3
4

3. In the last month, how often have you felt nervous and "stressed"?

$\begin{array}{lllll}0 & 1 & 2 & 3 & 4\end{array}$

4. In the last month, how often have you felt confident about your ability to handle your personal problems?

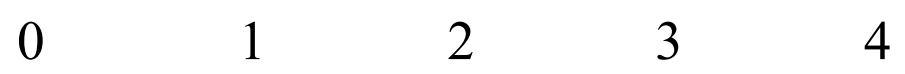

5. In the last month, how often have you felt that things were going your way?

$\begin{array}{lllll}0 & 1 & 2 & 3 & 4\end{array}$


$0=$ Never 1 =Almost Never 2 = Sometimes $3=$ Fairly Often $4=$ Very Often

6. In the last month, how often have you found that you could not cope with all the things that you had to do?

$\begin{array}{lllll}0 & 1 & 2 & 3 & 4\end{array}$

7. In the last month, how often have you been able to control irritations in your life?
0
12
34

8. In the last month, how often have you felt that you were on top of things?
0
2
3
4

9. In the last month, how often have you been angered because of things that were outside of your control?

$\begin{array}{lllll}0 & 1 & 2 & 3 & 4\end{array}$

10. In the last month, how often have you felt difficulties were piling up so high that you could not overcome them?
0
1
2
3
4 


\section{MOS-SSS}

People sometimes look to others for companionship, assistance, or other types of support. How often is each of the following kinds of support available to you if you need it? Circle one number from each line.

\begin{tabular}{lcccc} 
& $\begin{array}{c}\text { None of } \\
\text { the time }\end{array}$ & $\begin{array}{c}\text { A little of } \\
\text { the time }\end{array}$ & $\begin{array}{c}\text { Some of } \\
\text { the time }\end{array}$ & $\begin{array}{c}\text { All of } \\
\text { the time }\end{array}$ \\
\hline $\begin{array}{l}\text { Someone you can count on to listen to you } \\
\text { when you need to talk }\end{array}$ & 1 & 2 & 3 & 4 \\
\hline $\begin{array}{l}\text { Someone to give you information to help you } \\
\text { understand a situation }\end{array}$ & 1 & 2 & 3 & 4 \\
\hline $\begin{array}{l}\text { Someone to give you good advice about a } \\
\text { crisis }\end{array}$ & 1 & 2 & 3 & 4 \\
\hline $\begin{array}{l}\text { Someone to confide in or talk to about } \\
\text { yourself or your problems }\end{array}$ & 1 & 2 & 3 & 4 \\
\hline $\begin{array}{l}\text { Someone whose advise you really want } \\
\text { Someone to share your most private worries } \\
\text { and fears with }\end{array}$ & 1 & 2 & 3 & 4 \\
\hline $\begin{array}{l}\text { Someone to turn to for suggestions about how } \\
\text { to deal with a personal problem }\end{array}$ & 1 & 2 & 3 & 4 \\
\hline $\begin{array}{l}\text { Someone who understands your problems } \\
\text { Someone to help you if you were confined to } \\
\text { bed }\end{array}$ & 1 & 2 & 3 & 3 \\
\hline
\end{tabular}


None of A little of Some of All of

the time the time the time the time

Someone to take you to the doctor if you needed it

$\begin{array}{lllll}1 & 2 & 3 & 4\end{array}$

Someone to prepare your meals if you were

unable to do it yourself

1

2

3

4

Someone to help with daily chores if you

were sick

12

3

4

\begin{tabular}{lcccc}
\hline Someone who shows you love and affection & & & & \\
& 1 & 2 & 3 & 4 \\
\hline Someone to love and make you feel wanted & 1 & 2 & 3 & 4 \\
\hline Someone who hugs you & 1 & 2 & 3 & 4 \\
\hline Someone to have a good time with & 1 & 2 & 3 & 4 \\
\hline Someone to get together with for relaxation & 1 & 2 & 3 & 4 \\
\hline Someone to do something enjoyable with & 1 & 2 & 3 & 4 \\
\hline $\begin{array}{l}\text { Someone to do things with to help you get } \\
\text { your mind off things }\end{array}$ & 1 & 2 & 3
\end{tabular}




\section{HPEAS}

Item

Not at all

Completely

true

True

1. I can choose to do things for myself

2. I am forced to let other people do things for me

$\square \quad \square$

$\square$
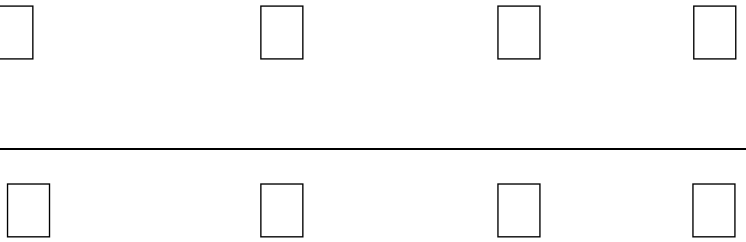

$\square$

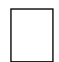

3. I try to get what I want out of life

4. I have choices in my life

5. I do what I think is best for me in my life

6. In some ways I am special

7. Other people tell me when not to be active
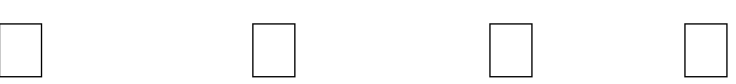

8. Other people help me get what they think I want out of life rather than what I want

9. Other people do what they think is best for me in my life rather than what I think is best
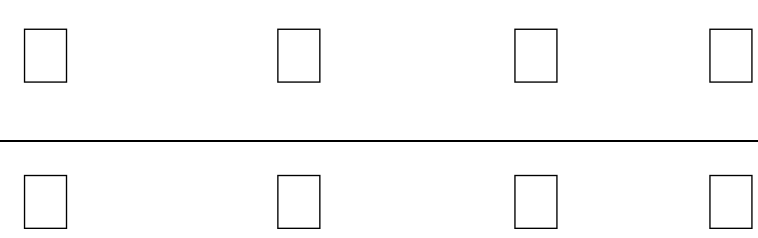

10. I know what is best for me 
Item

11. I am in control of what happens to me
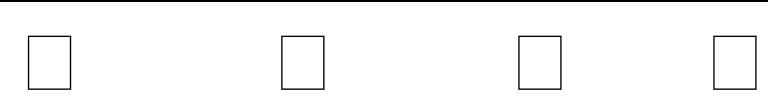

12. I know how to get what I want out of life
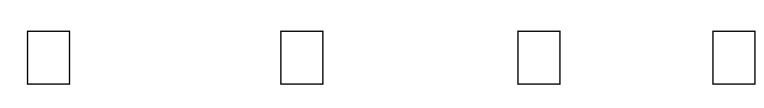

13. My present health allows me to do what I want to do

14. There are enough people nearby to help me do what I choose

15. I can choose to make my own decisions

16. I know myself

17. Other people act for me when I do not want them to

18. I have enough information to make choices

19. I lead my life the way other people want me to rather than the way I want to lead it

20. I have the freedom to move around as I please

21. I am forced to let other people make decisions for me
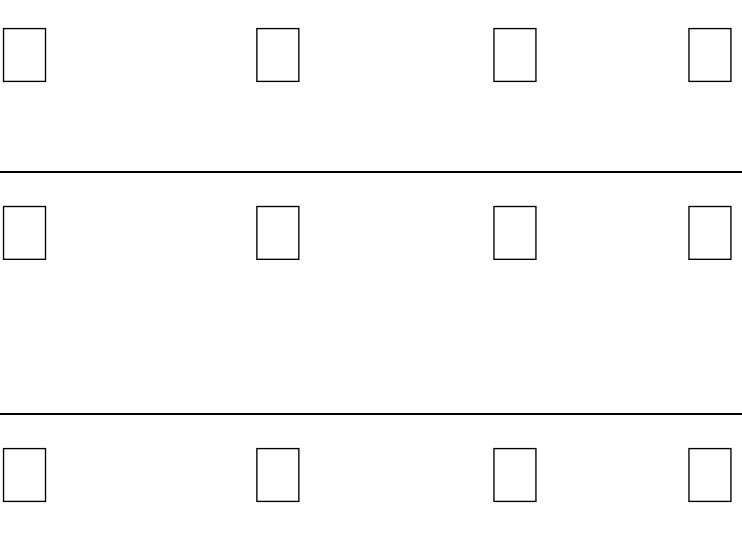
Item

Not at

Completely

all true

True

22. I can choose to be as active as I please

23. Other people know better than I do when I need to be with other people

24. Other people know better than I do when I need to be alone

25. I can choose not to be active

26. The way my home is furnished keeps me from doing what I want to do

27. I know when I need to do things for myself
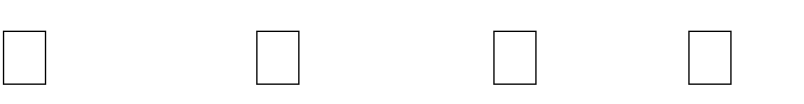
Appendix D

JAVA Music Club Interview Guide - Residents

Interview Questions

\begin{tabular}{|c|c|}
\hline Question: & Potential Question-Specific Probes: \\
\hline \multicolumn{2}{|c|}{$\begin{array}{l}\text { SCRIPT: For the past three months you have been taking part in the JAVA Music Club, which } \\
\text { is a social group that is intended to foster discussion and sharing between you and your } \\
\text { fellow residents at (name of retirement home here). During this interview, I will be asking } \\
\text { you some general questions about your experience with the group. } \\
\text { Estimated interview time: } 30 \text { minutes }\end{array}$} \\
\hline How did you hear about the Java Music Club? & $\begin{array}{l}\text { What were you expecting the Java Music } \\
\text { Club to be like when you first heard about it? }\end{array}$ \\
\hline $\begin{array}{l}\text { Why did you want to participate in the Java } \\
\text { Music Club? }\end{array}$ & $\begin{array}{l}\text { What made you interested in participating? } \\
\text { Were you interested in the social aspect of } \\
\text { the group? In the musical aspect? Did it } \\
\text { sound like any other program that your } \\
\text { residence currently offers? Did it sound } \\
\text { different from the other programs? What } \\
\text { were you looking for in the Java Music Club? }\end{array}$ \\
\hline What other programs do you participate in? & $\begin{array}{l}\text { During these other programs are there } \\
\text { opportunities to interact with one another? } \\
\text { Are there opportunities to provide support to } \\
\text { others? Are their opportunities to receive } \\
\text { support? }\end{array}$ \\
\hline $\begin{array}{l}\text { How was your general experience } \\
\text { participating in the JAVA Music Club? }\end{array}$ & $\begin{array}{l}\text { How did you get to the group every week? } \\
\text { Was it easy for you? How was this experience } \\
\text { for you? Easy? Tough to get going? } \\
\text { Were there any barriers to you attending? } \\
\text { Did you need any assistance getting to the } \\
\text { Java Music Club? Was this assistance always } \\
\text { there for you when needed? } \\
\text { Is there anything you can suggest that would } \\
\text { make regular attendance more manageable } \\
\text { for you and your fellow residents? } \\
\text { What was your favourite part? What was } \\
\text { your least favourite part? Is there anything } \\
\text { that you would change about the program to } \\
\text { improve it? }\end{array}$ \\
\hline
\end{tabular}




\begin{tabular}{|l|l|}
\hline $\begin{array}{l}\text { How did you find the social aspect of the } \\
\text { group? }\end{array}$ & $\begin{array}{l}\text { Did you find that the JMC facilitated } \\
\text { discussion? Did you feel comfortable sharing } \\
\text { with the group? Do you interact with any of } \\
\text { the other members of the group outside of } \\
\text { the JMC? Did you feel supported by members } \\
\text { of the group? } \\
\text { Do you feel that this group provided an } \\
\text { opportunity for social interaction above and } \\
\text { beyond what you already had before } \\
\text { participation? }\end{array}$ \\
\hline $\begin{array}{l}\text { Do you feel that you have benefited from the } \\
\text { group in any way? }\end{array}$ & $\begin{array}{l}\text { In what way? What part of the group do you } \\
\text { believe is most responsible for this change? } \\
\text { Did you feel that your fellow group members } \\
\text { benefited from the Java Music Club? } \\
\text { Do you feel that other people in your } \\
\text { residence could have benefited more from } \\
\text { the program? Why is that? Why do you think } \\
\text { they did not join? What do you think could } \\
\text { have been done to reach out to the residents } \\
\text { who could have benefited the most from this } \\
\text { program? }\end{array}$ \\
\hline $\begin{array}{l}\text { If you had a message to give to the facilitator } \\
\text { of the group, what would that be? }\end{array}$ \\
your experience with the JMC?
\end{tabular} \mid \begin{tabular}{l}
$\mid$ \\
\hline
\end{tabular}

\section{JAVA Music Club Interview Guide - Recreation Coordinator}

\section{Interview Questions}

\begin{tabular}{|c|c|}
\hline Question: & Potential Question-Specific Probes: \\
\hline \multicolumn{2}{|c|}{$\begin{array}{l}\text { SCRIPT: For the past three months (name of residence) has been taking part in the JAVA } \\
\text { Music Club, which is a social group that is intended to foster discussion and sharing between } \\
\text { residents. During this interview, I will be asking you some general questions about your } \\
\text { observations of the group, how it was implemented, and reactions from participants. } \\
\text { Estimated interview time: } 30 \text { minutes }\end{array}$} \\
\hline $\begin{array}{l}\text { Had you heard about the Java Music Club } \\
\text { before being approached by Geneva about } \\
\text { her research project? }\end{array}$ & $\begin{array}{l}\text { If yes, what had you heard? } \\
\text { If you heard about the program from } \\
\text { colleagues, what was their experience with } \\
\text { Java? }\end{array}$ \\
\hline
\end{tabular}




\begin{tabular}{|c|c|}
\hline $\begin{array}{l}\text { Why were you interested in bringing the Java } \\
\text { Music Club to }\end{array}$ & $\begin{array}{l}\text { What made you interested in having - } \\
\text { participate? } \\
\text { Were you interested in the social aspect of } \\
\text { the group? In the musical aspect? } \\
\text { Did it sound like any other program that your } \\
\text { residence currently offers? Did it sound } \\
\text { different from the other programs? } \\
\text { What were you looking for in the Java Music } \\
\text { Club? }\end{array}$ \\
\hline $\begin{array}{l}\text { How was the implementation of the } \\
\text { program? }\end{array}$ & $\begin{array}{l}\text { Was it relatively easy to organize everything } \\
\text { such that Geneva could start facilitating Java } \\
\text { Music Club at_? Were there any hurdles } \\
\text { to implementation? } \\
\text { If you did not encounter any hurdles, were } \\
\text { there some that you could foresee being a } \\
\text { concern at another home? } \\
\text { Could you see Java being implemented here } \\
\text { full time? What would that look like? Do you } \\
\text { think it would be a popular program? } \\
\text { Could anything about the Java Music Club be } \\
\text { changed so that it is more appropriate for } \\
\text { ? }\end{array}$ \\
\hline $\begin{array}{l}\text { Did any participants speak with you about } \\
\text { the Java Music Club? (no names required) }\end{array}$ & $\begin{array}{l}\text { If so, what did they have to say about the } \\
\text { program? } \\
\text { Did they speak to others about the program? } \\
\text { Did family members mention anything to } \\
\text { you? }\end{array}$ \\
\hline $\begin{array}{l}\text { Did you witness any effects of the group } \\
\text { outside of the sessions? }\end{array}$ & $\begin{array}{l}\text { Did you notice any residents socializing more } \\
\text { outside of the group? Reaching out to } \\
\text { others? }\end{array}$ \\
\hline $\begin{array}{l}\text { How do you feel your residence may have } \\
\text { benefited from the group? }\end{array}$ & $\begin{array}{l}\text { Do you feel that other people who did not } \\
\text { participate in the study could have benefited } \\
\text { more from the program? Why is that? Why } \\
\text { do you think they did not join? What do you } \\
\text { think could have been done to reach out to } \\
\text { the residents who could have benefited the } \\
\text { most from this program? }\end{array}$ \\
\hline $\begin{array}{l}\text { 4. Would you like to share anything else } \\
\text { about your experience with the JMC? }\end{array}$ & \\
\hline
\end{tabular}




\section{References}

Aartsen, M. J., van Tilburg, T. G., Smits, C. H. M., \& Knipscheer, C. P. M. (2004). A longitudinal study on the impact of physical and cognitive decline on the personal network in old age. Journal of Social and Personal Relationships, 21, 249-266. doi:10.1177/0265407504041386

Adams, T. R., Rabin, L. A., Da Silva, V. G., Katz, M. J., Fogel, J., \& Lipton, R. B. (2016). Social support buffers the impact of depressive symptoms on life satisfaction in old age. Clinical Gerontologist, 39, 139-157. doi:10.1080/07317115.2015.1073823

Aggarwal, N. T., Wilson, R. S., Beck, T. L., Rajan, K. B., Mendes de Leon, Carlos F, Evans, D. A., \& Everson-Rose, S. A. (2014). Perceived stress and change in cognitive function among adults 65 years and older. Psychosomatic Medicine, 76, 80-85.

doi:10.1097/PSY.0000000000000016

Alzheimer Disease International. (2013). World Alzheimer Report 2013: Journey of caring: An analysis of long-term care for dementia. London, England: Alzheimer Disease International.

Alzheimer Society of Canada (2016). Prevalence and Monetary Costs of Dementia in Canada. Retrieved from http://www.alzheimer.ca/en/Home/About-dementia/What-isdementia/Dementia-numbers

American Psychiatric Association. (2013). Diagnostic and statistical manual of mental disorders (DSM-5®). American Psychiatric Pub.

Amieva, H., Stoykova, R., Matharan, F., Helmer, C., Antonucci, T. C., \& Dartigues, J. (2010). What aspects of social network are protective for dementia? not the quantity but the 
quality of social interactions is protective up to 15 years later. Psychosomatic Medicine, 72, 905-911. doi:10.1097/PSY.0b013e3181f5e121

Andresen, M., \& Puggaard, L. (2008). Autonomy among physically frail older people in nursing home settings: A study protocol for an intervention study. BMC Geriatrics, 8, 32-32. doi:10.1186/1471-2318-8-32

Antonucci, T. C., \& Jackson, J. S. (1990). The role of reciprocity in social support. In B. R. Sarason, I. G. Sarason, \& G. R. Pierce (Eds.), Wiley series on personality processes. Social support: An interactional view (pp. 173-198). Oxford, England: John Wiley \& Sons.

Ball, M. M., Whittington, F. J., Perkins, M. M., Patterson, V. L., Hollingsworth, C., King, S. V., \& Combs, B. L. (2000). Quality of life in assisted living facilities: Viewpoints of residents. Journal of Applied Gerontology, 19, 304-325. doi: $10.1177 / 073346480001900304$

Barg, F. K., Huss-Ashmore, R., Wittink, M. N., Murray, G. F., Bogner, H. R., \& Gallo, J. J. (2006). A mixed-methods approach to understanding loneliness and depression in older adults. The Journals of Gerontology Series B: Psychological Sciences and Social Sciences, 61(6), S329-S339.

Beekman, A. T., Deeg, D. J. H., Van Limbeek, J., Braam, A. W., De Vries, M. Z., \& Van Tilburg, W. (1997). Criterion validity of the Center for Epidemiologic Studies Depression scale (CES-D): results from a community-based sample of older subjects in the Netherlands. Psychological medicine, 27, 231-235. 
Bohlmeijer, E., Roemer, M., Cuijpers, P., \& Smit, F. (2007). The effects of reminiscence on psychological well-being in older adults: A meta-analysis. Aging and Mental Health, 11(3), 291-300.

Bradshaw, S. A., Playford, E. D., \& Riazi, A. (2012). Living well in care homes: A systematic review of qualitative studies. Age and Ageing, 41, 429-440. doi:10.1093/ageing/afs069

Braun, V., \& Clarke, V. (2012). Thematic analysis. In Cooper, H. (Ed.), APA Handbook of Research Methods in Psychology: Vol. 2. Research Designs (57-71). American Psychological Association.

Brigola, A. G., Manzini, C. S. S., Oliveira, G. B. S., Ottaviani, A. C., Sako, M. P., \& Vale, F. A. C. (2015). Subjective memory complaints associated with depression and cognitive impairment in the elderly: A systematic review. Dementia \& Neuropsychologia, 9(1), 5157.

Brownie, S., Horstmanshof, L., \& Garbutt, R. (2014). Factors that impact residents' transition and psychological adjustment to long-term aged care: a systematic literature review. International Journal of Nursing Studies, 51(12), 1654-1666.

Butters, M. A., Becker, J. T., Nebes, R. D., Zmuda, M. D., Mulsant, B. H., Pollock, B. G., \& Reynolds, C. F. (2000). Changes in cognitive functioning following treatment of late-life depression. American Journal of Psychiatry, 157, 1949-1954. doi:10.1176/appi.ajp.157.12.1949

Cacioppo, J. T., Hawkley, L. C., \& Thisted, R. A. (2010). Perceived social isolation makes me sad: 5-year cross-lagged analyses of loneliness and depressive symptomatology in the Chicago Health, Aging, and Social Relations Study. Psychology and aging, 25(2), 453463. 
Cacioppo, J. T., Hughes, M. E., Waite, L. J., Hawkley, L. C., \& Thisted, R. A. (2006).

Loneliness as a specific risk factor for depressive symptoms: Cross-sectional and longitudinal analyses. Psychology and Aging, 21, 140-151. doi: 10.1037/08827974.21.1.140

Canadian Institute for Health Information (2016). CCRS Continuing Care Reporting System: Profile of Residents in Continuing Care Facilities 2015-2016. Ottawa, ON: CIHI.

Canadian Institute for Health Information. (2013). When a nursing home is home: How do Canadian nursing homes measure up on quality? Ottawa, ON: CIHI.

Chodosh, J., Kado, D. M., Seeman, T. E., \& Karlamangla, A. S. (2007). Depressive symptoms as a predictor of cognitive decline: MacArthur studies of successful aging. The American Journal of Geriatric Psychiatry, 15, 406-415. doi:10.1097/01.JGP.0b013e31802c0c63

Choi, N. G., Marti, C. N., DiNitto, D. M., \& Kunik, M. E. (2019). Longitudinal associations of falls and depressive symptoms in older adults. The Gerontologist.

Cohen, S., Kamarck, T., and Mermelstein, R. (1983). A global measure of perceived stress. Journal of Health and Social Behavior, 24, 386-396.

Cohen, S., \& Wills, T. A. (1985). Stress, social support, and the buffering hypothesis. Psychological Bulletin, 98, 310-357.

Comijs, H. C., Jonker, C., Beekman, A. T., \& Deeg, D. J. (2001). The association between depressive symptoms and cognitive decline in community-dwelling elderly persons.International Journal of Geriatric Psychiatry, 16, 361-367. doi:10.1002/gps.343

Crawford, J.R., Henry, J.D., Ward, A.L., Blake, J. (2006). The prospective and retrospective memory questionnaire (PMRQ): Latent structure, normative data and discrepancy analysis for proxy-ratings. British Journal of Clinical Psychology, 45, 83-104. 
Cunningham, P. M. (2016). Java Music Club: A Standardized Mutual Support Program for Adults with Cognitive Change. J Alzheimers Neurodegener, 2.

Delis, D.C., Kramer, J.H., Kaplan, E., \& Ober, B.A. (2000). Verbal learning test-second edition. Adult version. Manual. San Antonio, Texas: Psychological Corporation.

Dickinson, W. J., Potter, G. G., Hybels, C. F., McQuoid, D. R., \& Steffens, D. C. (2011). Change in stress and social support as predictors of cognitive decline in older adults with and without depression. International Journal of Geriatric Psychiatry, 26, 1267-1274. doi:10.1002/gps.2676

Donovan, N. J., Wu, Q., Rentz, D. M., Sperling, R. A., Marshall, G. A., \& Glymour, M. M. (2016). Loneliness, depression and cognitive function in older U.S. adults: Loneliness, depression and cognition. International Journal of Geriatric Psychiatry,32, 564573. doi:10.1002/gps.4495

Dotson, V. M., Resnick, S. M., \& Zonderman, A. B. (2008). Differential association of concurrent, baseline, and average depressive symptoms with cognitive decline in older adults. The American Journal of Geriatric Psychiatry, 16, 318-330. doi:10.1097/JGP.0b013e3181662a9c

Damschroder, L. J., Aron, D. C., Keith, R.E., Kirsh, S.R., Alexander, J. A., \& Lowery, J. C. (2009). Fostering implementation of health services research findings into practice: a consolidated framework for advancing implementation science. Implementation Science, 4, 50. doi:10.1186/1748-5908-4-50 
Ellis, J. M. (2010). Psychological transition into a residential care facility: Older people's experiences. Journal of Advanced Nursing, 66, 1159-1168. doi:10.1111/j.13652648.2010.05280.x

Ellwardt, L., Aartsen, M., Deeg, D., \& Steverink, N. (2013). Does loneliness mediate the relation between social support and cognitive functioning in later life? Social Science \& Medicine, 98, 116-124. doi:10.1016/j.socscimed.2013.09.002

Elo, S., \& Kyngäs. (2008). The qualitative content analysis process. Journal of Advanced Nursing, 62, 107-115.

Faul, F., Erdfelder, E., Lang, A.-G., \& Buchner, A. (2007). G*Power 3: A flexible statistical power analysis program for the social, behavioral, and biomedical sciences. Behavior Research Methods, 39, 175-191.

Folstein, M. F., Folstein, S. E., \& Fanjiang, G. (2001). MMSE Mini-Mental State Examination. Clinical Guide. Lutz,Fl.: Psychological Assessment Resources, Inc.

Folstein, M., Folstein, S.E., \& McHugh, P.R. (1975). "Mini-Mental State" a practical method for grading the cognitive state of patients for the clinician. Journal of Psychiatric Research, $12,189-198$.

Fratiglioni, L., Paillard-Borg, S., \& Winblad, B. (2004). An active and socially integrated lifestyle in late life might protect against dementia. The Lancet Neurology, 3(6), 343-353.

Gardiner, C., Geldenhuys, G., \& Gott, M. (2018). Interventions to reduce social isolation and loneliness among older people: an integrative review. Health $\&$ social care in the community, 26(2), 147-157.

Genziani, M., Stewart, R., Béjot, Y., Amieva, H., Artero, S., \& Ritchie, K. (2013). Subjective memory impairment, objective cognitive functioning and social activity in French older 
people: Findings from the Three Cities study. Geriatrics \& Gerontology International, 13(1), 139-145.

Glass, T. A., Kasl, S. V., \& Berkman, L. F. (1997). Stressful life events and depressive symptoms among the elderly: Evidence from a prospective community study. Journal of Aging and Health, 9, 70-89. doi:10.1177/089826439700900104

Glei, D. A., Landau, D. A., Goldman, N., Chuang, Y., Rodríguez, G., \& Weinstein, M. (2005). Participating in social activities helps preserve cognitive function: An analysis of a longitudinal, population-based study of the elderly. International Journal of Epidemiology, 34, 864-871. doi:10.1093/ije/dyi049

Golden, J., Conroy, R. M., Bruce, I., Denihan, A., Greene, E., Kirby, M., \& Lawlor, B. A. (2009). Loneliness, social support networks, mood and wellbeing in community-dwelling elderly.International Journal of Geriatric Psychiatry, 24, 694-700. doi:10.1002/gps.2181

Goll, J. C., Charlesworth, G., Scior, K., \& Stott, J. (2015). Barriers to social participation among lonely older adults: the influence of social fears and identity. PloS one, 10(2), e0116664.

Gow, A. J., Corley, J., Starr, J. M., \& Deary, I. J. (2013). Which social network or support factors are associated with cognitive abilities in old age? Gerontology, 59, 454-463. doi:10.1159/000351265

Gow, A. J., Pattie, A., Whiteman, M. C., Whalley, L. J., \& Deary, I. J. (2007). Social support and successful aging: Investigating the relationships between lifetime cognitive change and life satisfaction. Journal of Individual Differences, 28, 103-115. doi:10.1027/16140001.28 .3 .103 
Harper, M., \& Cole, P. (2012). Member checking: can benefits be gained similar to group therapy? The Qualitative Report, 17(2), 510-517.

Haslam, C., Haslam, S. A., Jetten, J., Bevins, A., Ravenscroft, S., \& Tonks, J. (2010). The social treatment: The benefits of group interventions in residential care settings. Psychology and Aging, 25, 157-167. doi:10.1037/a0018256

Hays, J. C., Steffens, D. C., Flint, E. P., Bosworth, H. B., \& George, L. K. (2001). Does social support buffer functional decline in elderly patients with unipolar depression? American Journal of Psychiatry, 158, 1850-1855. doi:10.1176/appi.ajp.158.11.1850

Heppenstall, C. P., Keeling, S., Hanger, H. C., \& Wilkinson, T. J. (2014). Perceived factors which shape decision-making around the time of residential care admission in older adults: A qualitative study: Influences upon residential care decisions. Australasian Journal on Ageing, 33, 9-13. doi:10.1111/j.1741-6612.2012.00644.x

Hertz, J. E., \& Anschutz, C. A. (2002). Relationships among perceived enactment of autonomy, self-care, and holistic health in community-dwelling older adults. Journal of Holistic Nursing, 20, 166-186. doi:10.1177/08910102020002006

Hillcoat-Nallétamby, S. (2014). The meaning of "independence" for older people in different residential settings. The Journals of Gerontology. Series B, Psychological Sciences and Social Sciences, 69, 419-430. doi:10.1093/geronb/gbu008

Holtzman, R. E., Rebok, G. W., Saczynski, J. S., Kouzis, A. C., Wilcox Doyle, K., \& Eaton, W. W. (2004). Social network characteristics and cognition in middle-aged and older adults. The Journals of Gerontology. Series B, Psychological Sciences and Social Sciences, 59, P278-284. doi:10.1093/geronb/59.6.P278 
Hwang, H., Lin, H., Tung, Y., \& Wu, H. (2006). Correlates of perceived autonomy among elders in a senior citizen home: A cross-sectional survey. International Journal of Nursing Studies, 43, 429-437. doi:10.1016/j.ijnurstu.2005.06.002

Johansson, L., Guo, X., Waern, M., Ostling, S., Gustafson, D., Bengtsson, C., \& Skoog, I. (2010). Midlife psychological stress and risk of dementia: A 35-year longitudinal population study. Brain : A Journal of Neurology, 133, 2217-2224.

doi:10.1093/brain/awq116

Kahana, E., Kelley-Moore, J., \& Kahana, B. (2012). Proactive aging: A longitudinal study of stress, resources, agency, and well-being in late life. Aging \& Mental Health, 16, 438451. doi:10.1080/13607863.2011.644519

Kane, R. A., Caplan, A. L., Urv-Wong, E. K., Freeman, I. C., \& Aroskar, M. A., \& Finch, M. (1997). Everyday matters in lives of nursing home residents: wish for an perception of choice and control. Journal of American Geriatrics Society, 45, 1086-1093.

Kawachi, I., \& Berkman, L. F. (2001). Social ties and mental health. Journal of Urban Health, 78, 458-467. doi:10.1093/jurban/78.3.458

Katz, S. (2000). Busy bodies: Activity, aging and the management of everyday life. Journal of Aging Studies, 14, 135-152. doi: 10.1016/S0890-4065(00)80008-0

Kim, H. Y. (2013). Statistical notes for clinical researchers: assessing normal distribution (2) using skewness and kurtosis. Restorative Dentistry \& Endodontics, 38(1), 52-54.

Knight, T., \& Mellor, D. (2007). Social inclusion of older adults in care: Is it just a question of providing activities? International Journal of Qualitative Studies on Health and Wellbeing, 2, 76-85. doi:10.1080/17482620701320802 
Koopmans, R. T. C. M, Zuidema, S. U., Leontjevas, R., \& Gerritsen, D. L. (2010).

Comprehensive assessment of depression and behavioral problems in long-term care. International Psychogeriatrics, 22, 1054-1062. doi:10.1017/S1041610210000736

Krause, N. (2001). Social support. In R. H. Binstock \& L. K. George (Eds.), Handbook of aging and the social sciences (5th ed., pp. 272-294). San Diego, CA: Academic Press.

Krueger, K. R., Wilson, R. S., Kamenetsky, J. M., Barnes, L. L., Bienias, J. L., \& Bennett, D. A. (2009). Social engagement and cognitive function in old age. Experimental Aging Research, 35, 45-60. doi:10.1080/03610730802545028

Lazarus, R. S., \& Launier, R. (1978). Stress-related transactions between person and environment. In Perspectives in interactional psychology (pp. 287-327). Springer, Boston, MA.

Lee, V. S. P., Simpson, J., \& Froggatt, K. (2013). A narrative exploration of older people's transitions into residential care. Aging \& Mental Health, 17, 48-56. doi:10.1080/13607863.2012.715139

Lee, D. T. F., Woo, J., \& Mackenzie, A. E. (2002). A review of older people's experiences with residential care placement. Journal of Advanced Nursing, 37, 19-27. doi:10.1046/j.13652648.2002.02060.x

Leung, D. Y., Lam, T., \& Chan, S. S. (2010). Three versions of perceived stress scale: Validation in a sample of chinese cardiac patients who smoke. BMC Public Health, 10, 513-513. doi:10.1186/1471-2458-10-513

Leung, P., Orrell, M., \& Orgeta, V. (2015). Social support group interventions in people with dementia and mild cognitive impairment: A systematic review of the literature. International Journal of Geriatric Psychiatry, 30, 1-9. doi:10.1002/gps.4166 
Lewin, S., Glenton, C., \& Oxman, A. D. (2009). Use of qualitative methods alongside randomised controlled trials of complex healthcare interventions: methodological study. Bmj, 339, b3496.

Luchesi, B. M., Souza, É. N., Gratão, A. C. M., de Oliveira Gomes, G. A., Inouye, K., da Silva Alexandre, T., ... Iost Pavarini, S. C. (2016). The evaluation of perceived stress and associated factors in elderly caregivers. Archives of Gerontology and Geriatrics, 67, 713. doi:10.1016/j.archger.2016.06.017

Lockwood, K. A., Alexopoulos, G. S., \& van Gorp, W. G. (2002). Executive dysfunction in geriatric depression. American Journal of Psychiatry, 159, 1119-1126. doi:10.1176/appi.ajp.159.7.1119

Maas, M. L., Kelley, L. S., Park, M., \& Specht, J. P. (2002). Issues in conducting research in nursing homes. Western Journal of Nursing Research, 24, 373-389. doi:10.1177/01945902024004006

Magaziner, J., German, P., Zimmerman, S. I., \& al, E. (2000). The prevalence of dementia in a statewide sample of new nursing home admissions aged 65 and older: Diagnosis by expert panel. The Gerontologist, 40, 663-672. doi:10.1093/geront/40.6.663

McDermott, L. M., \& Ebmeier, K. P. (2009). A meta-analysis of depression severity and cognitive function. Journal of Affective Disorders, 119, 1-8. doi:10.1016/j.jad.2009.04.022

Mimura, C., \& Griffiths, P. (2008). A Japanese version of the Perceived Stress Scale: crosscultural translation and equivalence assessment. BMC psychiatry, 8, 85-85.

Moos, R. H., Schutte, K. K., Brennan, P. L., \& Moos, B. S. (2005). The interplay between life stressors and depressive symptoms among older adults. The Journals of Gerontology. 
Series B, Psychological Sciences and Social Sciences, 60, P199-206.

doi:10.1093/geronb/60.4.P199

Morse, D.L. (2000). Relocation stress syndrome is real. American Journal of Nursing, 100, 2430. doi: $10.2307 / 3522152$

Morse, J. M., Barrett, M., Mayan, M., Olson, K., \& Spiers, J. (2002). Verification strategies for establishing reliability and validity in qualitative research. International Journal of Qualitative Methods, 1, 13-22. doi:10.1177/160940690200100202

Murphy, K., \& Welford, C. (2012). Agenda for the future: Enhancing autonomy for older people in residential care: Agenda for the future. International Journal of Older People Nursing, 7, 75-80. doi:10.1111/j.1748-3743.2012.00309.x

Newall, N. E., \& Menec, V. H. (2019). Loneliness and social isolation of older adults: Why it is important to examine these social aspects together. Journal of Social and Personal Relationships, 36(3), 925-939.

Nyqvist, F., Cattan, M., Andersson, L., Forsman, A. K., \& Gustafson, Y. (2013). Social capital and loneliness among the very old living at home and in institutional settings: A comparative study. Journal of Aging and Health, 25, 1013-1035.

doi:10.1177/0898264313497508

Oakley, A., Strange, V., Bonell, C., Allen, E., \& Stephenson, J. (2006). Process evaluation in randomised controlled trials of complex interventions. Bmj, 332(7538), 413-416.

Osmanovic-Thunström, A., Mossello, E., Åkerstedt, T., Fratiglioni, L., \& Wang, H. (2015). Do levels of perceived stress increase with increasing age after age 65? A population-based study. Age and Ageing, 44, 828-834. doi:10.1093/ageing/afv078 
Ownby, R. L., Crocco, E., Acevedo, A., John, V., \& Loewenstein, D. (2006). Depression and risk for alzheimer disease: Systematic review, meta-analysis, and metaregression analysis.Archives of General Psychiatry, 63, 530-538. doi:10.1001/archpsyc.63.5.530

Paterniti, S., Verdier-Taillefer, M., Dufouil, C., \& Alpérovitch, A. (2002). Depressive symptoms and cognitive decline in elderly people: Longitudinal study. The British Journal of Psychiatry, 181, 406-410. doi:10.1192/bjp.181.5.406

Pearce, E., Launay, J., \& Dunbar, R. I. (2015). The ice-breaker effect: singing mediates fast social bonding. Royal Society Open Science, 2(10), 150221.

Pfeiffer, E. (1975). A short portable mental status questionnaire for the assessment of organic brain deficit in elderly patients. Journal of the American Geriatric Society, 23, 433-41.

Pillemer, S. C., \& Holtzer, R. (2016). The differential relationships of dimensions of perceived social support with cognitive function among older adults. Aging \& Mental Health, 20, 727-735. doi:10.1080/13607863.2015.1033683

Pin, S., Guilley, E., Spini, D., \& Lalive d'Epinay, C. (2005). The impact of social relationships on the maintenance of independence in advanced old age: Findings of a swiss longitudinal study. Zeitschrift Für Gerontologie Und Geriatrie, 38, 203-209. doi:10.1007/s00391-005-0250-9

Pinquart, M., \& Sörensen, S. (2001). Influences on loneliness in older adults: A metaanalysis. Basic and Applied Social Psychology, 23, 245-266. doi: $10.1207 / 153248301753225702$

Potter, G. G., Hartman, M., \& Ward, T. (2009). Perceived stress and everyday memory complaints among older adult women. Anxiety, Stress \& Coping, 22, 475-481. doi:10.1080/10615800802449610 
Radloff, L.S. The CES-D scale: a self-report depression scale for research in the general population. (1977). Applied Psychological Measurement,1, 385-401.

Reid, L. M., \& MacLullich, A. M. (2006). Subjective memory complaints and cognitive impairment in older people. Dementia and geriatric cognitive disorders, 22(5-6), 471485.

Reinhardt, J. P., Boerner, K., \& Horowitz, A. (2006). Good to have but not to use: Differential impact of perceived and received support on well-being. Journal of Social and Personal Relationships, 23, 117-129. doi:10.1177/0265407506060182

Reitan, R. M. (1958). Validity of the Trail Making Test as an indicator of organic brain damage. Perceptual and motor skills, 8, 271-276.

Rico-Uribe, L. A., Caballero, F. F., Olaya, B., Tobiasz-Adamczyk, B., Koskinen, S., Leonardi, M., ... \& Miret, M. (2016). Loneliness, social networks, and health: a cross-sectional study in three countries. PloS one, 11(1), e0145264.

Rock, P. L., Roiser, J. P., Riedel, W. J., \& Blackwell, A. D. (2014). Cognitive impairment in depression: A systematic review and meta-analysis. Psychological Medicine, 44, 20292040. doi:10.1017/S0033291713002535

Rönnlund, M., Sundström, A., Sörman, D. E., \& Nilsson, L. (2013). Effects of perceived longterm stress on subjective and objective aspects of memory and cognitive functioning in a middle-aged population-based sample. The Journal of Genetic Psychology, 174, 2541. doi:10.1080/00221325.2011.635725

Rowe, J. W., \& Kahn, R. L. (1997). Successful aging. The Gerontologist, 37, 433-440. doi:10.1093/geront/37.4.433 
Royall, D. R., Palmer, R., Chiodo, L. K., \& Polk, M. J. (2012). Depressive symptoms predict longitudinal change in executive control but not memory. International Journal of Geriatric Psychiatry, 27, 89-96. doi:10.1002/gps.2697

Russell, D. (1996). The UCLA Loneliness Scale (Version 3): Reliability, validity and factor structure. Journal of Personality Assessment, 66, 20-40.

Saraçlı, Ö., Akca, A. S. D., Atasoy, N., Önder, Ö., Şenormancı, Ö., Kaygisız, İ., \& Atik, L. (2015). The relationship between quality of life and cognitive functions, anxiety and depression among hospitalized elderly patients. Clinical Psychopharmacology and Neuroscience, 13, 194-200. doi:10.9758/cpn.2015.13.2.194

Scocco, P., Rapattoni, M., \& Fantoni, G. (2006). Nursing home institutionalization: A source of eustress or distress for the elderly? International Journal of Geriatric Psychiatry, 21, 281-287.

Seeman, T. E., Lusignolo, T. M., Albert, M., \& Berkman, L. (2001). Social relationships, social support, and patterns of cognitive aging in healthy, high-functioning older adults: MacArthur studies of successful aging. Health Psychology, 20, 243-255. doi:10.1037/0278-6133.20.4.243

Seitz, D., Purandare, N., \& Conn, D. (2010). Prevalence of psychiatric disorders among older adults in long-term care homes: A systematic review. International Psychogeriatrics, 22, 1025-1039. doi:10.1017/S1041610210000608

Shawler, C., Rowles, G. D., \& High, D. M. (2001). Analysis of key decision-making incidents in the life of a nursing home resident. Gerontologist, 41, 612-622. doi:10.1093/geront/41.5.612 
Sherbourne, C. D., \& Stewart, A. L. (1991). The MOS social support survey. Social Science \& Medicine, 32, 705-714. doi:10.1016/0277-9536(91)90150-B

Schnittger, R. I., Wherton, J., Prendergast, D., \& Lawlor, B. A. (2012). Risk factors and mediating pathways of loneliness and social support in community-dwelling older adults. Aging \& Mental Health, 16(3), 335-346.

Sims, R. C., Hosey, M., Levy, S., Whitfield, K. E., Katzel, L. I., \& Waldstein, S. R. (2014). Distinct functions of social support and cognitive function among older adults. Experimental Aging Research, 40, 40-59. doi:10.1080/0361073X.2014.857551

Smetanin, P., Kobak, P., Briante, C., Stiff, D., Sherman, G., \& Ahmad, S. (2009). Rising Tide: The Impact of Dementia in Canada 2008 to 2038. Alzheimer's Society of Canada.

Smith, G., Della Sala, S., Logie, R.H. \& Maylor, E.A. (2000). Prospective and Retrospective Memory in Normal Aging and Dementia: A Questionnaire Study. Memory, 8, 311-321.

Snyder, L., Jenkins, C., \& Joosten, L. (2007). Effectiveness of support groups for people with mild to moderate alzheimer's disease: An evaluative survey. American Journal of Alzheimer's Disease and Other Dementias, 22, 14-19. doi:10.1177/1533317506295857

Spira, A. P., Ph.D, Rebok, G. W., Ph.D, Stone, K. L., Ph.D, Kramer, J. H., Psy.D, \& Yaffe, K., M.D. (2012). Depressive symptoms in oldest-old women: Risk of mild cognitive impairment and dementia. American Journal of Geriatric Psychiatry, 20, 1006-1015. doi:10.1097/JGP.0b013e318235b611

Statistics Canada (2011). Living Arrangements of Seniors. Retrieved from http://www12.statcan.gc.ca/census-recensement/2011/as-sa/98-312-x/98-312x2011003_4-eng.cfm 
Stawski, R. S., Sliwinski, M. J., \& Smyth, J. M. (2006). Stress-related cognitive interference predicts cognitive function in old age. Psychology and Aging, 21, 535-544. doi:10.1037/0882-7974.21.3.535

Stroop, J. R. (1935). Studies of interference in serial verbal reactions. Journal of experimental psychology, 18, 643-662.

Subramaniam, P., \& Woods, B. (2012). The impact of individual reminiscence therapy for people with dementia: systematic review. Expert Review of Neurotherapeutics, 12, $545-555$.

Tak, S. H., Kedia, S., Tongumpun, T. M., \& Hong, S. H. (2015). Activity engagement: Perspectives from nursing home residents with dementia. Educational gerontology, 41(3), 182-192.

Taylor, H. O., Wang, Y., \& Morrow-Howell, N. (2018). Loneliness in senior housing communities. Journal of Gerontological Social Work, 61(6), 623-639. Doi: $10.1080 / 01634372.2018 .1478352$

Teresi, J., Abrams, R., Holmes, D., Ramirez, M., \& Eimicke, J. (2001). Prevalence of depression and depression recognition in nursing homes. Social Psychiatry and Psychiatric Epidemiology, 36, 613-620. doi:10.1007/s127-001-8202-7

Theurer, K., Mortenson, W. B., Stone, R., Suto, M., Timonen, V., \& Rozanova, J. (2015). The need for a social revolution in residential care. Journal of Aging Studies, 35, 201-210. doi:10.1016/j.jaging.2015.08.011

Theurer, K., Wister, A., Sixsmith, A., Chaudhury, H., \& Lovegreen, L. (2014). The development and evaluation of mutual support groups in long-term care homes. Journal of Applied Gerontology, 33, 387-415. doi:10.1177/0733464812446866 
Thompson, R. G., Moulin, C. J. A., Hayre, S., \& Jones, R. W. (2005). Music enhances category fluency in healthy older adults and Alzheimer's disease patients. Experimental aging research, 31(1), 91-99.

Uehara, E. S. (1995). Reciprocity reconsidered: Gouldner'smoral norm of reciprocity'and social support. Journal of Social and Personal Relationships, 12, 483-502.

Van Malderen, L., Mets, T., \& Gorus, E. (2013). Interventions to enhance the quality of life of older people in residential long-term care: A systematic review. Ageing Research Reviews, 12, 141-150. doi:10.1016/j.arr.2012.03.007

Victor, C. R. (2012). Loneliness in care homes: a neglected area of research?. Aging health, 8 , 637-646.

VonDras, D. D., Powless, M. R., Olson, A. K., Wheeler, D., \& Snudden, A. L. (2005). Differential effects of everyday stress on the episodic memory test performances of young, mid-life, and older adults. Aging \& Mental Health, 9, 60-70. doi:10.1080/13607860412331323782

Welford, C., Murphy, K., Rodgers, V., \& Frauenlob, T. (2012). Autonomy for older people in residential care: A selective literature review: Autonomy for older people in residential care. International Journal of Older People Nursing, 7, 65-69. doi:10.1111/j.17483743.2012.00311.x

Wiersma, E., \& Dupuis, S. L. (2010). Becoming institutional bodies: Socialization into a longterm care home. Journal of Aging Studies, 24, 278-291. doi:10.1016/j.jaging.2010.08.003

Wilson, R. S., Mendes De Leon, C F, Bennett, D. A., Bienias, J. L., \& Evans, D. A. (2004). Depressive symptoms and cognitive decline in a community population of older persons.Journal of Neurology, Neurosurgery, and Psychiatry, 75, 126-129. 
Winningham, R. G., \& Pike, N. L. (2007). A cognitive intervention to enhance institutionalized older adults' social support networks and decrease loneliness. Aging \& Mental Health, 11, 716-721. doi:10.1080/13607860701366228

Winstead, V., Yost, E. A., Cotten, S. R., Berkowsky, R. W., \& Anderson, W. A. (2014). The impact of activity interventions on the well-being of older adults in continuing care communities. Journal of Applied Gerontology, 33, 888-911. doi:

$10.1177 / 0733464814537701$

World Health Organization. (2015). World report on ageing and health. Luxembourg: WHO Publications.

Yoon, S., Moon, S. S., \& Pitner, R. (2018;2015;). Effective treatments of late-life depression in long-term care facilities: A systematic review. Research on Social Work Practice, 28(2), 116-130. doi:10.1177/1049731515621165

Yoon, S., Shin, C., \& Han, C. (2017). Depression and cognitive function in mild cognitive impairment: A 1-year follow-up study. Journal of Geriatric Psychiatry and Neurology, 30, 280-288. doi:10.1177/0891988717723741

Ysseldyk, R., Paric, A., \& Luciani, T. (2016). Transferable practices for knowledge mobilization: Lessons learned from a community-engaged health study. Technology Innovation Management Review. 6, 46-52.

Zahodne, L. B., Nowinski, C. J., Gershon, R. C., \& Manly, J. J. (2014). Which psychosocial factors best predict cognitive performance in older adults? Journal of the International Neuropsychological Society : JINS, 20, 487-495. doi:10.1017/S1355617714000186

Zlatar, Z. Z., Moore, R. C., Palmer, B. W., Thompson, W. K., \& Jeste, D. V. (2014). Cognitive complaints correlate with depression rather than concurrent objective cognitive 
impairment in the successful aging evaluation baseline sample. Journal of geriatric psychiatry and neurology, 27(3), 181-187.

Zlatar, Z. Z., Muniz, M., Galasko, D., \& Salmon, D. P. (2018). Subjective cognitive decline correlates with depression symptoms and not with concurrent objective cognition in a clinic-based sample of older adults. The Journals of Gerontology: Series B, 73(7), 11981202. 